University of Louisville

ThinkIR: The University of Louisville's Institutional Repository

Electronic Theses and Dissertations

$5-2006$

\title{
Mechanism of 4-Hydroxynonenal induced toxicity in Jurkat CD4+ T lymphocytes.
}

Wei Yuan Chang

University of Louisville

Follow this and additional works at: https://ir.library.louisville.edu/etd

\section{Recommended Citation}

Chang, Wei Yuan, "Mechanism of 4-Hydroxynonenal induced toxicity in Jurkat CD4+ T lymphocytes."

(2006). Electronic Theses and Dissertations. Paper 232.

https://doi.org/10.18297/etd/232

This Doctoral Dissertation is brought to you for free and open access by ThinkIR: The University of Louisville's Institutional Repository. It has been accepted for inclusion in Electronic Theses and Dissertations by an authorized administrator of ThinkIR: The University of Louisville's Institutional Repository. This title appears here courtesy of the author, who has retained all other copyrights. For more information, please contact thinkir@louisville.edu. 


\title{
MECHANISM OF 4-HYDROXYNONENAL INDUCED TOXICITY IN JURKAT
} $\mathrm{CD}^{+} \mathrm{T}$ LYMPHOCYTES

\author{
By \\ Wei Yuan Chang \\ M.S. University of Louisville, 2004
}

\begin{abstract}
A Dissertation
Submitted to the Faculty of the

Graduate School of the University of Louisville in Partial Fulfillment of the Requirements

for the Degree of

Doctor of Philosophy

Department of Pharmacology and Toxicology

University of Louisville

Louisville, KY
\end{abstract}

May 2006 
MECHANISM OF 4-HYDROXYNONENAL INDUCED TOXICITY IN JURKAT CD4 ${ }^{+}$LYMPHOCYTES

\author{
By \\ Wei Yuan Chang \\ M.S., University of Louisville, 2004
}

A Dissertation Approved on

April 24, 2006

By the following Dissertation Committee:

Dissertation Director

Co-Director 


\section{DEDICATION}

This dissertation is dedicated to my Lord and grandparents

Mr. Chin-Huan Kuo

and

Mrs. Yang Hsueh-Chen Kuo

who have given invaluable Salvation, love and enable me to complete this project 


\section{ACKNOWLEDGMENTS}

I would like to express my gratitude to Professors Theresa S. Chen and Barve S. Shirish for their continued guidance, leadership, and support throughout this work. I would like to indicate my appreciation to Marcia Liu for his assistance during the course of this project. Thanks are also due to Professors Walter M. Williams, Craig J. McClain, Donald E. Nerland and Frederick W. Benz for their contributions as members of my dissertation committee. Special thanks to go Professor Herbert T. Nagasawa for providing the test compound that allowed this project to proceed. I would also like to thank the Department of Pharmacology and Toxicology faculty, staff, and graduate students, for giving me the opportunity to work with them and prepare for my future. Last, I would like to thank Rev. Winston Wen, the pastor of Taiwanese Presbyterian Church, and Rev. Vincent Kuo, my uncle and the pastor of Redeemer Church PCA. Without their love, support, and encouragement, I could not have completed this dissertation. 


\section{ABSTRACT \\ MECHANISM OF 4-HYDROXYNONENAL INDUCED TOXICITY IN JURKAT \\ $\mathrm{CD4}^{+}$T LYMPHOCYTES \\ Wei-Yuan Chang}

April 24, 2006

Oxidative stress-induced immunosuppression could be due to a decrease in $\mathrm{CD}^{+} \mathrm{T}$ lymphocyte activation or proliferation. 4-Hydroxynonenal (HNE), an end product of lipid peroxidation, and its protein adducts act as markers of oxidative stress. In this study, the effects of HNE on a human $\mathrm{CD}^{+}$Jurkat $\mathrm{T}$ cells were examined. Systematic determinations of the effects of HNE on cytotoxicity, Akt and protein phosphatase 2A(PP2A)activation, Fas/FasL-mediated apoptotic signaling, methionine adenosyltransferase (MAT) II activity, MAT 2A and c-Myb expression and cellular glutathione (GSH) and S-adenosylmethionine (SAMe) levels were performed. The results showed that HNE induced cytotoxicity, downregulated Akt and upregulated PP2A activation, and resulted in enhanced FasL expression, death-inducing signaling complex (DISC) formation, Fas-associated death domain (FADD) recruitment, and caspases cleavages, and comitantly decreased c-FLIP ${ }_{S}$ expression. Further, HNEinduced cytotoxicity and lost of survival is associated with GSH depletion in a threshold phenomena and can be potentiated by inhibition of GSH synthesis. In addition, HNE toxicity was also involved with SAMe metabolism by inhibition of MAT II activity, MAT 2A and c-Myb expression and which resulted in decreases in 
SAMe concentrations and lead to caspase-3 dependent apoptosis. $2(R S)-n-$ propylthiazolidine-4(R)-carboxylic acid (PTCA), a GSH precursor, restored GSH and SAMe as well as upregulated Akt and MAT activities, protected against HNE toxicity. It was concluded that HNE toxicity may be due to an Akt regulated, Fas/FasLmedoated, and caspase- 8 dependent apoptotic signaling pathway, that HNE toxicity is associated with GSH depletion and can be prevented by a GSH precursor, and that MAT and SAMe may be involved in HNE toxicity. 


\section{TABLE OF CONTENTS}

PAGE

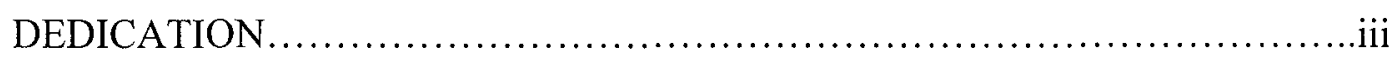

ACKNOWLEDGMENTS ................................................. iv

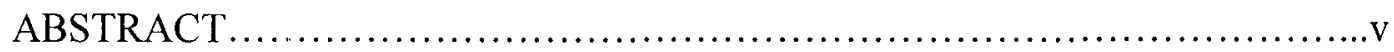

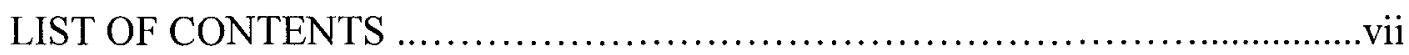

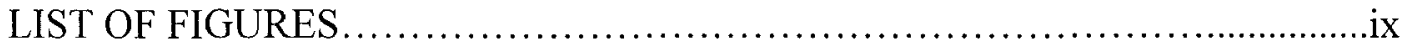

CHAPTER

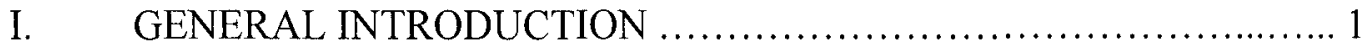

II. HNE-INDUCED CYTOTOXICITY IN CD4 ${ }^{+}$T LYMPHOCYTES ...... 21

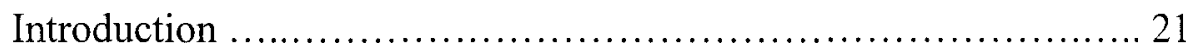

Material and Methods ......................................... 22

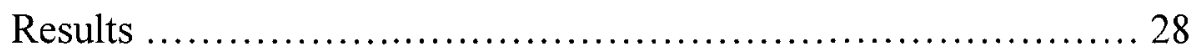

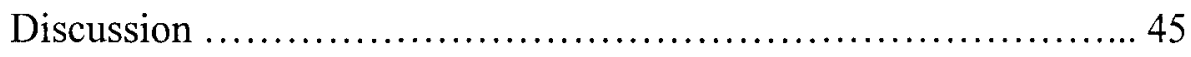

III. ROLE OF GSH AND PTCA PROTECTION IN HNE-INDUCED

CYTOTOXICITY ......................................... 52

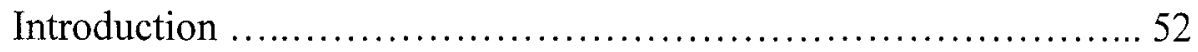

Material and Methods .......................................... 52

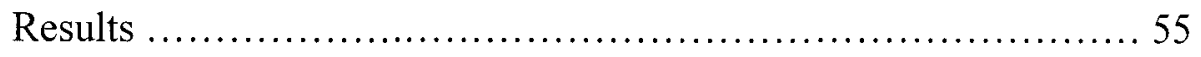

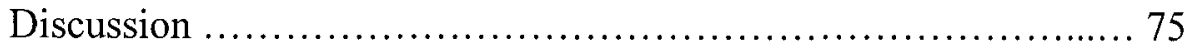


IV. ROLE OF MAT AND SAME IN HNE-INDUCED

CYTOTOXICITY …................................................. 84

Introduction .................................................. 84

Material and Methods ......................................... 84

Results ........................................................ 87

Discussion ............................................... 98

V. SUMMARY AND CONCLUSIONS ............................ 106

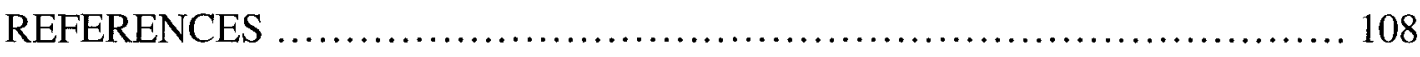

LIST OF ABBREVIATIONS ........................................... 118

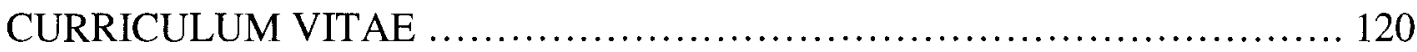




\section{LIST OF FIGURES}

FIGURE

PAGE

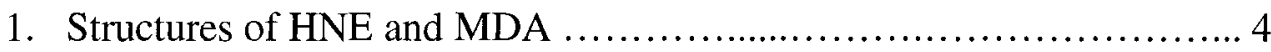

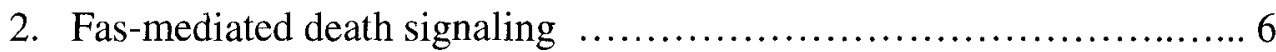

3. GSH synthesis and structures of PTCA and NAC .................. 10

4. Proposed SAMe synthetic pathway in T lymphocytes ................ 11

5. The effects of PTCA on transsulfuration pathway $\ldots \ldots \ldots \ldots \ldots \ldots \ldots$

6. Role of Akt in regulation of survival signaling .................... 17

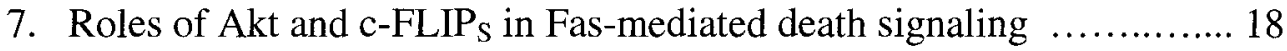

8. Effects of HNE and MDA on cell viability ........................ 29

9. HNE downregulates Akt activation ............................. 31

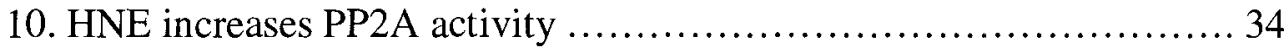

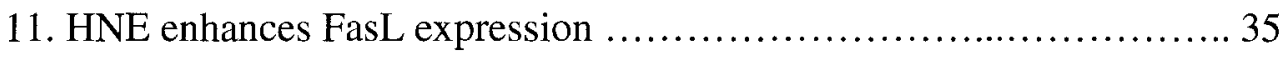

12. HNE increases binding of FADD to the DISC ......................... 38

13. HNE induces caspase -8 activation $\ldots \ldots \ldots \ldots \ldots \ldots \ldots \ldots \ldots \ldots \ldots \ldots \ldots, 40$

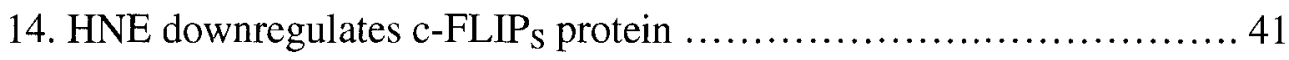

15. HNE induces Caspase-8 dependent apoptosis .................... 42

16. Neutralization of FasL protects Jurkat T cells from apoptosis

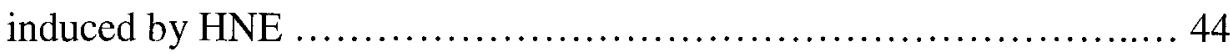

17. PTCA protects against HNE-induced cytotoxicity .................... 56

18. PTCA attenuates HNE-induced GSH depletion and cytotoxicity ....... 57 
19. Effects of MDA and BSO on intracellular GSH concentration and cytotoxicity

20. PTCA protects against HNE-induced downregulation of Akt

kinase expression 62

21. PTCA inhibits HNE-induced PP2A activation 65

22. PTCA protects against HNE-induced upregulation of FasL 68

23. PTCA protects against HNE-induced downregulation of c-FLIP protein 70

24. Effects of BSO on Akt, $p$-Akt, FasL and c-FLIP protein expression $\ldots 72$

25. HNE decreases MAT II activity 88

26. HNE decreases MAT 2A mRNA levels 90

27. PTCA attenuates HNE-induced decreases of MAT II activity 91

28. PTCA attenuates HNE-induced decreases MAT 2A mRNA 92

29. Relationship between intracellular GSH concentrations and MAT II activity 94

30. PTCA protects against HNE-induced c-Myb expression 95

31. PTCA protects against HNE-induced caspase-3 dependent apoptosis 97 


\section{CHAPTER I}

\section{GERNERAL INTRODUCTION}

Oxidative stress associated with intracellular cell signaling is an important pathological factor in several immunosuppressive diseases, such as diabetes mellitus, chronic hepatis C, chronic alcoholism and AIDS (Smith et al., 1976; MacGregor, 1986; Raju et al., 1994; Sen, 1997; Kajimoto et al., 2002). The balance of reactive oxygen species (ROS) and antioxidants regulate both cell activation and cell death in T-cellbased immunodeficiency, allergy, and autoimmune disease by affecting $T$ cell function and numbers (Serafini, 2000). The goals of this project are to: (1) elucidate the mechanisms involved in oxidative stress induced suppression of $\mathrm{T}$ lymphocytes, and (2) develop potential therapeutic interventions for oxidative stress related diseases.

\section{Oxidative stress and immune dysfunction}

\section{Oxidative stress and disease}

Clinically, oxidative stress has been shown to be associated with decreased immune function in aging and in diseases (Shellito and Olariu, 1998; Calabrese et al., 2002). Oxidative stress results in the production of ROS, such as superoxide radicals, hydroxyl radicals, and hydrogen peroxide $\left(\mathrm{H}_{2} \mathrm{O}_{2}\right)$, and leads to an imbalancé of prooxidant-antioxidant status. ROS is known to play a role in chronic inflammation and human immunodeficiency virus (HIV) infection in immune cells (Cederbaum, 1989; 
Nakamura et al., 2002). The association of oxidative stress with HIV infection was originally implied from the finding of reduced levels of glutathione (GSH) in the plasma and lymphocytes of AIDS patients (Nakamura et al., 2002; Shan et al., 1990). Alcoholic patients have significantly reduced numbers of $\mathrm{CD}^{+} \mathrm{T}$ lymphocytes in the periphery and the spleen, as well as a reduction in immune function (Shellito and Olariu, 1998). In acute or chronic active hepatitis C, oxidative stress increases free radical generation and membrane lipid peroxidation in the liver and peripheral blood mononuclear cells (Navas et al., 1998). These are associated with hepatic damage, GSH depletion, and increased serum malondialdehyde (MDA) and 4-hydroxynonenal (HNE) (Esterbauer et al., 1991). Any process that interferes with the ability of $\mathrm{T}$ cell division is likely to have major implications for the effectiveness of an immune response (Hamilos and Wedner, 1985; Droge et al., 1986).

\section{$T$ cells and immunosuppression}

The immune system is generally divided into two categories: innate and adaptive (acquired) immunity. Adaptive immunity is characterized by the responses of antigen-specific lymphocytes to antigen. Lymphocytes are critical cellular components for the adaptive immune response, and regulate both the humoral and cell mediated immunity, which resist invaders such as viruses that reproduce within the cells of the body. T lymphocytes are further classified by glycoprotein receptors present on the cell surface into $\mathrm{CD}^{+} \mathrm{T}$ lymphocytes (also known as cytotoxic/killer $\mathrm{T}$ cells) and $\mathrm{CD}^{+} \mathrm{T}$ lymphocytes (also known as helper $\mathrm{T}$ cells). Upon antigen presentation by an antigen presenting cell (APC), all these cell types act differently to combat the presented antigen. While stimulation of $\mathrm{CD} 8^{+} \mathrm{T}$ cells activates them to kill the target 
antigen, stimulation of $\mathrm{CD}^{+} \mathrm{T}$ cells leads to their activation and clonal expansion (Droge et al., 1986). CD4 ${ }^{+} \mathrm{T}$ lymphocytes are the main regulators of both humoral and cell-mediated immunity. They mediate the immunogenic response through release of cytokines signaling other immune cells to kill the target antigen (Brunner et al., 2003). Most importantly, the loss of $\mathrm{CD} 4^{+} \mathrm{T}$ lymphocytes has been clearly related to impairment of several immune functions and ensuing immunosuppression.

\section{Lipid peroxidation and CD4+ T lymphocyte death}

There is increasing evidence that reactive aldehydic molecules generated as a consequence of lipid peroxidation are causally linked to most of the pathophysiological effects associated with oxidative stress in cells and tissues (Uchida, 2003). Lipid hydroperoxides are derived from unsaturated phospholipids, glycolipids, and cholesterol. They are prominent intermediates of peroxidative reactions induced by activated species such as hydroxyl radical, lipid oxyl or peroxyl radicals, singlet oxygen, and peroxynitrite (Fig. 1). Among them, MDA and HNE are clinically and structurally relevant lipid peroxides (Kalinich et al., 1999). HNE is considered to be a physiological messenger molecule signaling for various cellular responses (Uchida, 2003). HNE may play a central role in the down-regulation of cell proliferation and in the modulation of $\mathrm{T}$ cell differentiation (Liu et al., 2000). In addition, HNE has been detected in several oxidative stress related immune diseases including diabetes mellitus, alcoholism, and atherosclerosis (Romero et al., 1998). Studies suggest that the formation of HNE and HNE-protein conjugates is a marker of oxidative stress in tissues or cells (Kruman et al., 1997). It was found that after chronic administration of ethanol to rats for 20 months there were significant increases in free radicals and HNE 
HNE

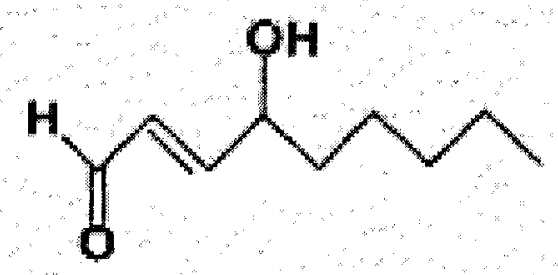

M DA

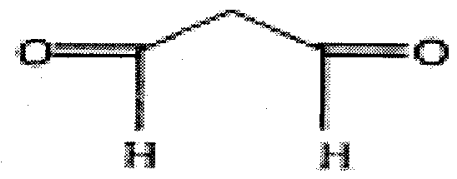

Fig. 1. Structures of HNE and MDA. Uchida, K. (2003) 
in the hippocampus and cerebellum, which correlated with decreased GSH reductase activity in these regions (Calabrese et al., 2002). The results of several clinical studies suggest that alcoholism, HIV-, and HCV-infected patients were all observed to have enhanced lipid peroxidation with high plasma MDA and HNE concentrations (Haughey et al., 2004; Rigamonti et al., 2003). Recent findings show HNE induced apoptotic cell death with concomitantly decreased GSH and glutathione disulfide (GSSG) in human lymphoma cells (Jurkat) (Liu et al., 2000). Other results, along with our studies, suggest that oxidative stress induced by HNE caused T lymphocyte dysfunction. Hence, it is essential to understand the underlying mechanism involved in the cytotoxic effects of HNE on $\mathrm{CD} 4^{+} \mathrm{T}$ cells.

\section{Fas-mediated cell death}

T lymphocyte death is essential for proper function of the immune system. Under normal physiological as well as pathophysiological conditions, T lymphocytes undergo activation-induced apoptotic cell death (AICD), which is primarily mediated by Fas/FasL dependent signaling (Brunner et al., 2003). Induction of FasL expression has been implicated in drug and stress induced apoptotic death of $\mathrm{T}$ lymphocytes (Hueber et al., 2002; Green et al., 2003). Upon activation, Fas undergoes trimerization and initiates the formation of the death-inducing signaling complex (DISC) by recruiting the proapoptotic adapter protein Fas-associated death domain (FADD) and procaspase-8, also called FADD-like interleukin $1 \beta$-converting enzyme (FLICE) (Peter and Krammer, 2003) (Fig. 2).

Proteolytic activation of procaspase- 8 is initiated by its recruitment to the DISC and triggers a caspase cascade leading to apoptosis (Tibbetts et al., 2003). FLICE 


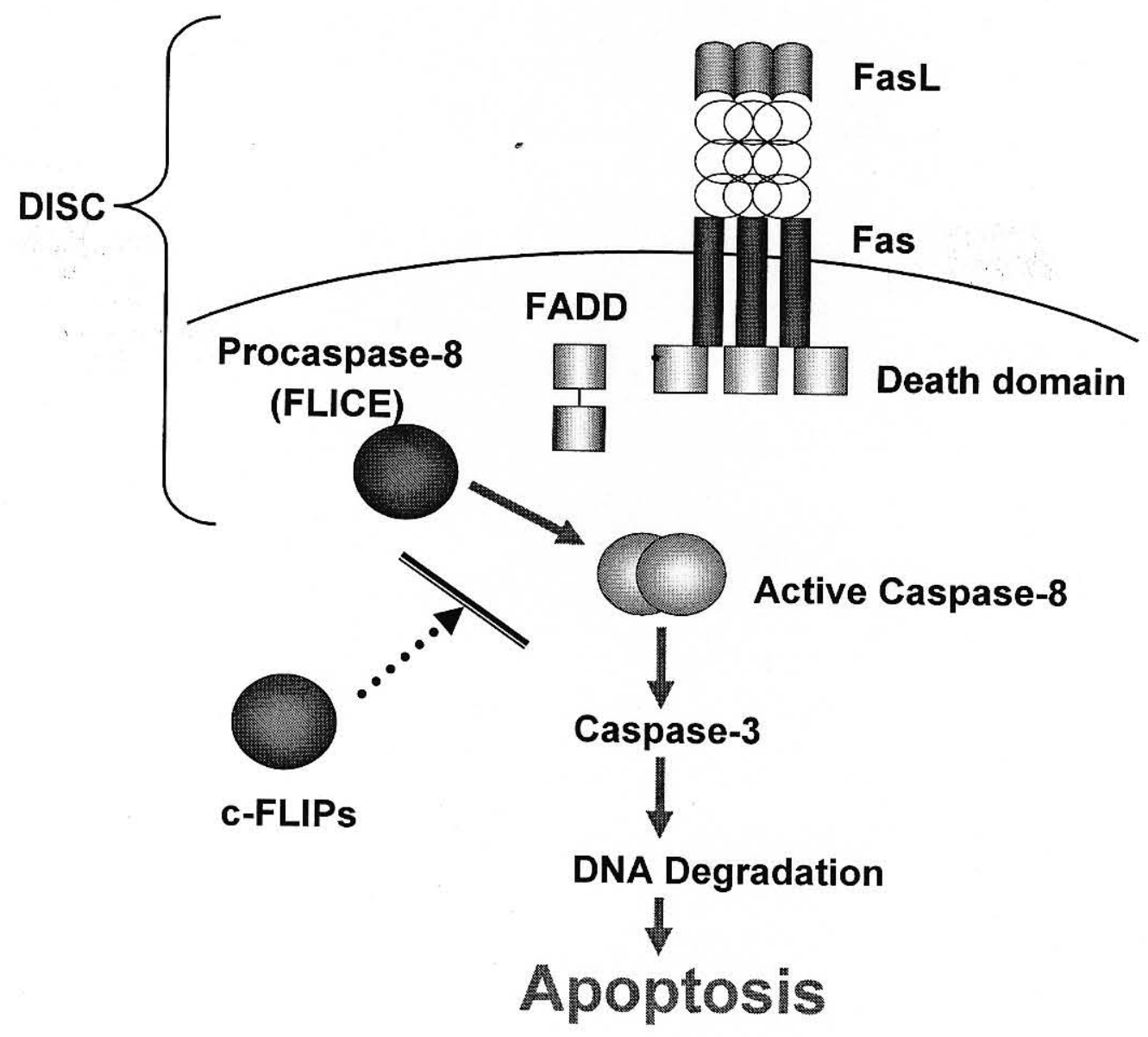

Fig. 2. Fas-mediated death signaling. Modified from Peter and Krammer (2003). 
inhibitory protein (c-FLIP) is an antiapoptotic cytoplasmic protein with sequence homology to caspase-8. c-FLIP is unable to undergo cleavage to an active caspase due to substitution of a tyrosine for an active site cysteine, and hence can function as a dominant-negative inhibitor of caspase-8, thereby preventing Fas-induced apoptosis (Hueber et al., 2002; Green et al., 2003; Peter and Krammer, 2003). Alternative splicing yields multiple isoforms of c-FLIP; two commonly occurring isoforms are designated c-FLIP $\mathrm{L}_{\mathrm{L}}$ (long isoform) and c-FLIP (short isoform) (Krueger et al., 2001a; Tibbetts et al., 2003). c-FLIP has been shown to play an anti-apoptotic role in a number of cell types and elevated c-FLIP expression renders cells resistant to Fasinduced apoptosis (Krueger et al., 2001). In fact, the susceptibility of T lymphocytes to Fas-mediated apoptosis correlates with c-FLIP levels, which are elevated during early stages of activation but are significantly reduced upon re-stimulation when the T cells undergo AICD (Rigamonti et al., 2003; Irmler et al., 1997; Uriarte et al., 2005). The molecular mechanisms involved in the regulation of expression of c-FLIP in T lymphocytes are not completely understood.

\section{Oxidative Stress, GSH and SAMe}

$\mathrm{GSH}$, a cysteine-containing tripeptide, plays an important role in the circumvention of cellular oxidative stress and the maintenance of intracellular thiol redox status (Khanna et al., 1998; Sen, 1998; Meister, 1989) (Fig. 3). S-Adenosylmethionine (SAMe) is a major methyl donor for cellular transmethylation reactions involving proteins, nucleic acids, and various lipids, and it functions as an antioxidant. SAMe is a GSH synthesis precursor via the transsulfuration pathway and decreases in SAMe result in GSH deficiency (Honchel et al., 1992). Chronic alcohol abuse not only 
results in hepatic SAMe depletion, but is also associated with a decrease in the levels of intracellular GSH (Honchel et al., 1992; Koch et al., 1991; Wang and Spitzer, 1997; Shan et al., 1990). SAMe is also required for cell proliferation upon activation of T lymphocytes, after which both the SAMe pool size and the rate of SAMe utilization increase (German et al., 1983). In Jurkat T cells, GSH content plays an important role in the cell cycle, rising steadily from the G1 phase through the S phase, and reaching a maximum at G2/M (Soderdahl et al., 2003). Clinically, patients with chronic diseases such as genitourinary, gastrointestinal, cardiovascular, and musculoskeletal diseases including cancer had a marked decrease in total GSH content in the blood (Lang et al, 2000). Oxidative stress diseases and the resultant GSH depletion can adversely affect normal CD4 ${ }^{+} \mathrm{T}$ lymphocyte function, proliferation and survival (Peterson et al., 1998; Hamilos and Wedner, 1985; Droge et al., 1986).

$\mathrm{CD}^{+} \mathrm{T}$ cells are the targets of HIV infection, and the decrease of $\mathrm{CD}^{+} \mathrm{T}$ cells occurs AIDS. A recovery of the human $\mathrm{CD}^{+} \mathrm{T}$ lymphocyte count was seen in several studies after supplementation with antioxidant agents, such as $\mathrm{N}$-acetyl-cysteine (NAC), oxothiazolidine carboxylic acid (OTC), and Vitamin E. This finding indicates that oxidative stress can affect human $\mathrm{CD}^{+} \mathrm{T}$ lymphocyte survival (Mato et al., 2002; Nakamura et al., 2002). Our preliminary data showed that NAC rescues $\mathrm{CD} 4^{+} \mathrm{T}$ cells from $\mathrm{H}_{2} \mathrm{O}_{2}$ induced caspase- 3 activation and apoptosis, while depletion of GSH by buthionine sulfoximine (BSO), which inhibits GSH synthesis, exacerbates it. 2(RS)-nPropylthiazolidine-4(R)-carboxylic acid (PTCA) is a sulfhydryl-protected compound containing a cyclized form of L-cysteine (Cys) that can be non-enzymatically converted to Cys at physiological pH and room temperature (Nagasawa et al., 1984) 
(Fig. 3). PTCA has been shown to attenuate acetaminophen (APAP)- and paraaminophenol (PAP)-induced hepatic GSH depletion both in mice (Srinivasan et al., 2001) and hamsters (Fu, 2001). Whether PTCA can protect against HNE-induced cytotoxicity and depletion of GSH and SAMe has not been investigated. Thus, our aim is to investigate the role of antioxidants in HNE-induced cytotoxicity in human $\mathrm{CD} 4^{+} \mathrm{T}$ cell immunotoxicity. Further, we plan to explore whether PTCA, a GSH precursor, can attenuate HNE-induced decreases in intracellular GSH and SAMe, and thereby prevent its cytotoxicity.

\section{SAMe and MAT II}

SAMe also participates in polyamine biosynthesis and is a precursor for the synthesis of GSH through its conversion to Cys via the transsulfuration pathway. As vital as GSH is in alleviating endogenous oxidative stress and in functioning as an antioxidant, SAMe is known to be absolutely critical for T lymphocytes (German et al., 1983). Methionine adenosyltransferase (MAT, also know as S-adenosyl-L-methionine synthetase) is the enzyme that catalyzes the formation of SAMe from methionine and adenosine triphosphate (ATP) (Cantoni, 1953) (Fig. 4). In mammals, there are two genes coding for MAT: MAT 1A and MAT 2A, and their products are know as MAT I/III and MAT II, respectively (Cantoni, 1953; Lu, 2000). In Jurkat T cells, the MAT 2A gene is highly expressed. Recently, Jani et al. in this laboratory have shown that inhibition of MAT II activity by cycloleucine leads to a decrease of intracellular SAMe levels in Jurkat T cells and loss of survival in MOLT-4 and Jurkat T cells. Studies have shown that $\mathrm{T}$ cell activation is associated with increased MAT II expression, and the turnover of SAMe in activated lymphocytes is five times greater than other extra- 


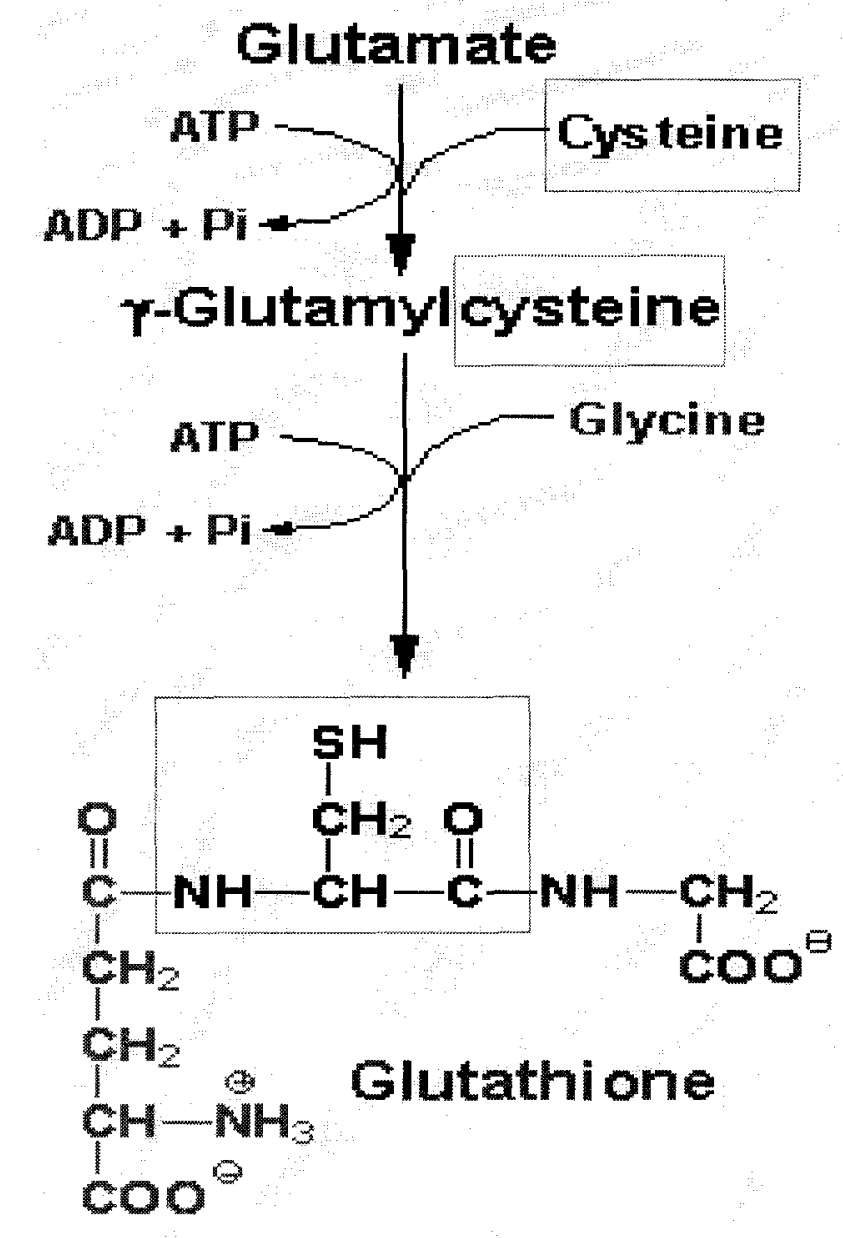

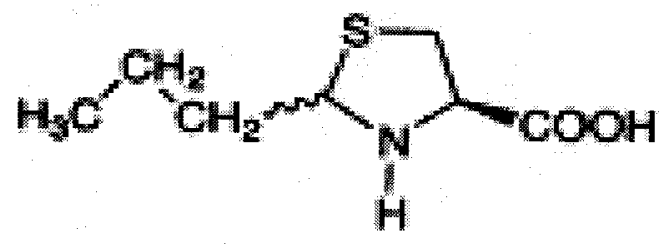

PTCA

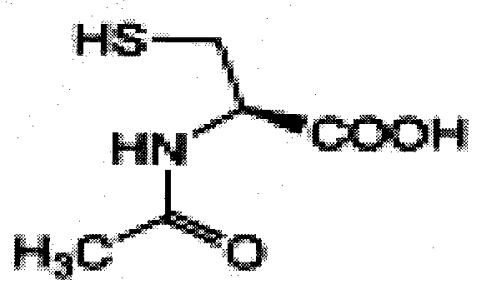

NAC

Fig. 3. GSH synthesis and structures of PTCA and NAC. Nagasawa et al. (1984). 


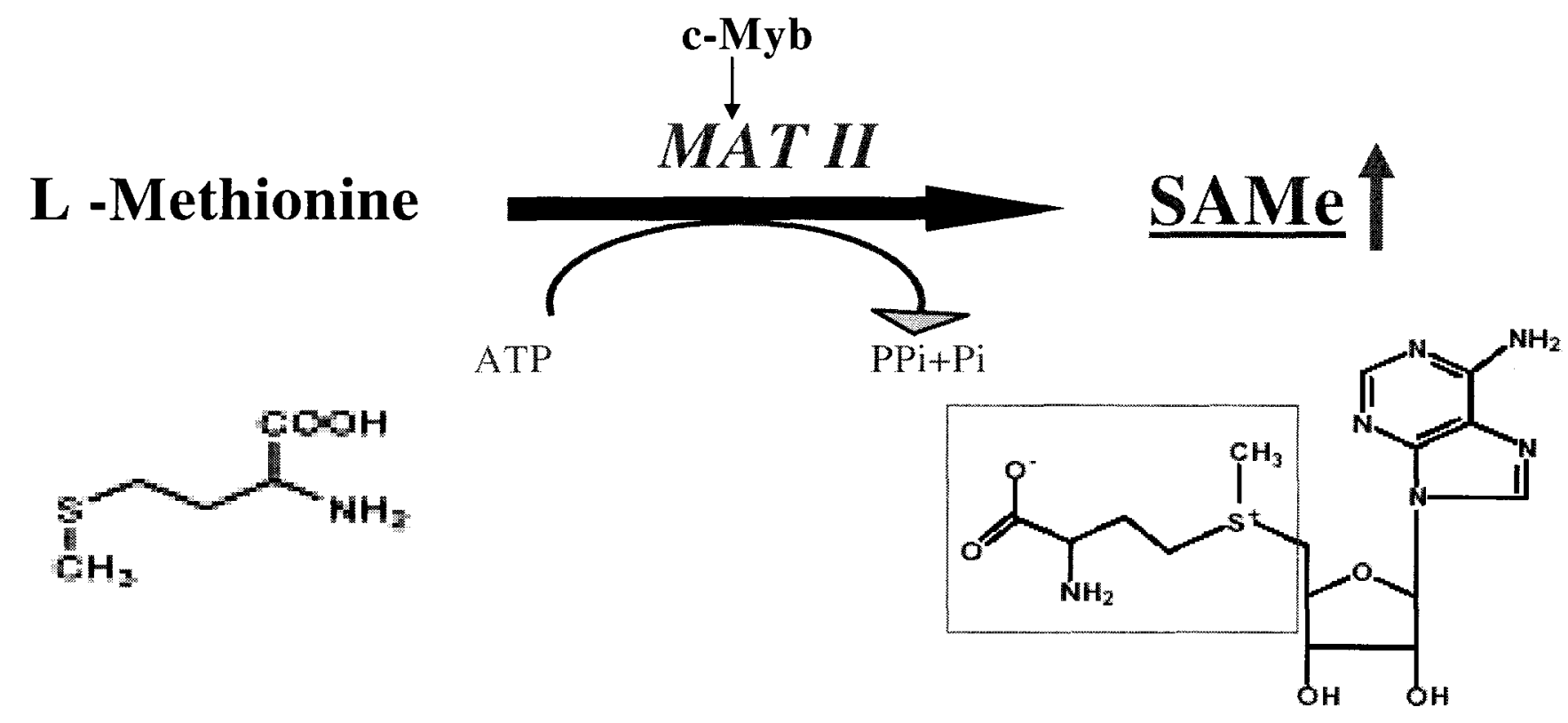

Fig. 4. Proposed SAMe synthetic pathway in T lymphocytes. Modified from Lu, S.C. (2000). 
hepatic tissues, suggesting that MAT II and SAMe play important roles in T cell activation and survival (German et al., 1983). Since SAMe deficiency often leads to GSH depletion via the transsulfuration pathway, more studies suggest that intracellular GSH or the GSH/GSSG ratio may play an important role for the integrity and activity of MAT (Shirota et al., 2002). However, the mechanisms involved in the regulation of MAT II activity are not completely understood.

Decreased MAT activity and expression are found in alcoholic liver disorders and viral induced cirrhosis, coinciding with SAMe depletion in both patients and animal models (Mato et al., 2002). It was also shown that administration of BSO, an inhibitor of the GSH biosynthesis, leads to a decrease of MAT activity and SAMe in rats (Corrales et al., 1991). Recently, studies demonstrated APAP administration rapidly depletes hepatic GSH followed by decreases in MAT activity in mice (Shirota et al., 2002). Similarly, carbon tetrachloride, galactosamine, and hypoxia decrease MAT activity in vivo as well (Corrales et al., 1992; Mato et al., 1997). These results have led us to propose that there is a casual relationship between oxidative stress, decreased levels of antioxidants, and inhibition of MAT activity (Fig. 5). However, whether MAT is compromised in HNE-induced cytotoxicity in $\mathrm{CD}^{+} \mathrm{T}$ lymphocytes is not known.

\section{Role of c-Myb}

$\mathrm{c}-\mathrm{Myb}$ is a $75-$ to $80-\mathrm{kDa}$ protein and is one of the three mammalian $\mathrm{Myb}$ proteins ( $\mathrm{A}, \mathrm{B}$ and $\mathrm{C})$, all of which function as transcriptional factors that are implicated in the regulation of proliferation, differentiation and apoptosis ( $\mathrm{Oh}$ and Reddy, 1999). c-Myb is a transcriptional activator of MAT 2A. In the context of MAT 


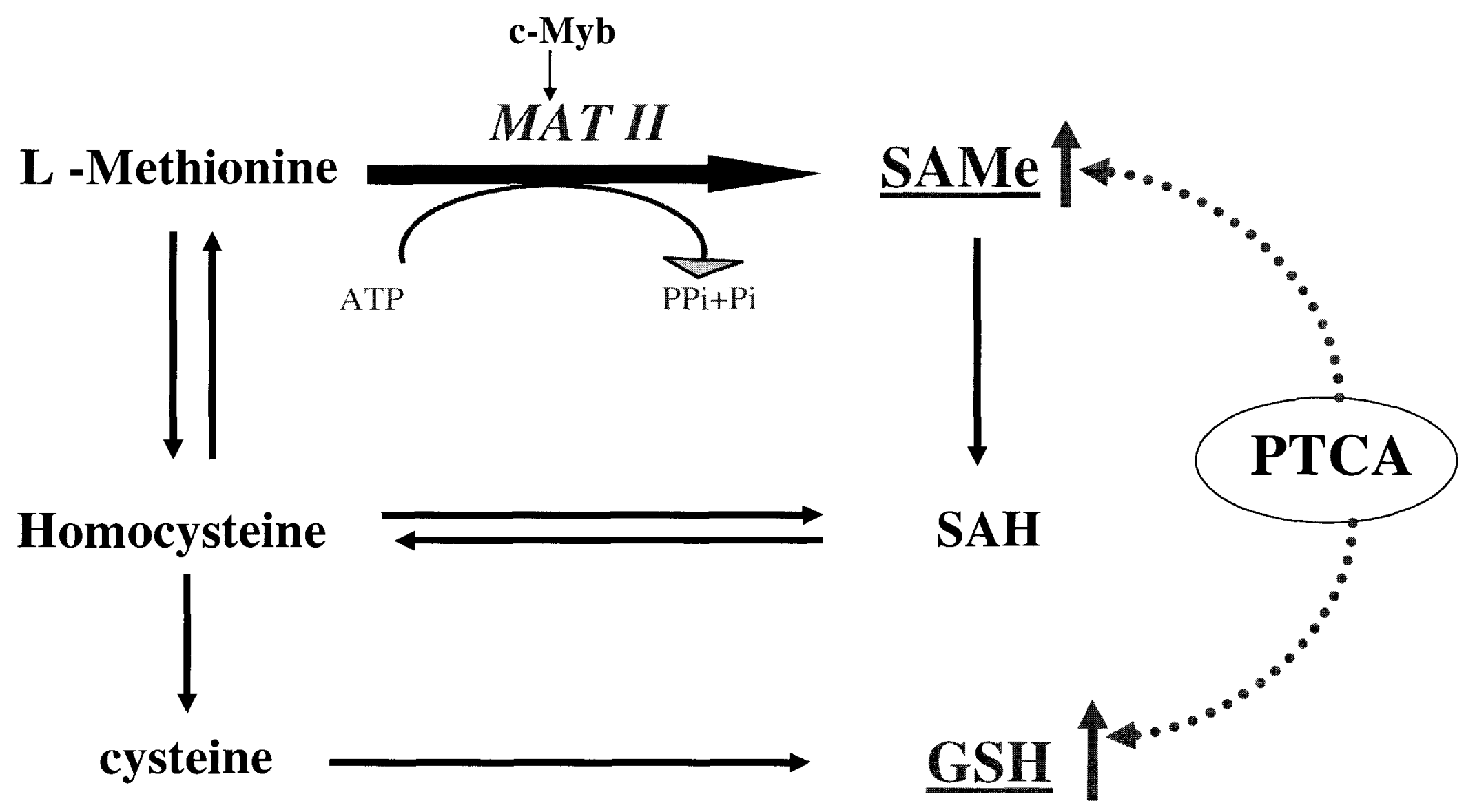

Fig. 5. The effects of PTCA on transsulfuration pathway. Modified from Lu, S.C. (2000). 
2A gene induction, c-Myb expression is induced upon T cell activation and transactivates the MAT 2A promoter by binding to the consensus c-Myb binding site located at -350 to -333 (Zeng et al., 2001). $c-M y b$ anti-sense oligonucleotide mediated inhibition of c-Myb prior to mitogen or antigen dependent stimulation, inhibits $\mathrm{T}$ cell proliferation, suggesting an essential role for c-Myb in $\mathrm{T}$ cell expansion (Venturelli et al., 1990; Furukawa et al., 1990). Studies have shown that c-Myb activity is required for Akt to act as a survival factor during T cell activation and that the $c-M y b$ gene is only regulated by the components of the PI3K pathway (Lauder et al., 2001). Although the effects of c-Myb are well studied in hematopoiesis, the regulation of c-Myb is not completely understood.

\section{Mediators of the survival pathway}

\section{Role of Akt}

The survival signal elicited by Akt, a serine/threonine protein kinase, proceeds through several mechanisms, including inactivation of BAD (Datta et al., 1997; del Peso et al., 1997), which is a death enhancer, and caspase-9 (Cardone et al., 1998), stimulation of $\mathrm{NF}-\mathrm{kB}$ activity, inactivation of the forkhead transcription factor (Kops and Burgering, 1999), and phosphorylation of apoptosis signal-regulating kinase 1 (ASK1) and glycogen synthase kinase 3 (GSK3) (Cross et al., 1999). In contrast to the activation of Akt, associated with its phosphorylation by 3'-phosphoinositide-dependent kinase-1 (PDK1) (Ouyang et al., 1999), downregulation of Akt is still not fully understood. Apoptosis is a programmed cell death distinct from necrosis and is under the control of caspases, a class of cysteine proteases (Cardone et al., 1998). The putative role of apoptotic proteases in the degradation of Akt is less defined, but Akt appears to be a 
substrate of caspase-3 in vitro, and caspase-3-dependent cleavage of Akt may be relevant in detachment-induced and FasL-mediated cell death (Liu et al., 2000). Survival factors were equally important in the regulation of the apoptotic process (Uriarte et al., 2005). Studies have demonstrated that the PI3K/Akt pathway prevents the accumulation of intracellular ROS by regulating the expression of the antioxidant enzyme heme oxygenase (HO-1) in dopaminergic PC12 cells (Salinas et al., 2003). It has also been shown that the PI3K/Akt pathway is indispensable for the survival of human $\mathrm{CD}^{+} \mathrm{T}$ lymphocytes (Salinas et al., 2003). Studies have demonstrated that Akt was significantly inactivated and down-regulated in $\mathrm{H}_{2} \mathrm{O}_{2}$-induced CD4 ${ }^{+} \mathrm{T}$ cell apoptosis (Khanna et al., 1998). However, little is known about the mechanism(s) employed by the apoptotic machinery to down-regulate Akt survival signals. Therefore, we used HNE as an oxidative stimulus to examine the role that Akt kinase plays in Jurakt $\mathrm{T}$ cell survival during oxidative stress. Another aim of this project was to determine whether there is a direct link between the antioxidants GSH and SAMe and the regulation of survival factor (Akt). In addition, we investigated the possible protective effect of increasing GSH concentrations with PTCA on Akt inactivation.

\section{Akt and PP2A}

Protein phosphatase-2A (PP2A) is one of four major cytoplasmic serine/threonine phosphatases that are known to play an important role in the regulation of diverse cellular proteins, including metabolic enzymes, hormone receptors, kinase cascades, and cell growth. PP2A is a heterotrimer consisting of a catalytic subunit "C" (36 kDa), a regulatory subunit "A" (60-kDa) and one of several "B" subunits (54, 55, 72, and $130 \mathrm{kDa}$ ) (Ivaska, et al., 2002; Van Kanegan et al., 2005). The physiologic 
importance of these forms and their regulation by hormones or extracellular stimuli has not been established. In vitro studies indicate that the catalytic subunit of PP2A is regulated by a variety of post-translational modifications, including phosphorylation (Chen et al., 1992) and methylation. PP2A has been shown to be the major phosphatase targeting and inactivating Akt in vitro (Van Kanegan et al., 2005), and several reports have documented the complex formation between these two enzymes (Ivaska et al, 2002; Resjo et al., 2002). A PP2A inhibitor, okadaic acid, has been found to activate Akt in Jurkat $\mathrm{T}$ cells treated with $\mathrm{HNE}$, suggesting that PP2A is a major antagonist of PDK1 in the downregulation of Akt (Liu et al., 2003). It is likely that Akt modulation involves direct dephosphorylation of Akt activity by PP2A (Fig. 6); however, the mechanism is not clear. An aim of this project was to investigate the mechanism.

\section{Akt and c-FLIPS}

Although several anti-apoptotic functions of Akt have been identified in T lymphocytes, the potential role of Akt in regulating c-FLIP expression and the impact on subsequent apoptotic signaling has not been examined. Through sensitizing Fasmediated death signals, the Akt activation was reported to promote c-FLIP expression in endothelial cells (Suhara et al., 2002, 2004) (Fig. 7). c-FLIP expression has been shown to regulate Fas-mediated apoptosis of activated $\mathrm{T}$ cells through competing with caspase-8 for recruiting to the DISC (Krueger et al., 2001a; Irmler et al., 1997). Studies have shown that inhibition of Akt, using either a PI3 kinase inhibitor or a selective Akt inhibitor, up-regulates FasL gene expression, and downregulates c-FLIP 


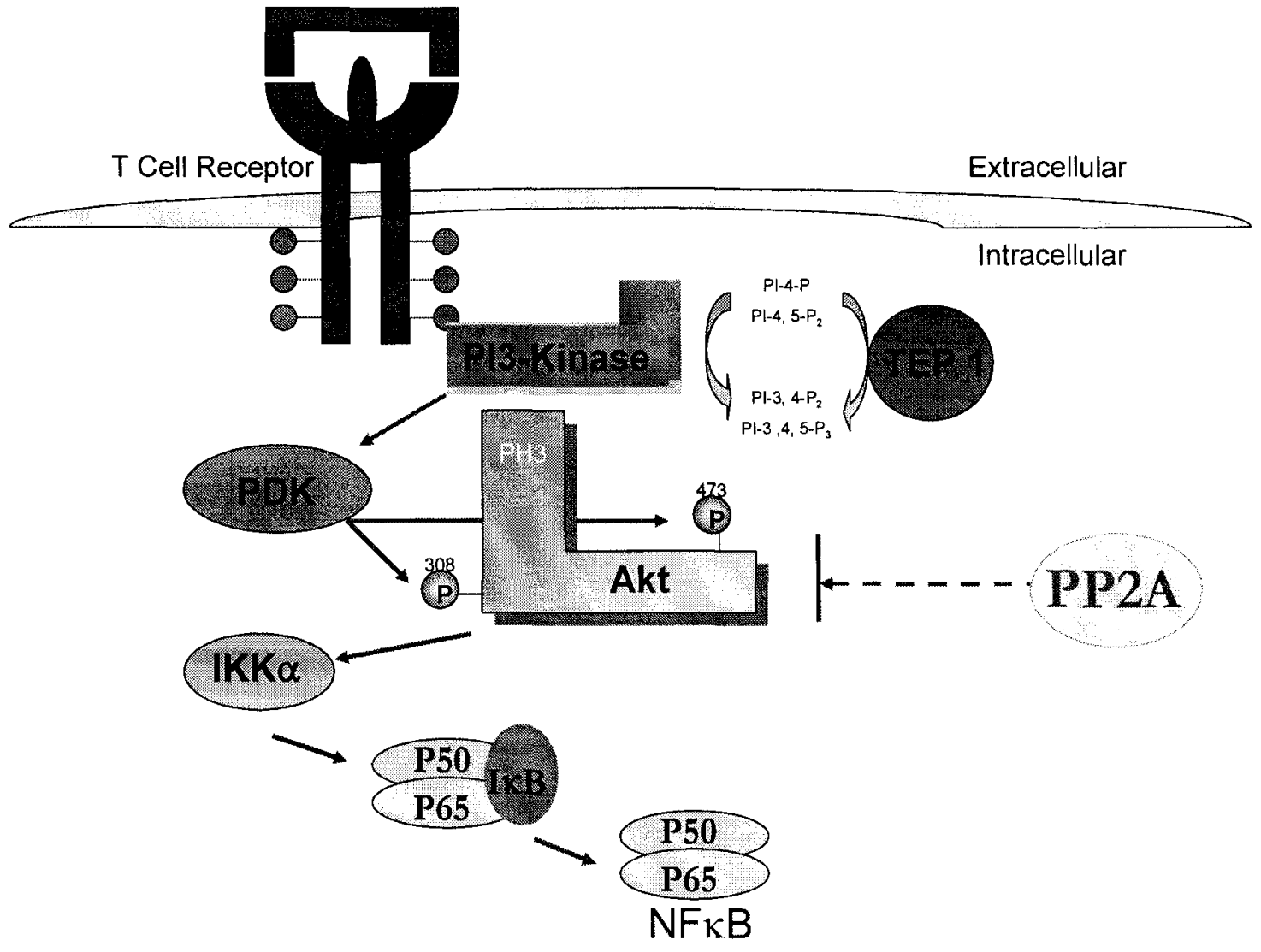

Cell Survival

Fig. 6. Proposed effects of HNE on Akt and PP2A in regulation of survival signaling. Modified from Bauer and Baier (2001). 


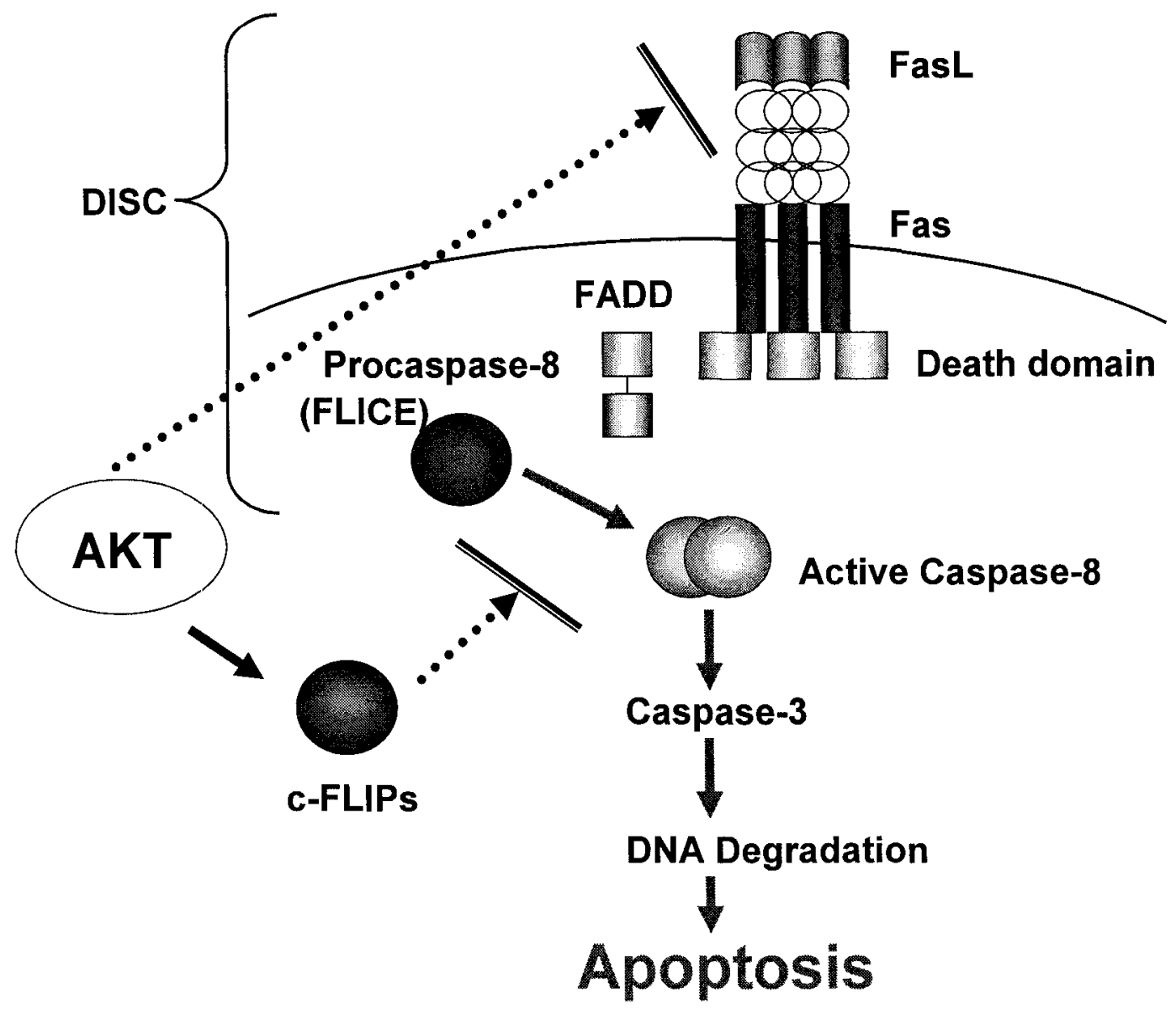

Fig. 7. Proposed roles of Akt and c-FLIPs in Fas-mediated death signaling. Modified from Peter and Krammer (2003). 
expression (Uriarte et al., 2005). However, regulation of c-FLIP expression in T cells induced by HNE is not completely understood.

Based on these findings, our working hypothesis is that HNE is involved in chronic disease induced oxidative damage in $\mathrm{CD}^{+} \mathrm{T}$ lymphocyte. We further propose that HNE, as well as oxidative stress, involves depletion of cellular GSH and SAMe, and that downregulation of Akt kinase and MAT II activity leading to an enhanced susceptibility of $\mathrm{CD}^{+} \mathrm{T}$ lymphocytes to Fas-mediated apoptotic death. The overall objectives of this proposal are to (1) elucidate the cellular and molecular mechanism(s) involved in $\mathrm{HNE}$-induced $\mathrm{CD} 4^{+} \mathrm{T}$ cell depletion and (2) develop possible therapeutic interventions for preventing $\mathrm{CD}^{+} \mathrm{T}$ cell depletion and following immunosuppression in HIV/HCV infected patients. The specific aims of this proposal are:

1. Determine the toxic effects of 4-hydroxynonenal (HNE) on human $\mathrm{CD}^{+} \mathrm{T}$ lymphoma Jurkat cells and its association with immune (dys)regulation.

2. Determine the expression of Fas on Jurkat $\mathrm{T}$ lymphocytes exposed to HNE and correlate Fas expression with increased susceptibility to Fas-mediated signaling and death.

3. Determine the effects of HNE on cellular antioxidant status by measuring cellular GSH and SAMe concentrations.

4. Investigate the role of Akt-mediated apoptosis in HNE-induced cytotoxicity in Jurkat T cells.

5. Determine whether the overall catalytic activity of PP2A and the involvement of PP2A are upregulated via HNE-mediated decreases of Akt activation in Jurkat $\mathrm{T}$ cells. 
6. Determine the effect of HNE on Jurkat T lymphocytes MAT II expression and activity, SAMe concentrations and metabolism and Fas-mediated apoptotic cell death.

7. Determine the effect of HNE on c-Myb, the transtription activator of MAT 2A, expression in Jurkat T cells.

8. Evaluate the efficacy of GSH enhancing precursors against HNE-induced cytotoxicity and apoptosis in Jurkat T cells by preventing $p$-Akt and c-FLIP $S$ expression. 


\section{CHPATER II}

\section{HNE-INDUCED CYTOTOXICITY IN CD4 ${ }^{+}$T LYMPHOCYTES}

\section{INTRODUCTION}

The studies of HNE toxicity in human $\mathrm{CD}^{+} \mathrm{T}$ lymphocytes described in this chapter were designed to test cellular and molecular mechanisms involved in HNEinduced T cell death. The effect of HNE on cytotoxicity was studied and the involvement of Fas-FasL mediated apoptotic death was further evaluated. Necrosis was assessed by elevations in LDH activity and trypan blue count and apoptosis was assessed by an increase in DNA fragmentation. To evaluate the involvement of Akt, a survival factor, in apoptotic cell death, the effects of HNE on Akt kinase activation were examined. To evaluate the involvement of FasL in apoptotic cell death, the effects of HNE on FasL expression, FADD recruitment and DISC formation were examined. To evaluate the involvement of caspase in apoptosis, the effects of HNE on caspase- 8 activity, procaspase- 8 cleavage and its dependent apoptosis were examined. Finally, to evaluate the role of anti-apoptotic factors in apoptosis, the effect of HNE on the expression of $\mathrm{c}-\mathrm{FLIP}_{\mathrm{S}}$ was examined. While the main focus of the study was HNE, the effect of MDA, the clinically relevant lipid peroxidation end product, was also examined. 


\section{MATERIALS AND METHODS}

\section{Cell culture}

Jurkat, clone E6-1, a human $\mathrm{CD}^{+} \mathrm{T}$ cell leukemia cell line, was obtained from ATCC (American Type Culture Collection, Rockville, MD). Jurkat cells were grown in RPMI 1640 supplemented with $10 \%$ fetal bovine serum, $10 \mathrm{U} / \mathrm{ml}$ penicillin, and 10

$\mu \mathrm{g} / \mathrm{ml}$ streptomycin in a $37^{\circ} \mathrm{C} 5 \% \mathrm{CO}_{2}$ incubator. Jurkat cells were resuspended at $1 \mathrm{x}$ $10^{6} \mathrm{cells} / \mathrm{ml}$ during treatment.

\section{Chemicals}

HNE and MDA were kindly provided by Dr. Sanjay Srivastava, Department of Internal Medicine. HNE was synthesized as its dimethylacetal starting from dimethylacetal of fumaraldehyde as described previously (Chandra et al., 2004). Phytohemoagglutinin (PHA), Nonidet P-40, sodium orthovanadate, sodium pyrophosphate, N,N-dimethylformamide (DMF), sodium dodecyl sulfate (SDS), aprotinin, leupeptin, benzamidine, and potassium fluoride were purchased from Sigma Chemical Co. (St. Louis, MO). FADD was purchased from Cell Signaling (Beverly, CA). Protein A/G agarose and antibodies Fas (B-10), Fas-L (C-178) and $\beta$-Actin were purchased from Santa Cruz Biotechnology (Santa Cruz, CA). Anti-FLIP $\gamma / \delta$ (191-209) antibody and caspase- 8 inhibitor II were purchased from Calbiochem (La Jolla, CA). Phospho-Akt (Ser 473), total Akt antibodies were purchased from Cell Signaling (Beverly, CA). Goat anti-rabbit/anti-mouse/anti-rat antibodies conjugated with horseradish peroxidase, which were used as secondary antibodies in immunoblotting, were purchased from Bioscience International (Rockville, MD). RPMI 1640 dry powdered medium was pursued from HyClone Co. (Logan, UT). Fetal bovine serum, 
penicillin/streptomycin, and trypan blue were purchased from Invitrogen Co. (Grand Island, NY). Phenylmethylsulfonyl fluoride (PMSF) was obtained from Boehringer Mannheim Co. (Indianapolis, IN). $\beta$-Glycerophosphate was purchased from TCI America (Portland, OR). Phosphate buffered saline (PBS) was obtained from BD Biosciences Pharmigen (San Diego, CA).

\section{DNA fragmentation ELISA assay}

To measure cell apoptosis, the treated Jurkat $\mathrm{T}$ cells were lysed after HNE treatment for $6 \mathrm{~h}$. DNA fragmentation was quantified using the Cell Death ELISA kit (Roche, Indianapolis, IN). The assay was based on the quantitative sandwich-enzymeimmunoassay principle using mouse monoclonal antibodies directed against DNA and histones to determine the presence of mono-and oligonucleosomes in the cytoplasmic fraction of cell lysates. The lysate was centrifuged at $200 \mathrm{x} \mathrm{g}$ for $10 \mathrm{~min}$ and $20 \mu \mathrm{l}$ of the cytoplasmic fraction was transferred to the streptavidin coated micro titer plate. A mixture of anti-histone-biotin labeled antibody and anti-DNA peroxidase conjugated antibody was added and the plate incubated for $2 \mathrm{~h}$. After removal of the antibodies by a washing step, the amount of nucleosome-bound fragmented DNA was quantified photometrically by the peroxidase retained in the immunocomplex, using ABTS $(9,2$, 2'-Azino-di [3-ethylbenzthiazolin-sulfonate]) as a substrate. The results were obtained as optical density values and expressed as fold over untreated cells.

\section{Akt [pS473] ELISA assay}

Treated Jurkat T cells were lysed at 0.5 to $6 \mathrm{~h}$ for determination of Akt. The concentration of Akt which was phosphorylated at serine residue 473 was determined by ELISA (Akt [pS473] kit; BioSource International Inc., Camarillo, CA). A 
monoclonal antibody specific for Akt has been coated onto the wells of the microtiter strips, standards, samples or positive controls were added to appropriate wells and the plate was incubated for $2 \mathrm{~h}$. After washing, a rabbit antibody, specific for Akt phosphorylated at serine 473 , was added to the wells and incubated for $1 \mathrm{~h}$ followed by the addition of a horseradish peroxidase-labeled anti-rabbit IgG (anti-rabbit IgG-HRP) working solution to conjugate the antibody for $30 \mathrm{~min}$. After a third incubation and washing to remove all the excess anti-rabbit IgG-HRP, $100 \mu \mathrm{l}$ of substrate solution was added, which was acted upon by the bound enzyme to produce color. After 20 to 25 min, $100 \mu \mathrm{l}$ of stop solution was added and the absorbance was measured at $450 \mathrm{~nm}$. The absorbance of the standards was plotted against concentration. The Akt [pS473] concentration for unknown samples and controls were calculated from the standard curve.

\section{PP2A enzymatic activity assay}

PP2A enzymatic activity was assessed following PP2A immunoprecipitation using a malachite green based phosphatase assay (PP2A Immunoprecipitation Phosphatase Assay Kit; Upstate). Following HNE treatment, cells were lysed with phosphatase extraction buffer (20mM imidazole-HCl, 2mM EDTA, 2mM EGTA, pH 7.0 with $10 \mu \mathrm{g} / \mathrm{ml}$ each of aprotinin, leupeptin, antipain, soybean trypsin inhibitor, 1 $\mathrm{mM}$ phenylmethylsulfonyl fluoride (PMSF), and $1 \mathrm{mM}$ benzamidine) and the lysate (450 $\mu \mathrm{g}$ of protein/per sample) was incubated with $4 \mu \mathrm{g}$ of an anti-PP2A antibody (clone 1D6; Upstate) and $35 \mu 1$ of protein A agarose slurry at $4^{\circ} \mathrm{C}$ with constant rocking for $2 \mathrm{~h}$. Agarose-bound immune complexes were collected and, following washing three times with $700 \mu 1$ TBS and $500 \mu \mathrm{l}$ optimized Ser/Thr buffer (final wash), 
were resuspended in $20 \mu \mathrm{l} \mathrm{Ser/Thr} \mathrm{buffer.} \mathrm{Phosphopeptide} \mathrm{(amino} \mathrm{acid} \mathrm{sequence:} \mathrm{K-}$

R-pT-I-R-R) was added $(60 \mu \mathrm{l})$ as a substrate for PP2A, and samples were incubated at $30^{\circ} \mathrm{C}$ in a shaking incubator for 10 minutes. Supernatants $(25 \mu 1)$ were transferred to a 96-well plate, and released phosphate was measured by adding $100 \mu 1$ malachite green phosphate detection solution. Color developed for 15 minutes before reading the plate at $650 \mathrm{~nm}$. The absorbance of the reactions was corrected by subtracting the absorbance of blank ( $25 \mu \mathrm{l} \mathrm{Ser/Thr} \mathrm{buffer).} \mathrm{Phosphate} \mathrm{concentrations} \mathrm{were} \mathrm{calculated}$ from a standard curve created using serial dilutions of a standard phosphate solution ( 0 to 2,000 pmol). Data were normalized to protein concentration and PP2A activity expressed as pmol phosphate/ $\mu \mathrm{g}$ protein/10 $\mathrm{min}$.

\section{Caspase-8 activity assay}

To measure caspase-8 activity, cytoplasmic extracts were prepared from Jurkat cells treated for $6 \mathrm{~h}$, and analyzed using the CASPASE- 8 Colorimetric Activity Assay kit (Chemicon International, Temecula, CA). The assay was based on spectophotometric detection of the chromophore $\rho$-nitroaniline $(\rho \mathrm{NA})$ after cleavage from the caspase- 8 specific substrate IETD- $\rho N A$. The free $\rho N A$ was quantified using a microtiter plate reader at $405 \mathrm{~nm}$. In brief, cell lysate was centrifuged at $10,000 \mathrm{xg}$ for $5 \mathrm{~min}$ and $45 \mu \mathrm{l}$ of the cytoplasmic fraction was transferred to a fresh tube and put on ice. A mixture of assay buffer (5X), sample supernatant, caspase- 8 substrate and distilled water were added and the plate incubated for $2 \mathrm{~h}$. Read samples at $405 \mathrm{~nm}$ with a microtiter plate reader. The optical density values obtained with the CASPASE8 Colorimetric Activity Assay kit for unknown samples were calculated from the standard curve. Comparison of the absorbance of $\rho$ NA from an apoptotic sample with 
an untreated control allows determination of the fold increase in caspase- 8 activity. The definition of one unit is the amount of enzyme that will cleave $1.0 \mathrm{nmol}$ of the colorimetric substrate Ac-IETD- $\rho$ NA per hour at $37^{\circ} \mathrm{C}$ under saturated substrate concentrations. The results were expressed as activity units per mg of protein.

\section{RNA isolation and real time PCR analysis}

Reverse transcriptase polymerase chain reaction (RT-PCR) assays were used to assess FasL mRNA levels in Jurkat cells. Total RNA was isolated from treated cells after $1 \mathrm{~h}$, using TRIZOL (Invitrogen, Carlsbad, CA). For real time PCR, the first strand cDNA was synthesized using TaqMan Reverse transcription reagents (Applied Biosystems). The reverse transcription was carried out using 1X Taqman RT buffer, $5.5 \mathrm{mM} \mathrm{MgCl}_{2}, 500 \mu \mathrm{M}$ of each dNTP, $2.5 \mu \mathrm{M}$ random hexamer, $8 \mathrm{U}$ of RNase inhibitor and $25 \mathrm{U}$ of Multiscribe Reverse Transcriptase with $200 \mathrm{ng}$ of total RNA. The RT conditions were $10 \mathrm{~min}$ at $25^{\circ} \mathrm{C}, 30 \mathrm{~min}$ at $48^{\circ} \mathrm{C}$ and $5 \mathrm{~min}$ at $95^{\circ} \mathrm{C}$. Reactions in which the enzyme or RNA were omitted were used as negative controls. Real time PCR was performed with an ABI prism 7000 sequence detection system and SYBR green I dye reagents. The specific primers were designed for human GAPDH and FasL using the Primer3 software program. The following primers were used in real time PCR:

hGAPDH-RT-FP1: 5' TGGGCTACACTGAGCACCAG 3'

hGAPDH-RT-RP1： 5' GGGTGTCGCTGTTGAAGTCA 3'

hFasL-RT-FP: $\quad$ 5' GGCCTGTGTCTCCTTGTGAT 3'

hFasL-RT-RP: $\quad$ 5' TGCCAGCTCCTTCTGTAGGT 3'

hFasR-RT-FP: $\quad$ 5' TTG CTA GAT TAT CGT CCA AAA GTG TT 3' 
hFasR-RT-RP: $\quad$ 5' AAC AGT CTT CCT CAA TTC CAA TCC 3'

The parameter $\mathrm{Ct}$ (threshold cycle) was defined as the fraction cycle number at which the fluorescence passed the threshold. The relative gene expression of FasL was analyzed using $2^{-\Delta \Delta C t}$ method (Livak and Schmittgen, 2001) by normalizing with GAPDH gene expression in all the experiments.

\section{Trypan blue dye exclusion}

To measure viability, cells were stained with trypan blue dye and then counted by light microscopy with a minimum of 100 total cells counted per slide, and scored as cells which were able to exclude the dye (alive) or unable to exclude the dye (dead). The results were expressed as the percentage of untreated cells (McClowskey et al., 1998).

\section{Immunoprecipitation and western blot analysis}

For immunoprecipitation (IP) of the Fas DISC, $20 \times 10^{6}$ Jurkat T cells were untreated or treated with HNE 2.5, 5 or $10 \mu \mathrm{M}$ for $3 \mathrm{~h}$. Following treatment, cells were lysed with IP lysis buffer (PBS pH 7.4, 1\% NP-40, $200 \mu \mathrm{M}$ sodium orthovanadate, 0.1 $\mathrm{mg} / \mathrm{ml}$ PMSF, $10 \mu \mathrm{g} / \mathrm{ml}$ aprotinin, $10 \mu \mathrm{g} / \mathrm{ml}$ leupeptin, $4 \mu \mathrm{g} / \mathrm{ml}$ benzamidine, $50 \mathrm{mM}$ potassium fluoride, $1 \mathrm{mM} \beta$-glycerophosphate, $5 \mathrm{mM}$ sodium pyrophosphate, $1 \mu \mathrm{M}$ okadaic acid) and the lysate (300 $\mu \mathrm{g}$ of protein/per sample) was incubated with $0.4 \mu \mathrm{g}$ of anti-Fas (B-10) antibody with overnight rotation at $4^{\circ} \mathrm{C}$. The following day, $20 \mu \mathrm{l}$ of protein $\mathrm{A} / \mathrm{G}$ plus agarose was added for $2 \mathrm{~h}$ rotation at $4^{\circ} \mathrm{C}$ and then immunoprecipitates were washed four times with IP lysis buffer, then separated on a 10\% SDS-PAGE and subjected to standard immunoblotting with an anti-FADD and anti-caspase- 8 antibody. 
Following treatment, cells were lysed and total cellular proteins $(55-65 \mu \mathrm{g}$ of protein) were resolved on a $10 \%$ SDS-PAGE and subjected to standard immunoblotting procedures. The primary antibodies used in this study were as follows: anti-FasL (C-178) 1:750; anti-FADD 1:1000; anti-caspase-8 1:100; antiFLIP $\gamma / \delta 1: 750$ and $\beta$-Actin 1:1000. The appropriate secondary antibodies were used at 1:2000 for FasL and FADD; 1:5000 for FLIP $\gamma / \delta$ and $\beta$-Actin and 1:15,000 for caspase8. Proteins signals were visualized using the ECL system (Amersham Pharmacia Biotech, Piscataway, NJ), as directed by the manufacturer. The molecular sizes of the developed proteins were estimated by comparison with prestained protein markers (Invitrogen, Carlsbad, CA).

\section{Statistical analysis}

Data are expressed as means \pm SD. Statistical analyses were performed using SPSS 11.5 (SPSS Ins., Chicago, IL) for Windows XP. Differences between the means of two groups were evaluated by a two-tailed t-test for independent samples. Differences between the means of three or four groups were evaluated by a single factor analysis of variance (ANOVA), and further assessed by Tukey tests. Differences were considered statistically significant for $\mathrm{P}<0.05$.

\section{RESULTS}

\section{Effect of HNE and MDA on cell viability}

Our previous studies have shown that HNE leads to a significant loss in survival due to the induction of apoptotic death. Treatment of Jurkat $\mathrm{T}$ cells with HNE significantly decreased survival to $32 \%$ (at $2.5 \mu \mathrm{M}$ ) and $22 \%$ (at $5 \mu \mathrm{M}$ ), respectively, 


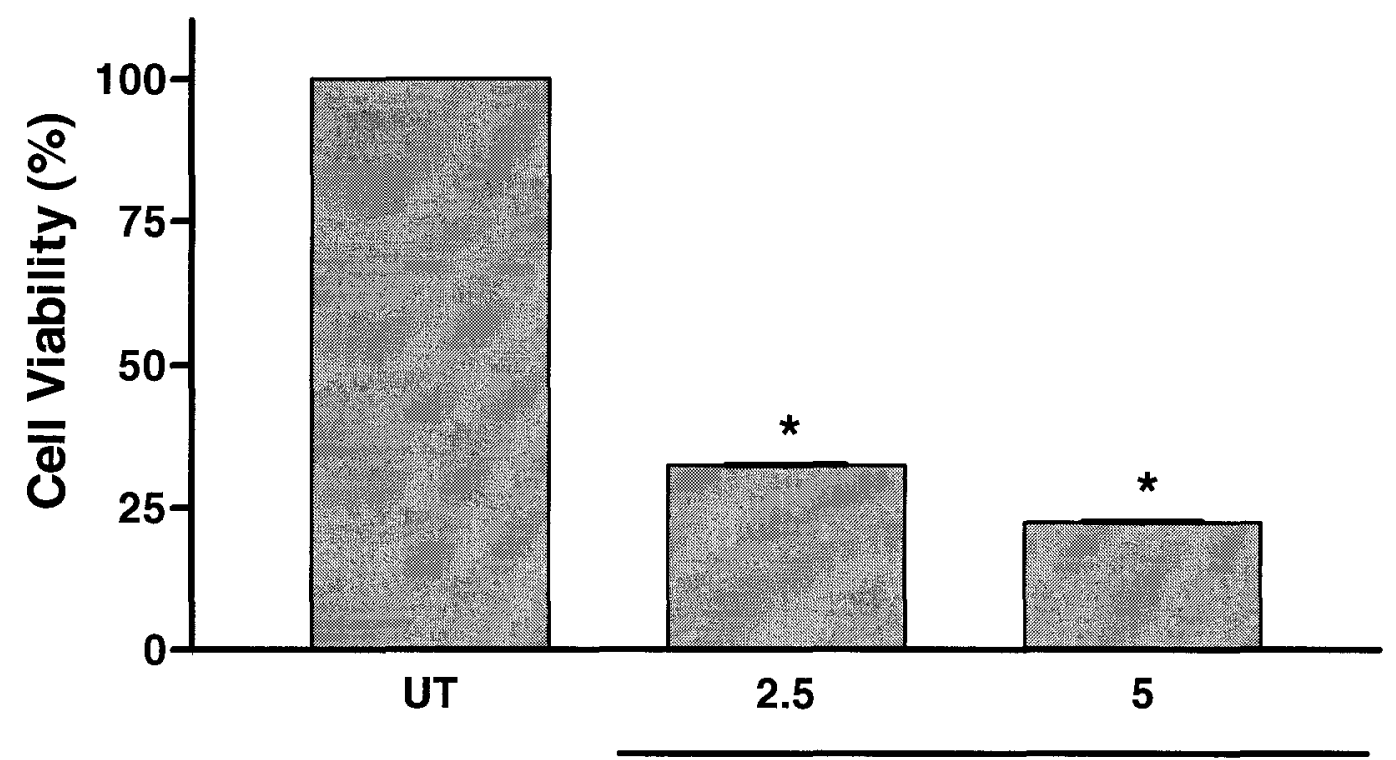

HNE $(\mu \mathrm{M})$

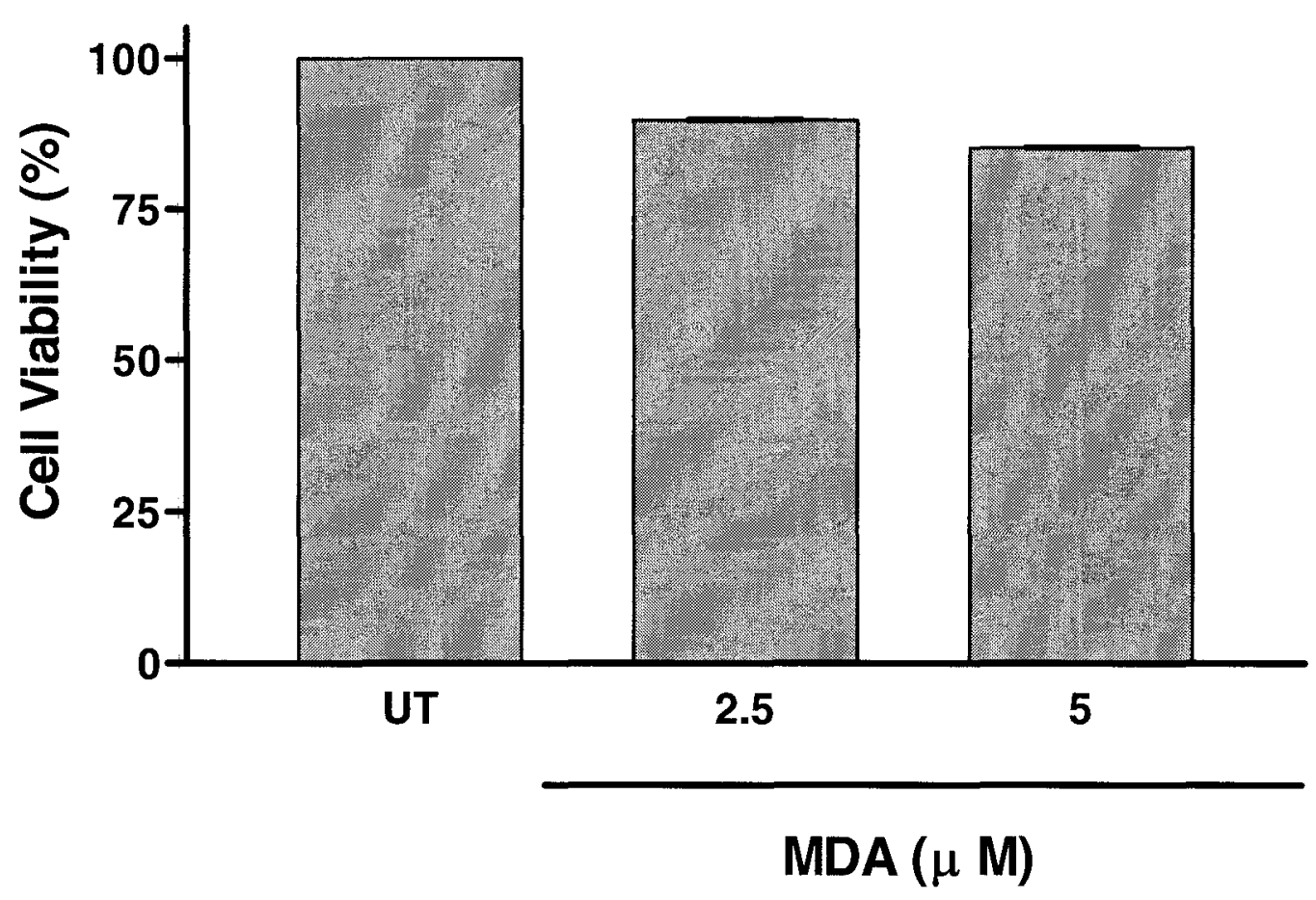

Fig. 8. Effects of HNE and MDA on cell viability. Cells were maintained in low serum medium ( $1 \%$ serum, ov er night) and then treated with 2.5 and $5 \mu \mathrm{M}$ HNE (A) or MDA (B) for $24 \mathrm{~h}$. Cell survival was measured by Trypan blue exclusion assay. Data were normalized to the untreated control (which is set to $100 \%$ ) and represented as mean $\pm \mathrm{SD}$ of three separate experiments . ${ }^{*} \mathrm{P}<0.05$ compared to UT . 
of the untreated value (Fig. 8A). HNE also induced a dose dependent increase (2 to 2.5 fold) in the DNA fragmentation in correspondence with the observed loss of T cell survival (data not shown).

Since HNE had a significant effect on T cell survival, we further examined the effect of another lipid peroxidation product, MDA (2.5 and $5 \mu \mathrm{M})$. In contrast to $\mathrm{HNE}$, treatment of Jurkat $\mathrm{T}$ cells with increasing concentrations of MDA had no effect on the T cell survival; the cell viabilities were $90 \pm 0.05 \%$ and $85 \pm 0.08 \%$ of untreated control at 2.5 and $5 \mu \mathrm{M}$, respectively (Fig. 8B).

\section{Effects of HNE on Akt kinase}

The serine-threonine kinase (PKB/Akt) has been shown to be critical for $\mathrm{T}$ lymphocyte survival and inhibition of Akt leads to apoptotic T cell death. To further investigate the mechanism of HNE-induced apoptotic cell death, we studied the role of Akt kinase in the survival pathway. In untreated cells, Akt was found to be constitutively phosphorylated at Ser 473. The basal level of $p$-Akt in untreated cells was $28.61 \pm 2.04 \mathrm{unit} / \mathrm{mg}$ protein. Cells were exposed to different concentrations of HNE $2.5,5$, and $10 \mu \mathrm{M}$ for $6 \mathrm{~h}$. The resulting $p$-Akt concentrations were found to be $20.99 \pm 3.13,3.17 \pm 3.28,1.45 \pm 0.06$ unit/mg protein, respectively, which were about 37, 11 and 5\% of the untreated values (Fig. 9A). The results of decreased phospho-Akt levels were further confirmed by western blot analysis. A dose-dependent dephosphorylation of phospho-Akt was observed in cells treated with HNE (2.5-10 $\mu \mathrm{M})$ at $3 \mathrm{~h}$. Similarly, HNE effectively decreased Akt activation at $6 \mathrm{~h}$. The most profound decrease in dephosphorylation of Akt was found at $10 \mu \mathrm{M}$ HNE. There were no significant changes in total Akt at $3 \mathrm{~h}$ after HNE treatment. However, HNE 


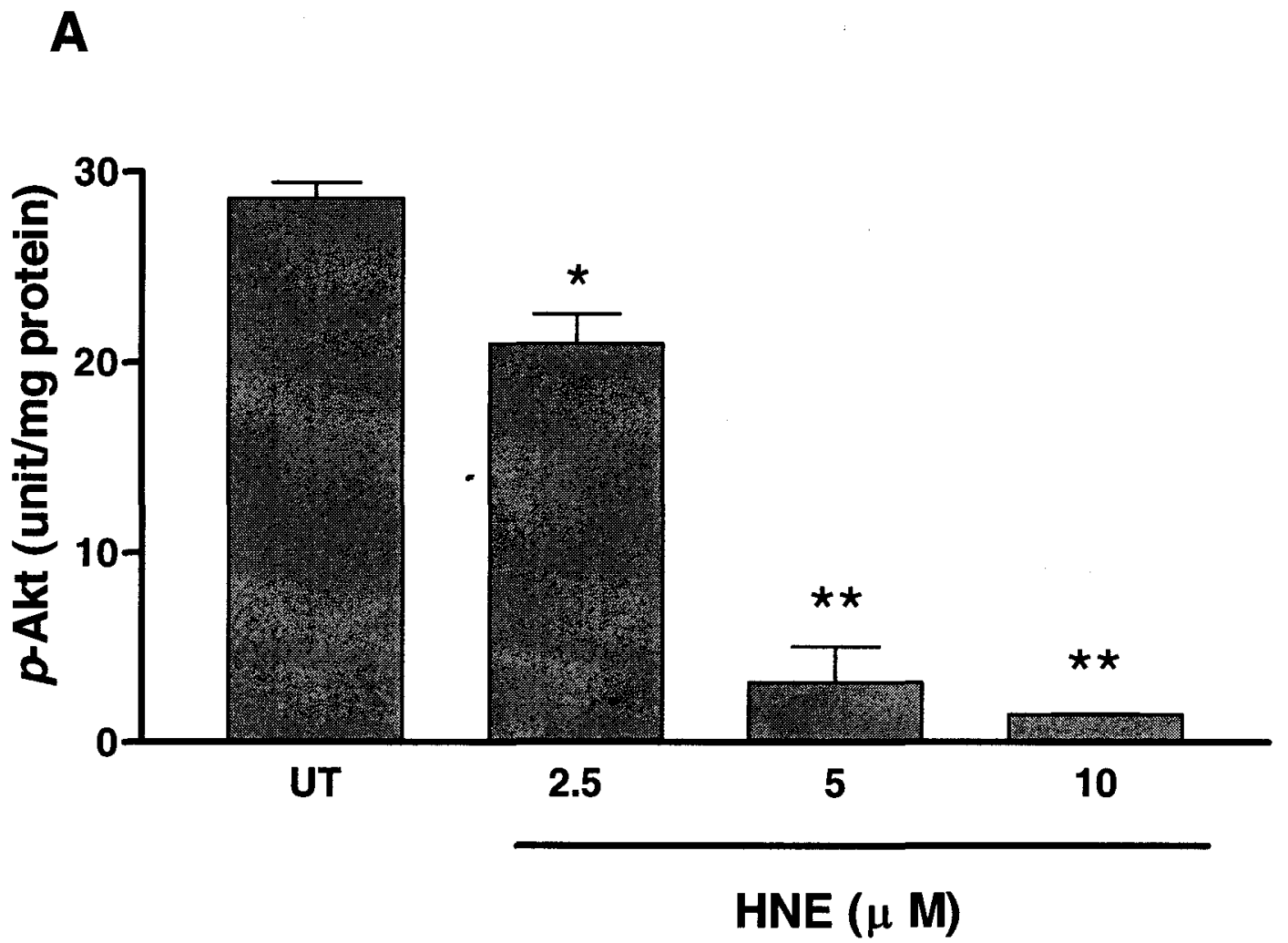

Fig. 9. HNE downregulates Akt activation. Sample preparation was as described in Fig. 8A. (A) $p$-Akt concentration. Cell extracts were harvested at $6 \mathrm{~h}$ after HNE treatment. Data were normalized to protein concentration and $p$-Akt concentrations expressed as unit/mg protein. Data are represented as mean $\pm \mathrm{SD}$ of three separate experiments . ${ }^{*} \mathrm{P}<0.01$ and ${ }^{* *} \mathrm{P}<0.001$ compared to UT. (B) Western blotting. Total cell lysates were collected for Western blot analysis as described in Materials and Methods. Akt and phospho-Akt were detected at $3 \mathrm{~h}$ (left panel) and $6 \mathrm{~h}$ (right panel) by immunoblot ting using anti-Akt and phospho-Akt antibodies. Blots were stripped and reprobed with antibody to $\beta$-actin to ensure equivalent loading. A representative gel out of three experiments is shown. 

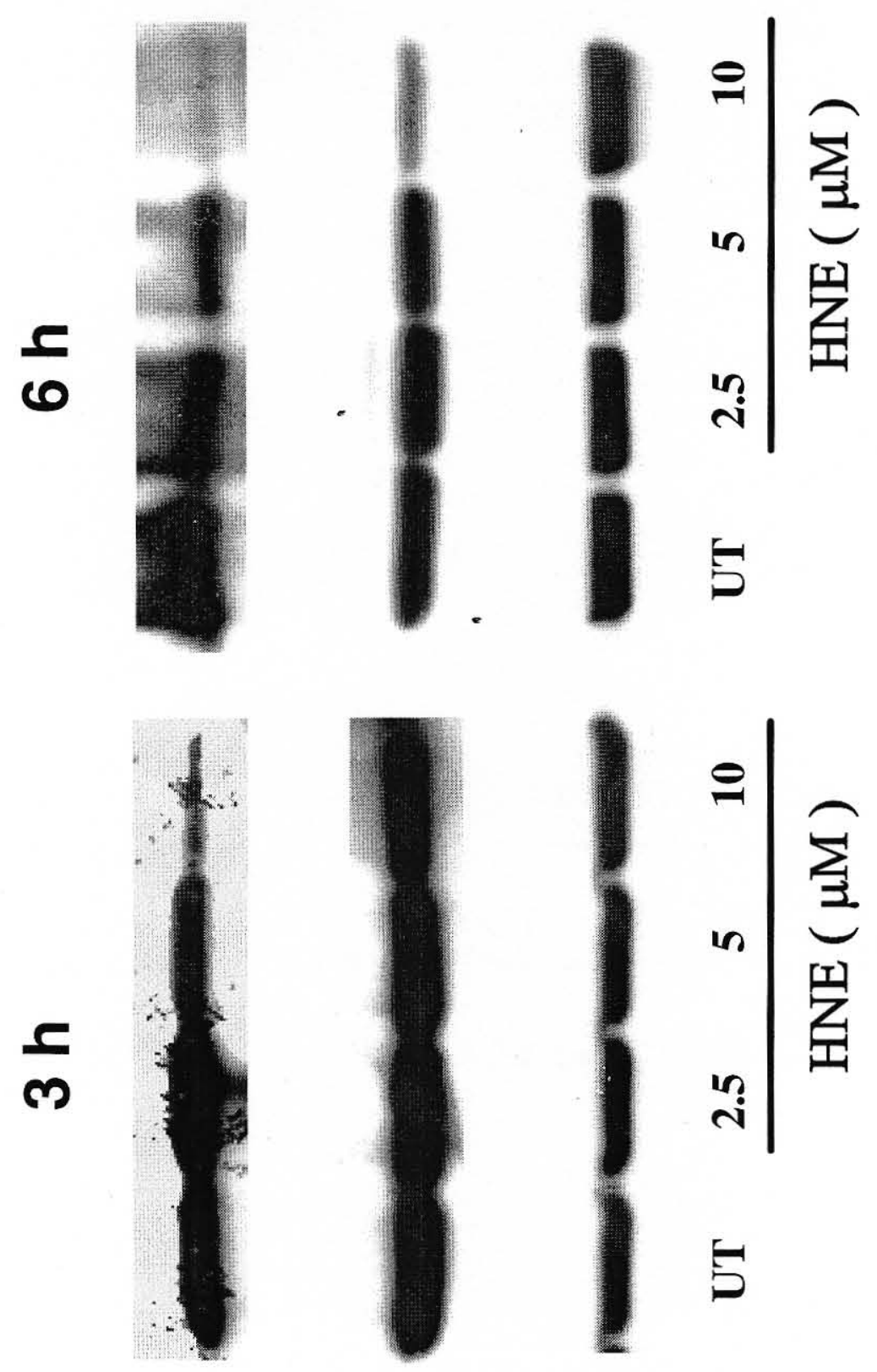

m

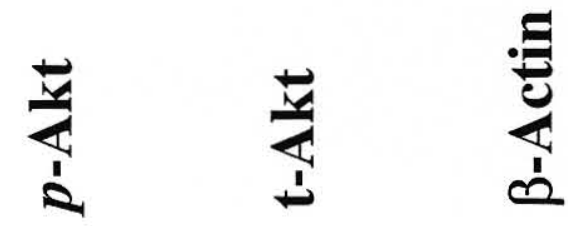


decreased phosphor- and total Akt expression at $6 \mathrm{~h}$ with $\mathrm{HNE}$ concentrations of 5 and $10 \mu \mathrm{M}$ (Fig. 9B). Thus, these results demonstrate that in a dose-dependent manner, HNE mediates the dephosphorylation of Akt in the early stage of apoptosis.

\section{Effects of HNE on PP2A activity}

PP2A is serine/threonine phosphatase and studies have shown that PP2A dephosphorylated and inactivated Akt in vitro (Van Kanegan et al., 2005). To confirm the involvement of PP2A in the process of HNE-mediated Akt dephosphorylation, we next examined whether the overall catalytic activity of PP2A was upregulated after HNE treatment. Using a nonradioactive serine/threonine phosphatase assay kit with the phosphopeptide K-R-pT-I-R-R as a substrate, we measured the amount of released phosphate, which indicates PP2A catalytic activity. In untreated Jurkat T cells, PP2A activity was determined by the phosphate release, which was $137 \pm 42$ pmol phosphate/ $\mu \mathrm{g}$ protein/ $10 \mathrm{~min}$. As shown in Fig. 10, at $30 \mathrm{~min}$ after $\mathrm{HNE}(2.5$ and $5 \mu \mathrm{M})$ treatment, PP2A activities increased 160\% (220 $\pm 43 \mathrm{pmol}$ phosphate/ $\mu \mathrm{g}$ protein $/ 10$ $\mathrm{min})$ and $212 \%(290 \pm 101 \mathrm{pmol}$ phosphate/ $\mu \mathrm{g}$ protein/ $10 \mathrm{~min})$, respectively, of the untreated value. Our results suggest that PP2A enzymatic activity is increased dosedependently in Jurkat $\mathrm{T}$ cells treated with HNE.

\section{Effect of HNE on FasL expression}

Since FasL is a well established apoptotic stimulus for T lymphocytes, we examined FasL expression in the HNE treated Jurkat T cells. Immunoblot analysis showed that treatment of cells with HNE $(2.5$ and $5 \mu \mathrm{M})$ for $6 \mathrm{~h}$ significantly increased FasL protein expression as compared to the untreated cells (Fig. 11A). On the other hand, corresponding to its minimal effect on cell survival, treatment of cells with MDA 


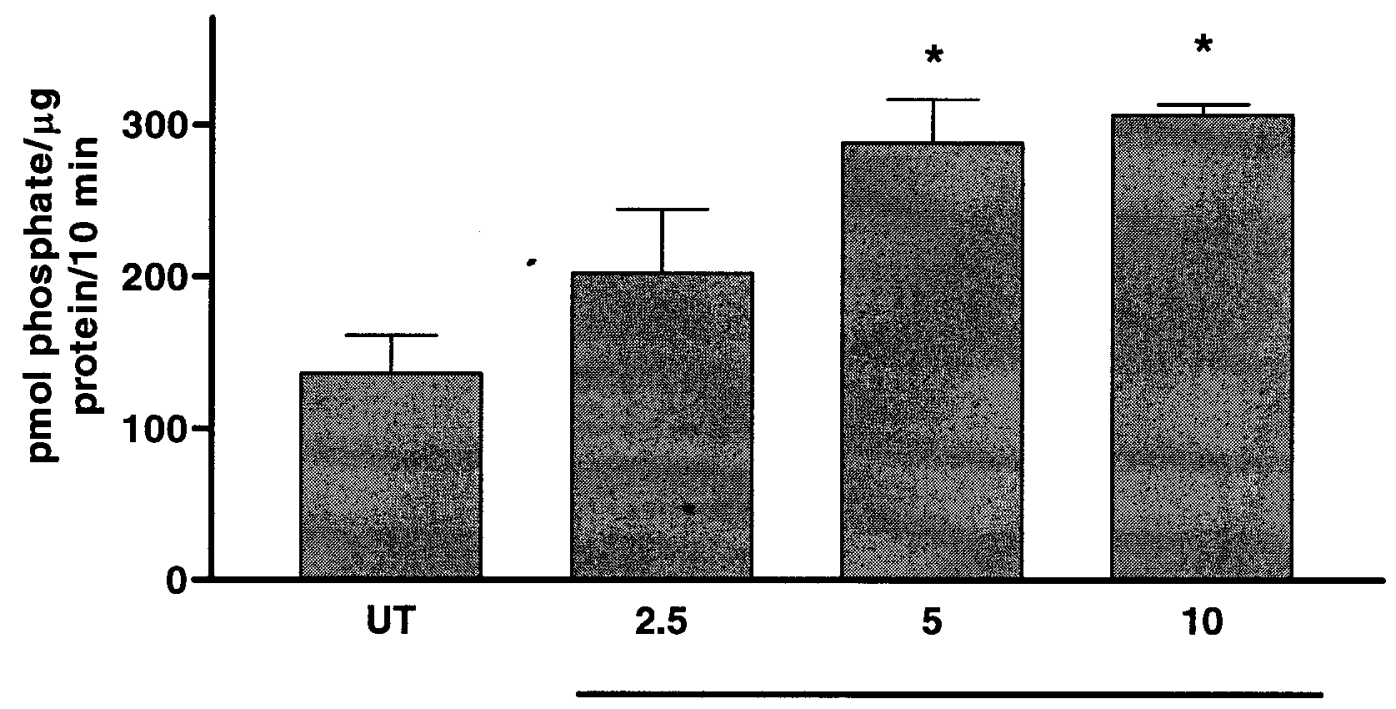

$\operatorname{HNE}(\mu \mathrm{M})$

Fig. 10. HNE increases PP2A activity. Sample preparation was as described in Fig. 8A. Cell extracts were harvested at $30 \mathrm{~min}$ after HNE treatment. PP2A activity was measured using PP2A immunoprecipitation assay kit as described in Materials and Methods. Data were normalized to protein concentration and PP2A activity expressed as pmol phosphate/ $\mu \mathrm{g}$ protein $/ 10$ min. Data are represented as mean $\pm \mathrm{SD}$ of three separate experiments. " $\mathrm{P}<0.05$ compared to UT. 

0.93
$1.06 \quad 1.09$
1.21
$\begin{array}{ll}0.87 & 0.85\end{array}$
0.70

\section{FasL}

\section{$\beta$-Actin}
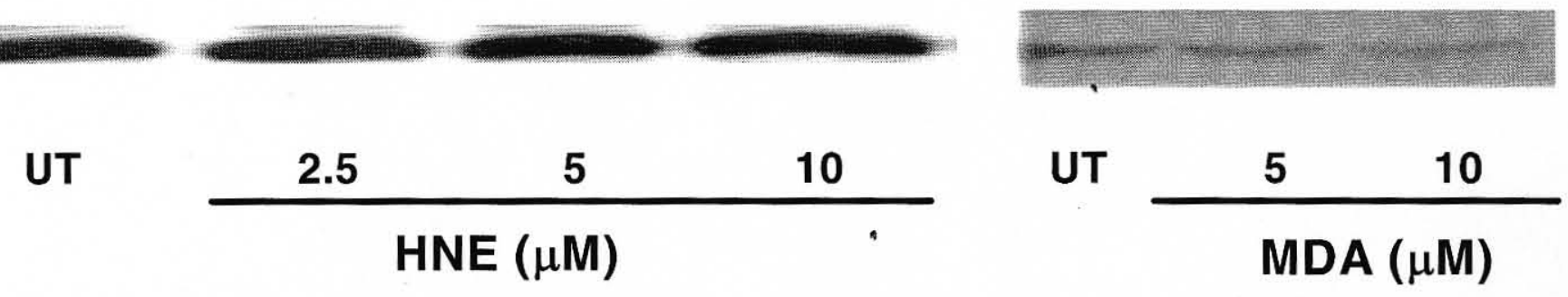

Fig. 11. HNE enhances FasL expression. (A) Western Blot Analysis: Cells exposed to different concentrations of $\operatorname{HNE}(2.5,5$ and $10 \mu \mathrm{M})$ and MDA $(5$ and $10 \mu \mathrm{M})$ for $6 \mathrm{~h}$. Total cell lysates were collected for Western blot analysis as described in Materials an d Methods. FasL was detected at $6 \mathrm{~h}$ by immunoblot ting using an anti-FasL-specific antibody. Blots were stripped and reprobed with antibody to $\beta$-actin to ensure equivalent loading. A representative gel out of three experiments is shown. (B) Real Time PCR: Total RNA was isolated from cells, untreated (UT) or treated with $\mathrm{HNE}(2.5$ and $5 \mu \mathrm{M})$ at $1 \mathrm{~h}$. (C) Real Time PCR: Total RNA was isolated from cells, untreated (UT) or treated with HNE $(5 \mu \mathrm{M})$ at 1,3 and $6 \mathrm{~h}$. FasL mRNA levels were determined by real time PCR. Data are represented as mean $\pm \mathrm{SD}$ of four separate experiments. ${ }^{*} \mathrm{P}<0.05$ compared to UT. 
B

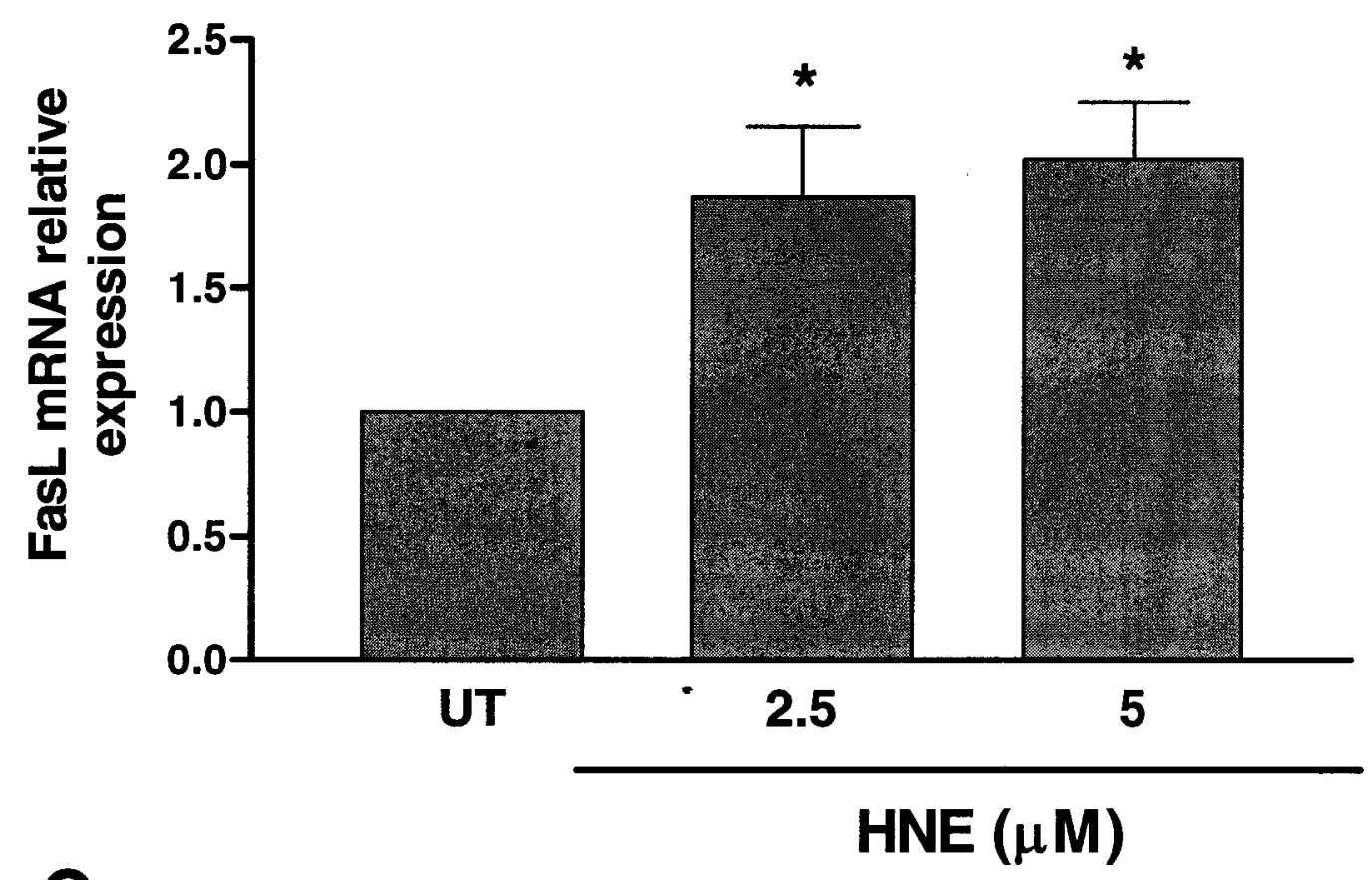

C

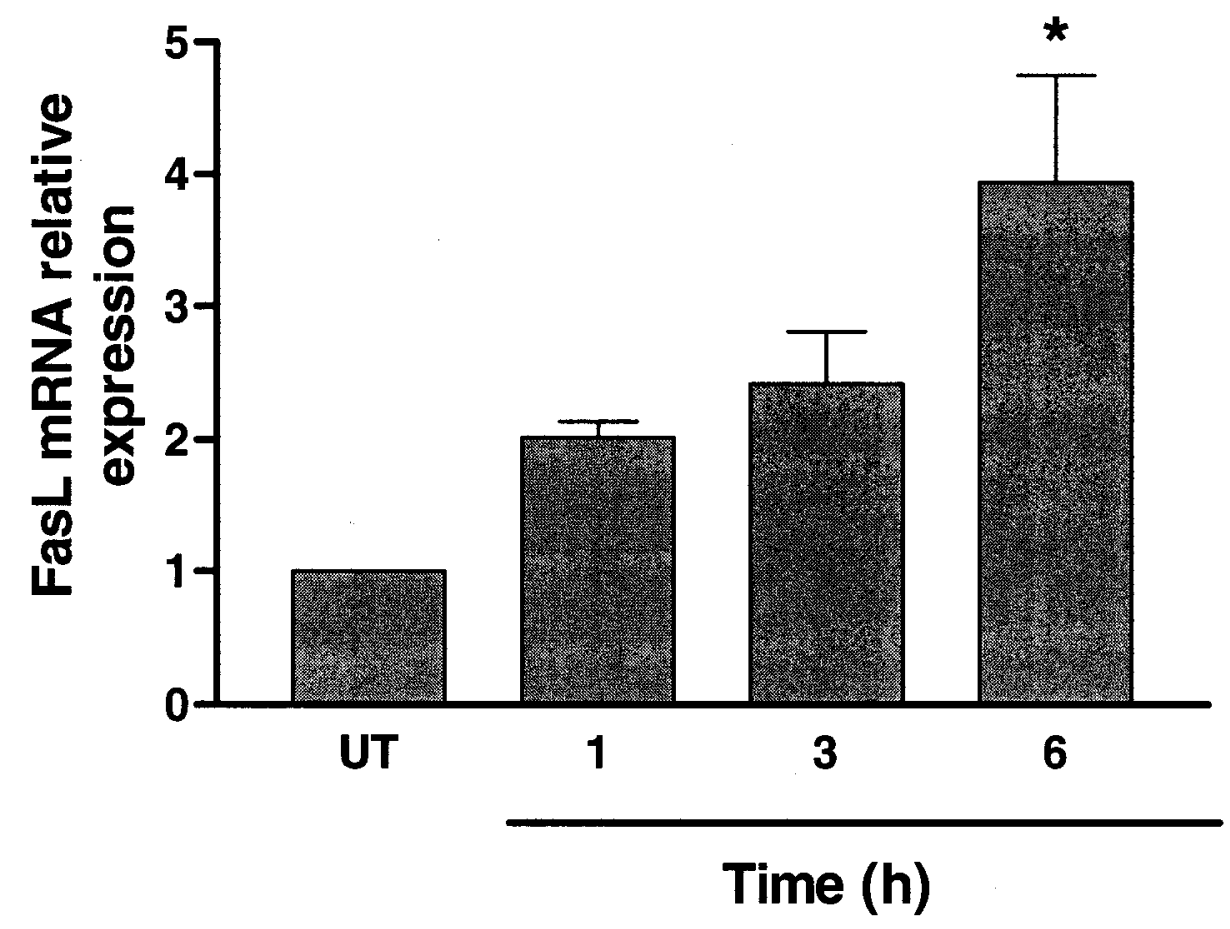


(5 and $10 \mu \mathrm{M}$ ) at $6 \mathrm{~h}$ showed no increase in FasL protein expression (Fig. 11A). To determine whether the enhancement in the FasL protein in response to HNE treatment was at the transcriptional level, we quantified the steady state FasL mRNA levels by real time PCR. Total RNA was isolated from T cells that were exposed to HNE (2.5 and $5 \mu \mathrm{M}$ ) in serum free medium for $15 \mathrm{~min}$ and then serum containing medium for $1 \mathrm{~h}$ and analyzed by real time PCR. The data showed that in correspondence with FasL protein expression, FasL mRNA was significantly induced (approximately 2 -fold) after $1 \mathrm{~h}$ treatment with HNE (Fig. 11B). Total RNA was isolated from $\mathrm{T}$ cells exposed to 5 $\mu \mathrm{M}$ HNE for 1,3 and $6 \mathrm{~h}$, the time effect analyzed by real time PCR. The data showed that FasL mRNA was induced ( 2 to 4 fold) after HNE treatment in a time-dependent manner (Fig. 11C).

\section{Effects of HNE on Fas mediated DISC formation}

To further elucidate the effect of HNE, components of the Fas/FasL apoptotic pathway were examined in HNE treated T cells. FasL binding to the Fas receptor (Fas) is known to induce the formation of DISC, involving the recruitment of FADD and subsequent recruitment and activation of caspase-8 (Peter and Krammer, 2003). Hence, the effect of HNE treatment on FADD recruitment to Fas was examined. A Fas antibody was used to immunoprecipitate the DISC from lysates (normalized for protein) of cells treated with $\operatorname{HNE}(2.5,5$ and $10 \mu \mathrm{M})$. Immunoprecipitates were resolved using SDS-PAGE and examined by Western blot analysis using antibodies against FADD and Fas. Increased recruitment of FADD was seen in HNE treated cells as compared to the control cells (Fig. 12). 
FADD

Fas (B-10)

\section{Caspase-8}
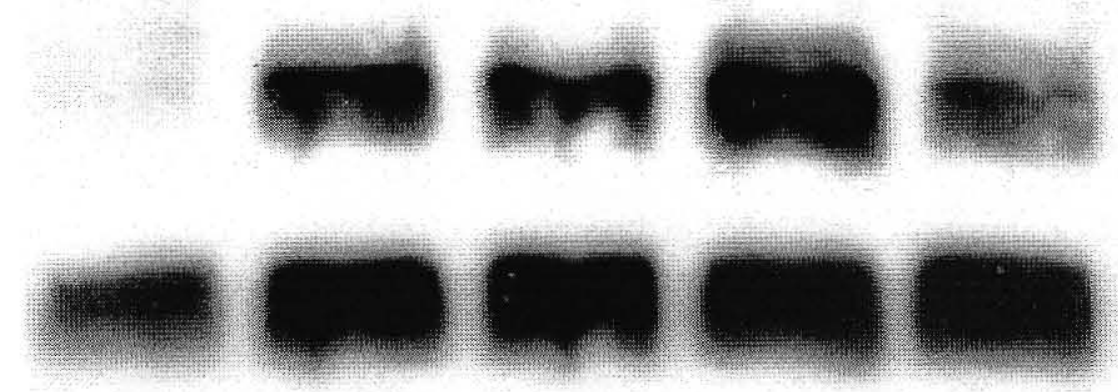

UT

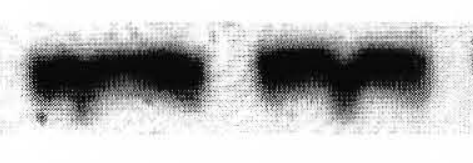

$-$

2.5

5

10

PHA

HNE $(\mu \mathrm{M})$

Fig. 12. HNE increases binding of FADD to the DISC. Cells were incubated with HNE (2.5, 5 , and $10 \mu \mathrm{M}$ ) for $3 \mathrm{~h}$. Total cell lysates were collected for immunoprecipitation with Fas receptor an tibody followed by immunoblotting analysis with FADD or caspase -8 antibodies as described in Materials and Methods. Untreated cells (UT) were used as a negative control; blots were stripped and reprobed with Fas receptor antibody (Fas B -10) to ensure equivalent loading. PHA $(10 \mu \mathrm{g} / \mathrm{ml})$ is a positive control. A repres entative gel out of three experiments is shown. 
Further analysis of the immunoprecipitates showed that the increase in FADD recruitment was accompanied by an increase in procaspase- 8 recruitment into the DISC (Fig. 12). The $56 \mathrm{kDa}$ procaspase- 8 undergoes several processing steps to generate cleaved fragments of p42-44 kDa, p28 kDa, p18 kDa and p10-12 kDa in different cells undergoing apoptosis. HNE was found to significantly increase caspase-8 activation. This activation was documented by the presence of the $\mathrm{p} 42 \mathrm{kDa}$ cleavage product of caspase-8 in HNE treated cell lysates (Fig. 13).

\section{Effect of HNE on c-FLIPs expression, caspase-8 activity and DNA fragmentation}

To further elucidate the molecular mechanism of Fas-mediated apoptosis in response to $\mathrm{HNE}$ in T lymphocytes, we examined the effect of HNE on expression of c-FLIP , since it has been demonstrated that c-FLIP is a dominant negative inhibitor of caspase-8. Western analysis was performed on Jurkat $\mathrm{T}$ cells showed that $\mathrm{c}-\mathrm{FLIP}_{\mathrm{S}}$ levels decreased after HNE treatment (Fig. 14). Corresponding with the increase in

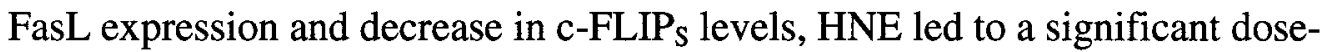
dependent increase in caspase-8 activity (Fig. 15A). Moreover, pretreatment of Jurkat cells with a caspase- 8 specific inhibitor blocked the DNA fragmentation induced by HNE (Fig. 15B). This data suggests that HNE leads to caspase-8 dependent apoptotic death was caused by the up-regulation of FasL expression and down-regulation of cFLIPS levels (Figs. 11 and 14).

\section{Relevance of FasL expression to cell death induced by HNE}

To test the functional relevance of FasL expression in HNE-induced cell death, we examined whether the blocking of Fas/FasL ligation would protect Jurkat T cells against apoptosis. With this intent, we used the anti-FasL IgG antibody (NOK-2), 


\section{$\begin{array}{llll}0 & 0.76 & 0.84 & 0.94\end{array}$}

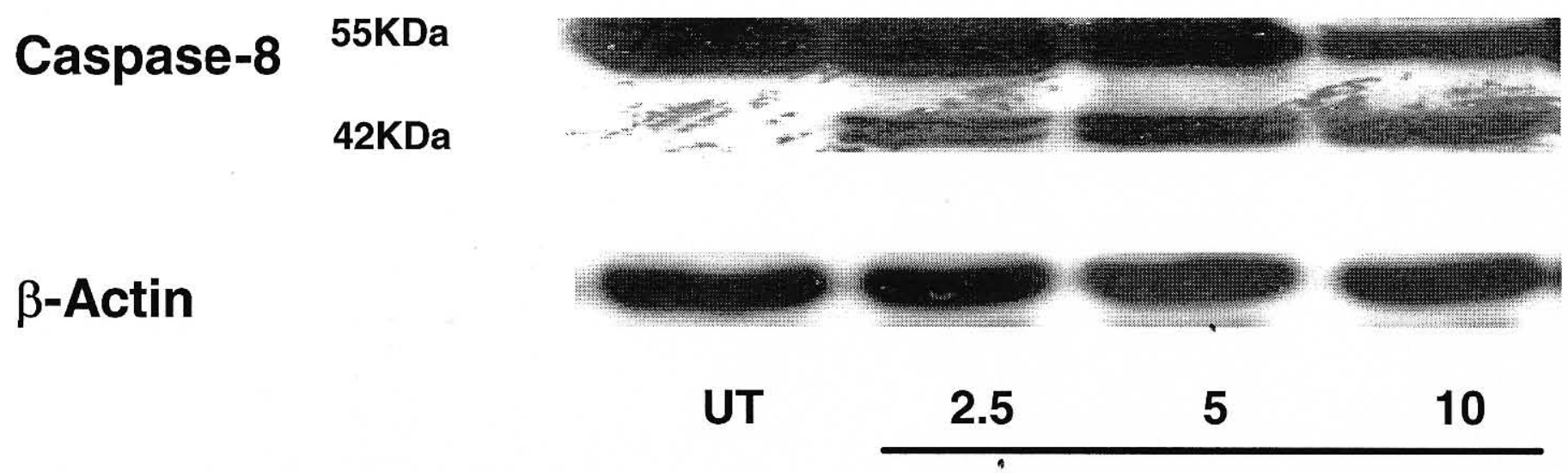

\section{HNE $(\mu \mathrm{M})$}

Fig. 13. HNE induces caspase -8 activation. Cells were exposed to different concentrations of $\operatorname{HNE}(2.5,5$ and $10 \mu \mathrm{M})$ for $6 \mathrm{~h}$. Total cell lysates were collected at $6 \mathrm{~h}$ for Western blot analysis as described in Materials and Methods. Untreated cells (UT) were used as a negative control. Pro and active caspase -8 was detected by immunoblotting using anti caspase- 8 antibody. Blots were stripped and reprobed with antibody to $\beta$-actin to ensure equivalent loading. A r epresentative gel out of three experiments is shown. 
$3 \mathbf{h}$

1.28

1.20

0.95

0.51

\section{c-FLIPs (26.5 KDa)}

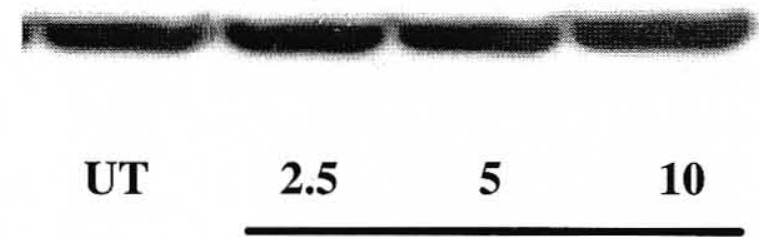

HNE $(\mu \mathrm{M})$
1.00

0.95

0.70

0

$6 \mathrm{~h}$

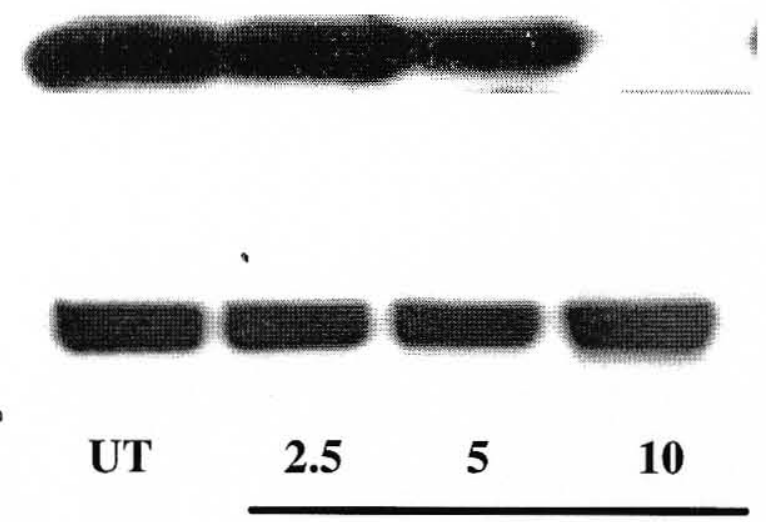

HNE $(\mu \mathrm{M})$

Fig. 14. HNE downregulates $\mathrm{c}-\mathrm{FLIP}_{\mathrm{S}}$ protein. Cells were exposed to different concentrations of $\operatorname{HNE}(2.5,5$ and $10 \mu \mathrm{M})$ for $3 \mathrm{~h}$ (left panel) and $6 \mathrm{~h}$ (right panel). Total cell lysates were collected for Western blot analysis as described in Materials and Me thods. c-FLIPS was detected at 3 and $6 \mathrm{~h}$ by immunoblotting using anti-c-FLIP $\delta / \gamma$ antibody. Blots were stripped and reprobed with antibody to $\beta$-actin to ensure equivalent loading. $\mathrm{A}$ representative gel out of three experiments is shown. 
Fig. 15. HNE induces Caspase-8 dependent apoptosis. (A) Cell apoptosis was measured by caspase- 8 activity assay. Cells were exposed to different concentrations of $\operatorname{HNE}(2.5,5$ and $10 \mu \mathrm{M})$ and the total cell lysates were collected at $6 \mathrm{~h}$ after HNE treatment for caspaspe- 8 activity assay as described in Materials and Methods. Data were expressed as unit per $\mathrm{mg}$ of protein and represented as mean $\pm \mathrm{SD}$ of six separate experiments. ${ }^{*} \mathrm{P}<0.05$ compared to UT. (B) DNA fragmentation: Cells were maintained in low serum medium (1\%, over night) and then pretreated with $100 \mu \mathrm{M}$ of Caspase- 8 inhibitor (CI) for $1 \mathrm{~h}$. After $1 \mathrm{~h}$, cells were treated with increasing concentrations of HNE $(2.5$ and $5 \mu \mathrm{M})$ for $8 \mathrm{~h}$. Cell survival was then measured by DNA fragmentation using the Cell Death ELISA kit. Data were normalized to the untreated control (which is set to 1 ) and represented as mean \pm SD of three separate experiments. In each experiment, duplicate wells are assayed separately for each treatment. ${ }^{*} \mathrm{P}<0.05$ compared to UT, ${ }^{\mathrm{a}, \mathrm{b}} \mathrm{P}<0.05$ compared to HNE 2.5 and $5 \mu \mathrm{M}$, respectively. 
A

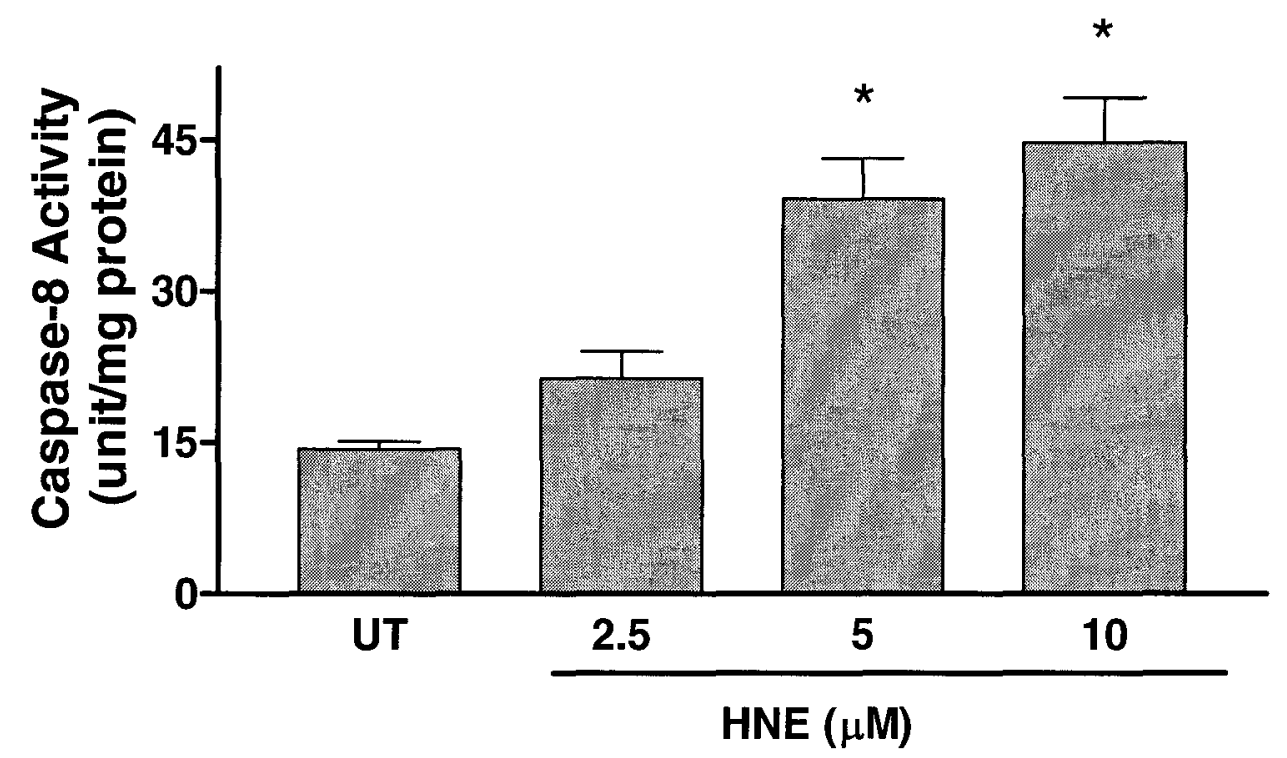

B

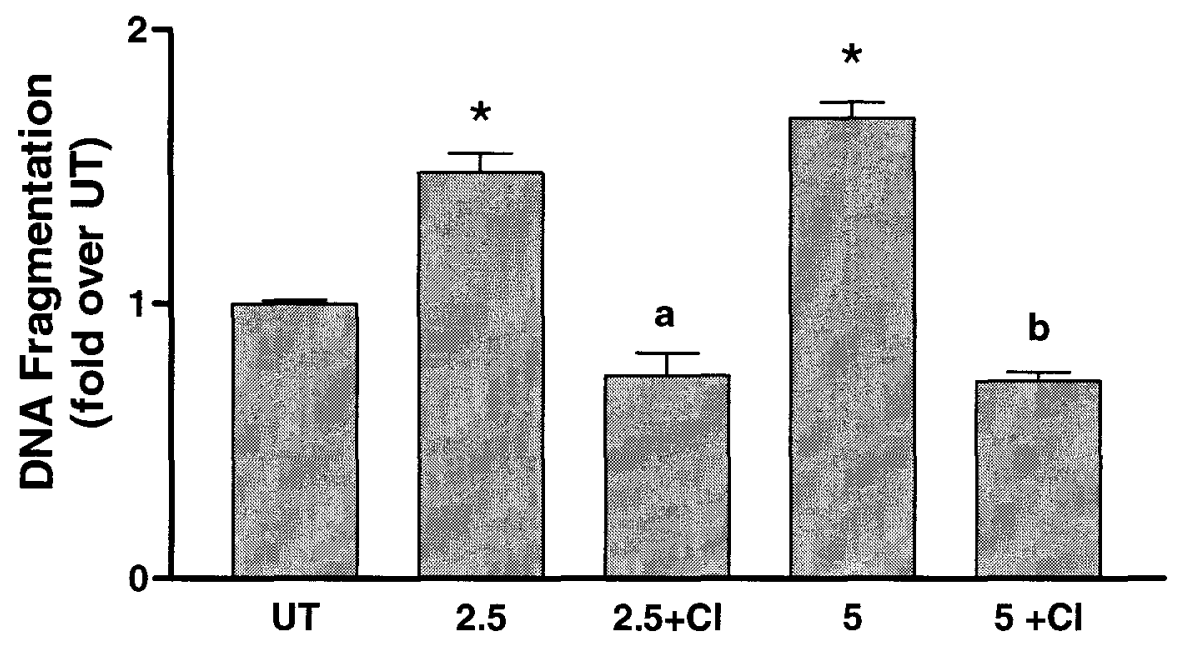




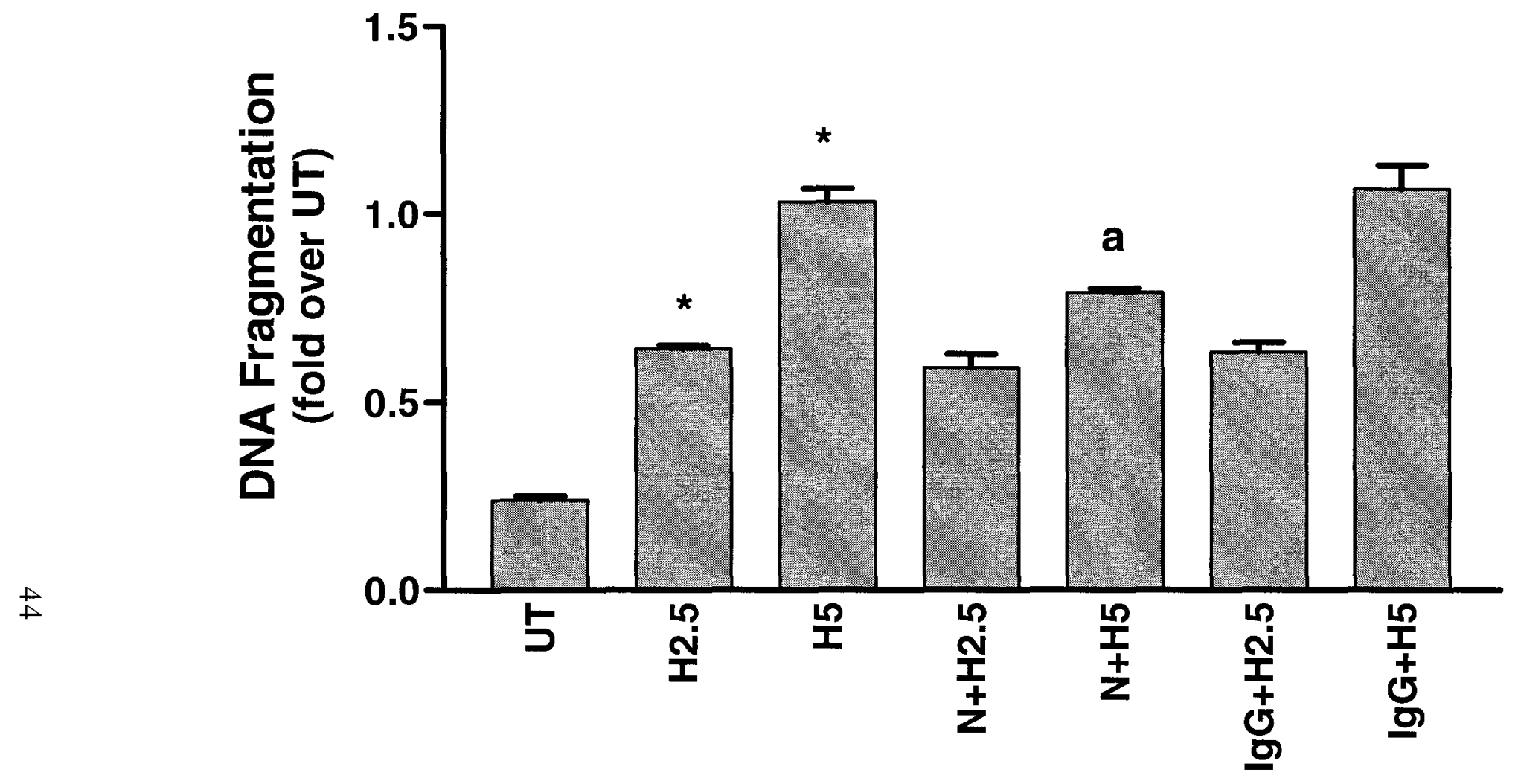

Fig. 16. Neutralization of FasL protects Jurkat T cells from apoptosis induced by HNE. Jurkat T cells were untreated (UT) or treated with HNE $(2.5$ and $5 \mu \mathrm{M})$. In one group, NOK-2 antibody $(50 \mu \mathrm{g} / \mathrm{ml})$ or the isotype $\operatorname{IgG}_{2 \mathrm{a}}(50 \mu \mathrm{g} / \mathrm{ml})$ control was added $15 \mathrm{mi} \mathrm{n}$ after treating the cells with HNE, and then the cells were harvested a $\mathrm{t} 6 \mathrm{~h}$ to measure apoptosis. Cytoplasmic extracts were prepared and analyzed for DNA fragmentation by Cell Death ELISA kit as described in Materials and Methods. Data were normalized to the untreated control and represented as mean $\pm \mathrm{SD}$ of three different experiments. ${ }^{*} \mathrm{P}<$ 0.05 compared to UT, ${ }^{a} \mathrm{P}<0.05$ compared to HNE $5 \mu \mathrm{M}$. 
which recognizes and neutralizes both membrane-bound and soluble forms of FasL in human by interfering with Fas/FasL ligation and inhibiting Fas signaling. Incubation of Jurkat T cells with NOK-2 antibody after HNE ( 2.5 and $5 \mu \mathrm{M})$ treatment for $15 \mathrm{~min}$ attenuated apoptosis by approximately 8 and $24 \%$, respectively. Treatment with the $\mathrm{IgG}_{2 \mathrm{a}}$ isotype antibody (negative control) did not protect cells from undergoing apoptosis (Fig. 16). The results showed the association between HNE and Fasmediated apoptosis, suggesting HNE-induced apoptosis is partly mediated by FasL expression.

\section{DISCUSSION}

During the process of lipid peroxidation, several reactive low-molecular weight products are formed, including reactive aldehydes, e.g., 4-hydroxynonenal (HNE). HNE is one of the major aldehydic products of the peroxidation of membrane $\omega-6$ poly-unsaturated fatty acids. It has been implicated as a causative agent in cytotoxic processes initiated by the exposure of cellular systems to oxidizing agents (Uchida, 2003; Minotti et al., 1991; Kalinich et al., 1999). In comparison to free radicals, the aldehydes are relatively stable and can diffuse within or be released extra-cellularly and attack targets distant from the site of the original event. Significantly, HNE functions as an endogenous lipid mediator to induce a variety of cellular processes that represent a cellular response program under oxidative stress (Benedetti et al., 1984). Clinically, HNE is highly likely to be causally involved in many of the pathophysiological effects associated with oxidative stress and immune dysfunction such as diabetes mellitus, alcoholism, and HIV and HCV infection (Clot et al., 1994; Cambiaggi et al., 1997; 
Kajimoto et al., 2002; Rigamonti et al., 2003). In the context of immune dysfunction, HNE has been demonstrated to play a critical role in the down-regulation of cell proliferation and in the modulation of cell differentiation in T lymphocytes (Barrera et al., 1991; Gioacchini et al., 1999). CD4 ${ }^{+}$T cells are critical regulators of both the humoral and cell mediated immunity and their loss plays a significant role in immune dysfunction. Hence, the mechanisms underlying the effect of $\mathrm{HNE}$ on $\mathrm{CD} 4^{+} \mathrm{T}$ cell survival were examined.

Our earlier results demonstrated that $\operatorname{HNE}(2.5$ and $5 \mu \mathrm{M})$ induced dosedependant cell death as assessed by trypan blue exclusion and apoptosis as assessed by DNA fragmentation in Jurkat cells (Chang, 2004). Others have also shown that HNE $(20-50 \mu \mathrm{M})$ induced dose-dependent apoptosis in human lymphoma Jurkat $\mathrm{T}$ cells. However, they showed that $\mathrm{HNE}$ at $20 \mu \mathrm{M}$ reduced cell viability to approximately $60 \%$ of the untreated cells, whereas at lower concentrations $(\leq 10 \mu \mathrm{M})$ HNE had no effect (Brunner et al., 2003; Liu et al., 2000). However, the difference of the result is possibly through the source of HNE. Thus, our results along with others confirmed that HNE can cause cytotoxicity. Further our results showed that MDA, another lipid peroxidation product, had no effect on cell viability, suggesting that HNE is more toxic than MDA. Others have shown a similar pattern of toxicity in human fibroblasts when treated with HNE and MDA (Michiels and Remacle, 1991). HNE is highly reactive and has three reactive groups (i.e., an aldehyde, a double-bond, and a hydroxy group), which might possibly explain its higher toxicity through the initiation and propagation of a free radical chain reaction. 
The serine-threonine kinase Akt (or PKB) is critical for survival and protection against apoptosis in various cells (Burgering and Coffer, 1995; Franke et al., 1995). The balance between survival and apoptosis, specifically in T lymphocytes, is directly associated with immune function. Up-regulated Akt promotes cell survival by phosphorylating and thereby inhibiting a variety of downstream key proapoptotic targets such as GSK-3 (Cross et al., 1995) and caspase-9 (Cardone et al., 1998), and by activating transcriptional factors such as nuclear factor- $\mathrm{kB}(\mathrm{NF \kappa B})$ and Forkhead (Kops and Burgering, 1999) in T lymphocytes. Survival factors are equally important in the regulation of the apoptotic process induced by oxidative stress. Studies demonstrated an early increase followed by a significant decrease in phosphorylation of Akt in methylpyridinium (MPP+)-induced apoptotic death in SH-SY5Y neuroblastoma cells (Halvorsen et al., 2002). Others reported that excessive damage can increase dephosphorylation of Akt without a transient increase in Akt phosphorylation after focal cerebral ischemia in mice (Noshita et al., 2001). Our results did not show that an early increase of Akt phosphorylation after HNE treatment could be due to HNE, a potent reactive oxidant which caused excessive damage in Jurkat $\mathrm{T}$ cells. These findings support the PI3-kinase pathway as being predominantly anti-apoptotic, and together, suggest that prevention of Akt shutdown or increasing Akt activation may block apoptosis.

Our results showed that $p$-Akt concentration in untreated Jurkat was about 30 unit per mg protein and constitutively activated and that HNE downregulated Akt activation (Fig. 9). Others have shown that $20 \mu \mathrm{M}$ HNE-induced dephosphorylation of Akt at Ser473 in Jurkat cells (Liu et al., 2003). In comparison, we found that Akt inactivation 
occurred at much lower concentrations of $\operatorname{HNE}(2.5-10 \mu \mathrm{M})$. This finding is relevant to pathophysiological conditions, since HNE at these concentrations was found to alter cell signaling, and to cause DNA damage, cytotoxicity, and apoptosis.

Similar results from other oxidative stimuli such as $\mathrm{H}_{2} \mathrm{O}_{2}$ on Akt activity were observed. We found that when Jurkat $\mathrm{T}$ cells were exposed to $\mathrm{H}_{2} \mathrm{O}_{2}(100-500 \mu \mathrm{M})$, there was a downregulation of Akt activation as assessed by Western blot analysis (data not shown). Others demonstrated that phospho-Akt expression was decreased in neonatal rat ventricular myocytes exposed to $\mathrm{H}_{2} \mathrm{O}_{2}$ for 15 min (Jamnicki-Abegg et al., 2005). In addition, decreases in both activating phosphorylation of Akt and total Akt in $\mathrm{H}_{2} \mathrm{O}_{2^{-}}$ induced apoptotic death were observed in cardiac H9c2 cells (Murata et al., 2003). Treatment of human embryonic kidney cells with $\mathrm{H}_{2} \mathrm{O}_{2}$ decreased Akt activities and increased apoptosis as indexed by cell shrinkage and DNA fragmentation (Shaw et al., 1998). Furthermore, treatment with a PI3K/Akt inhibitor (LY294002) resulted in Akt inactivation and apoptosis in mouse fibroblast and human leukemia cell lines (Uriarte et al., 2005). Thus, results from our findings and from others clearly demonstrate that HNE and other oxidative stimuli induced apoptotic cell death in T lymphocytes, and were closely related to the downregulation of Akt activity.

In mammalian cells, protein phosphorylation and dephosphorylation involved in distinct survival signaling pathways plays an important role in apoptosis. PP2A is the most abundant serine/threonine-specific phosphatase and plays a role in multiple cellular functions such as cell division, signal transduction, and development (Chen et al., 1992). PP2A plays a critical role in Akt inactivation, for it dephosphorylates two phosphorylation sites (Ser473 and Thr308) of Akt and forms a complex with Akt (Ivaska 
et al, 2002; Resjo et al., 2002). In this study, we showed that HNE increased PP2A catalytic activity (Fig. 10), and concomitantly downregulating Akt (Fig. 9). Others have also demonstrated that HNE increased PP2A activity, and pretreatment of Jurkat T cells with a PP2A inhibitor, okadaic acid, prevented this increase (Liu et al., 2003). $\mathrm{H}_{2} \mathrm{O}_{2}$ has been shown to increase apoptosis and the dephosphorylation of Akt by increasing interaction between PP2A and Akt in H9c2 cells. But, no direct increases of PP2A activity were observed (Murata et al., 2003). The involvement of PP2A is not completely understood. Recent studies have shown that TNF-induced endothelial apoptosis involves the activation of Bad via PP2A-dependent inhibition of MEK phosphorylation (Grethe and Pron-Ares, 2006). Together, these studies suggest that phosphorylation and dephosphorylation plays an important role in regulating HNE mediated cellular processes such as survival and apoptosis by Akt kinases and PP2A.

FasL expression plays a major role in the AICD of activated mature $\mathrm{T}$ cells and $\mathrm{T}$ cell hybridomas (Martinez-Lorenzo et al., 1998). Exposure of CD4 ${ }^{+} \mathrm{T}$ cells (Jurkat) to HNE led to an up-regulation in FasL mRNA and protein (Fig. 11). Apoptosis induced by HNE was blocked by incubation with FasL neutralizing antibody, demonstrating the functional relevance of FasL expression in T cells exposed to lipid peroxides. Although neutralization of FasL significantly protected $\mathrm{T}$ cells from undergoing apoptosis, the NOK-2 antibody did not completely abrogate DNA fragmentation (Fig. 12). This finding suggests the possible involvement of both Fas-dependent and Fas-independent pathways leading to $\mathrm{T}$ cell death under these conditions.

Activation of Fas by FasL leads to its trimerization and recruitment of the adaptor molecule FADD and procaspase 8, forming DISC (Chinnaiyan. et al., 1995; 
Schraven and Peter, 1995; Uriarte et al., 2005). Our data show that exposure of T cells to HNE induces FasL expression leading to Fas-FasL-dependent clustering of Fas and formation of DISC involving recruitment of FADD and procaspase-8 (Fig. 13). Also, the presence of cleaved caspase- 8 together with FADD and procaspase- 8 in the DISC assembly (Fig. 14) showed that caspase- 8 is activated at the DISC (Medema et al., 1997). Moreover, HNE treatment enhanced the recruitment of FADD and procaspase8 in a dose-dependent manner, suggesting that the enhancement in DISC formation corresponds with the levels of HNE or degree of lipid peroxidation experienced by the T lymphocytes. Apoptosis of activated T cells mediated by Fas has been shown to be regulated by c-FLIP expression (Krueger et al., 2001). There are two isoforms of cFLIP, c-FLIP ${ }_{S}$ and c-FLIP, , both of which can be recruited to the DISC (Krueger et al., 2001a; Tibbetts et al., 2003). Although the role of c-FLIP $P_{L}$ is controversial, in T cells c-FLIP ${ }_{S}$ was shown to be antiapoptotic and to confer resistance to Fas-mediated apoptosis by blocking proteolytic activation of caspase- 8 at the DISC (Krueger et al., 2001, 2001a; Irmler et al., 1997). Our study showed that HNE treatment downregulates c-FLIP $P_{S}$ expression, implicating c-FLIP ${ }_{S}$ as an important regulator of HNE-mediated apoptosis in T cells (Fig. 15).

In HNE treated cells the resultant increase in FasL expression, DISC assembly and caspase- 8 activation was accompanied by DNA fragmentation. Others have shown that HNE induces a cellular redox status related to the activation of caspases, including caspase-8, -9 and -3 and induction of apoptotic cell death in Jurkat $\mathrm{T}$ lymphocytes (Liu et al., 2000). Our findings further extend these observations and identify the formation 
of DISC leading to increased caspase-8 activation as the critical initiator of apoptotic death induced in T lymphocytes by HNE.

In conclusion, we showed that HNE induced significant loss of survival due to enhanced FasL expression, in turn, leading to the induction of the DISC and a corresponding decrease in c-FLIP protein and caspase-8 activation. These data identify a pathogenic molecular mechanism(s) induced by HNE in $\mathrm{CD} 4^{+} \mathrm{T}$ cells and is consistent with a potential role of lipid peroxidation-derived products in programmed cell death. Importantly, this work has begun to elucidate the potential role of lipid peroxidation products, in particular $\mathrm{HNE}$, in the pathogenesis of immunosuppressive disorders involving $\mathrm{CD}^{+} \mathrm{T}$ cell depletion such as HIV and $\mathrm{HCV}$ infection, and this work can lead to the development of much needed anti-oxidant therapies. 


\section{CHPATER III}

\section{ROLE OF GSH AND PTCA PROTECTION IN HNE-INDUCED \\ CYTOTOXICITY}

\section{INTRODUCTION}

The studies on HNE toxicity in human $\mathrm{CD}^{+} \mathrm{T}$ lymphocytes described in this chapter were design to test the protective role of PTCA in HNE-induced T cell death. The effect of PTCA on HNE-induced cytotoxicity was studied and the role of GSH and Akt kinase and Fas-mediated death signaling were further evaluated. Cytotoxicity was assessed as described in Chapter II. To evaluate the role of GSH in toxicity, the effects of HNE on GSH concentrations and the ability of GSH precursor PTCA to protect against HNE toxicity were determined. To evaluate the role of Akt kinase in toxicity, the effects of PTCA on HNE-induced Akt downregulation and PP2A activation were examined. To evaluate the protection of Fas-mediated death signaling, the effects of PTCA on FasL and c-FLIPS expression of HNE toxicity were examined. Finally, to evaluate the possibile sensitizating effect of GSH depletion, the effects of BSO, a GSH biosynthesis inhibitor, on MDA toxicity were examined.

\section{MATERIALS AND METHODS}

\section{Cell culture}

Jurkat T cells were obtained and prepared as described in Chapter II. 


\section{Chemicals}

2(RS)-n-propylthiazolidine-4(R)-carboxylic acids was synthesized and kindly provided by Dr. Herbert T. Nagasawa (VA Medical Center, Minneapolis, MN). BSO and MPA were purchased from Sigma Chemical Co. (St. Louis, MO).

\section{Analyses of GSH}

Cell pellets were dispersed with $0.25 \mathrm{ml}$ of $4 \%$ MPA and centrifuged at 10,000 $\mathrm{x} g$ for 2 min. The supernatants were collected for GSH analysis using an HPLC method with dual electrochemical detection (HPLC-DEC; Richie et al., 1987; Chen et al., 1990). In brief, $20 \mu \mathrm{l}$ samples were injected onto a $250 \times 4.6 \mathrm{~mm}, 5 \mu \mathrm{m}, \mathrm{C}-18$ column (Val-U-Pak HP, fully endcapped ODS, Chrom Tech Inc., Apple Valley, MN), eluted isocratically with a mobile phase consisting of $0.1 \mathrm{M}$ monochloroacetic acid, 2 $\mathrm{mM}$ heptane sulfonic acid, and $2 \%$ acetonitrile at $\mathrm{pH} 2.8$, and delivered at a flow rate of $1 \mathrm{ml} / \mathrm{min}$. The compounds were detected in the eluant with a Bioanalytical Systems model LC4B dual electrochemical detector using two Au-Hg electrodes in series with potentials of $-1.00 \mathrm{~V}$ and $+0.15 \mathrm{~V}$ for the upstream and downstream electrodes, respectively. Current (nA) was measured at the downstream electrode. Analytes were quantified from peak area measurements using authentic external standards.

\section{Akt [pS473] ELISA assay}

Jurkat T cells were pretreated with PTCA at $250 \mu \mathrm{M}$ for $1 \mathrm{~h}$ before the addition of $\mathrm{HNE}$ at 2.5 or $5 \mu \mathrm{M}$. Samples were collected at $6 \mathrm{~h}$ and lysed for determination of the phosphorylated Akt levels using an Akt [pS473] kit. Method details were described in Chapter II.

\section{DNA fragmentation ELISA assay}


Jurkat T cells were pretreated with PTCA at $250 \mu \mathrm{M}$ for $1 \mathrm{~h}$ before the addition of HNE at 2.5 or $5 \mu \mathrm{M}$. Method details were described in Chapter II.

\section{PP2A enzymatic activity assay}

Jurkat T cells were pretreated with PTCA at $250 \mu \mathrm{M}$ for $1 \mathrm{~h}$ before the addition of $\mathrm{HNE}$ at 2.5 or $5 \mu \mathrm{M}$. PP2A enzymatic activity was assessed following PP2A immunoprecipitation using a malachite green based phosphatase assay (PP2A Immunoprecipitation Phosphatase Assay Kit). Method details were described in Chapter II.

\section{Western blot analysis}

$15 \times 10^{6}$ Jurkat $\mathrm{T}$ cells were pretreated with PTCA at $250 \mu \mathrm{M}$ for $1 \mathrm{~h}$ before the addition of $\mathrm{HNE}$ at $2.5,5$, or $10 \mu \mathrm{M}$ for 3 and/or $6 \mathrm{~h}$. Following treatment, cells were lysed by immunoprecipitation lysis buffer and total cellular proteins (65 $\mu \mathrm{g}$ of protein) were resolved on a $10 \%$ SDS-PAGE and subjected to standard immunoblotting procedures. The primary antibodies used in this study were as follows: anti-phosphoAkt 1:500; anti-Akt 1:500; anti-Fas-L (C-178) 1:750; anti-FLIP $\gamma / \delta$ 1:750 and $\beta$-Actin 1:1000. The appropriate secondary antibodies were used at 1:2000 for phospho-Akt, total Akt, and FasL; 1:5,000 for FLIP $\gamma / \delta$ and $\beta$-Actin. Proteins signals were visualized using the ECL system (Amersham Pharmacia Biotech, Piscataway, NJ), as directed by the manufacturer. The molecular sizes of the developed proteins were estimated by comparison with prestained protein markers (Invitrogen, Carlsbad, CA).

\section{RNA isolation and real time PCR analysis}

Method details were described in Chapter II.

\section{Trypan blue dye exclusion}


Method details were described in Chapter II.

\section{Statistical analysis}

Analyses were performed as described in Chapter II.

\section{RESULTS}

\section{PTCA protects against HNE-induced cytotoxicity}

Our previous studies have shown HNE-induced dose-dependent cytotoxicity and apoptotic cell death in Jurkat cells. In this study, Jurkat T cells pretreated with PTCA, a GSH precursor, cell viabilities were increased by about $80 \%$ from the untreated value as compared to $20-25 \%$ survival with HNE alone (Fig. 17A). Pretreatment of Jurkat T cells with PTCA, DNA fragmentation, an index of apoptosis, were decreased to about 1.8 -fold of the untreated value as compared to 2.5 -fold of cells treated with HNE alone (Fig. 17B).

\section{PTCA attenuates HNE-induced decreases in GSH concentration}

Previously, we found that HNE produced a time-and dose-dependent depletion of intracellular GSH. The basal GSH concentration was $37.1 \pm 8.6 \mathrm{nmol} / \mathrm{mg}$ protein. GSH concentration was $70 \%$ depleted by 15 min after HNE treatment and reached a maximal depletion of $90 \%$ at $1 \mathrm{~h}$, and remained low through out $3 \mathrm{~h}$ (data not shown). At the lowest HNE concentration $(2.5 \mu \mathrm{M})$, GSH was $80 \%$ depleted at $3 \mathrm{~h}$. At higher HNE concentrations (5-20 $\mu \mathrm{M})$, GSH was completely depleted. Pretreatment of Jurkat T cells with PTCA markedly attenuated HNE-induced decreases in intracellular GSH concentration. GSH concentrations in cells pretreated with PTCA were increased to about $80 \%$ of the untreated value as compared to $8 \%$ with $\mathrm{HNE}$ alone (Fig. 18A). 


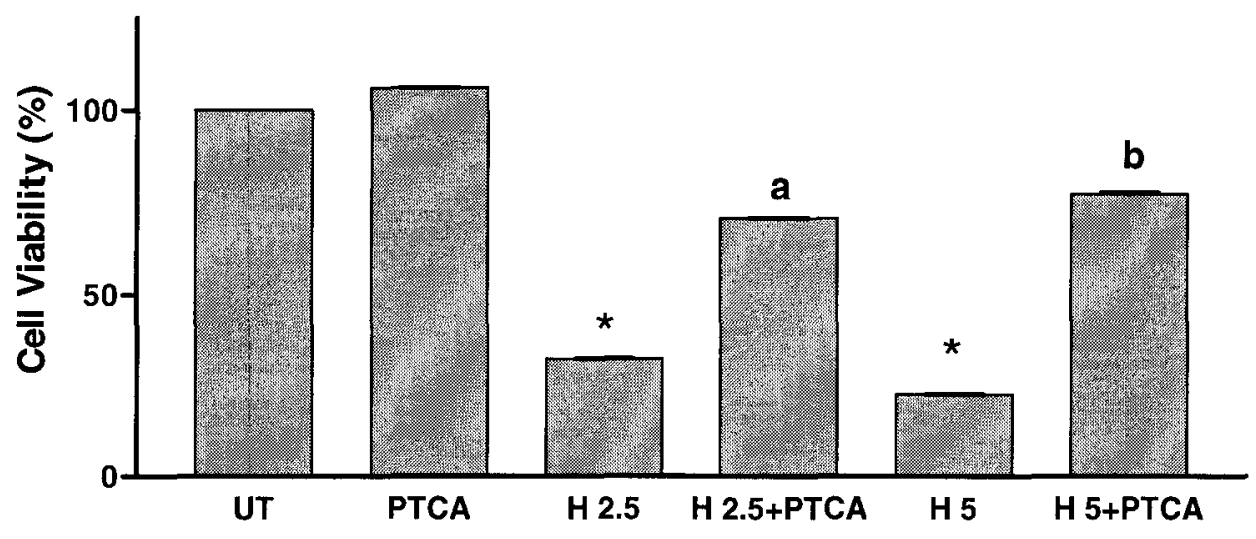

B

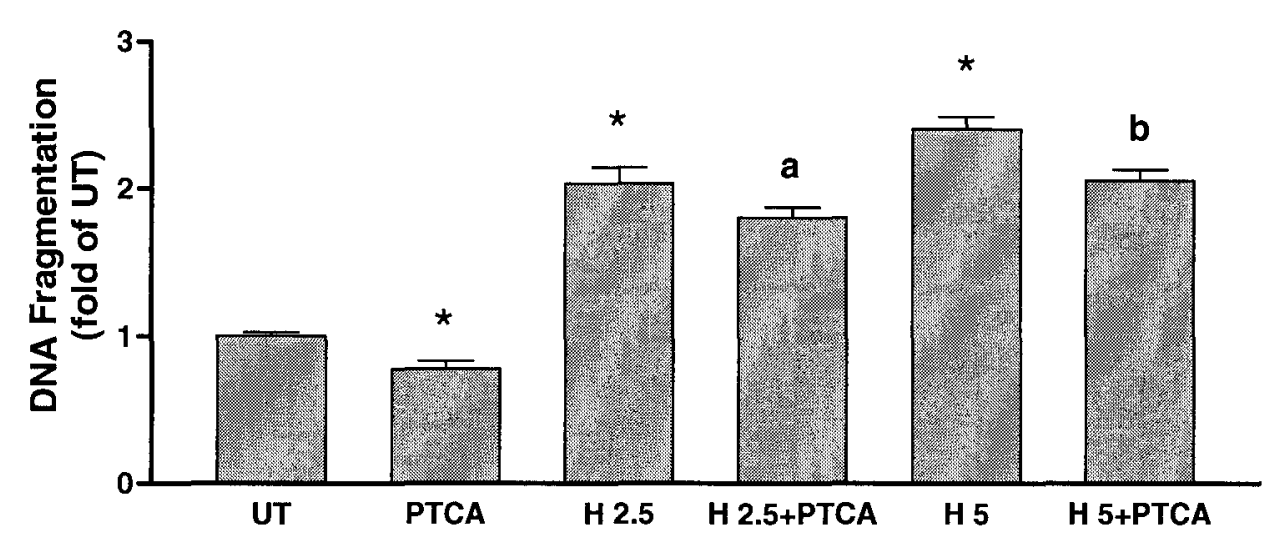

Fig. 17. PTCA protects against HNE-induced cytotoxicity. Jurkat T cells were pretreated with PTCA at $250 \mu \mathrm{M}$ for $1 \mathrm{~h}$ before the addition of $\mathrm{HNE}$ at 2.5 or $5 \mu \mathrm{M}$. Cells were untreated (UT), or treated with PTCA $(250 \mu \mathrm{M})$ or HNE $(2.5$ or $5 \mu \mathrm{M})$, or PTCA plus HNE. (A) Trypan blue exclusion assay. Cell survival was quantified at $24 \mathrm{~h}$. Data were normalized to the untreated control (which is set to 100\%) and represented as the mean \pm SD of five separate experiments. (B) DNA fragmentation assay.

Cytoplasmic extracts were prepared and analyzed at $6 \mathrm{~h}$ for DNA fragmentation by Cell Death ELISA kit as described in Materials and Methods. Data were normalized to the untreated control (which is set to 1) and represented as mean \pm SD of four separate experiments. In each experiment, duplicate wells are assayed separately for each treatment. ${ }^{*} \mathrm{P}<0.05$ compared to $\mathrm{UT},{ }^{\mathrm{a}, \mathrm{b}} \mathrm{P}<0.05$ compared to HNE 2.5 and $5 \mu \mathrm{M}$, respectively. 


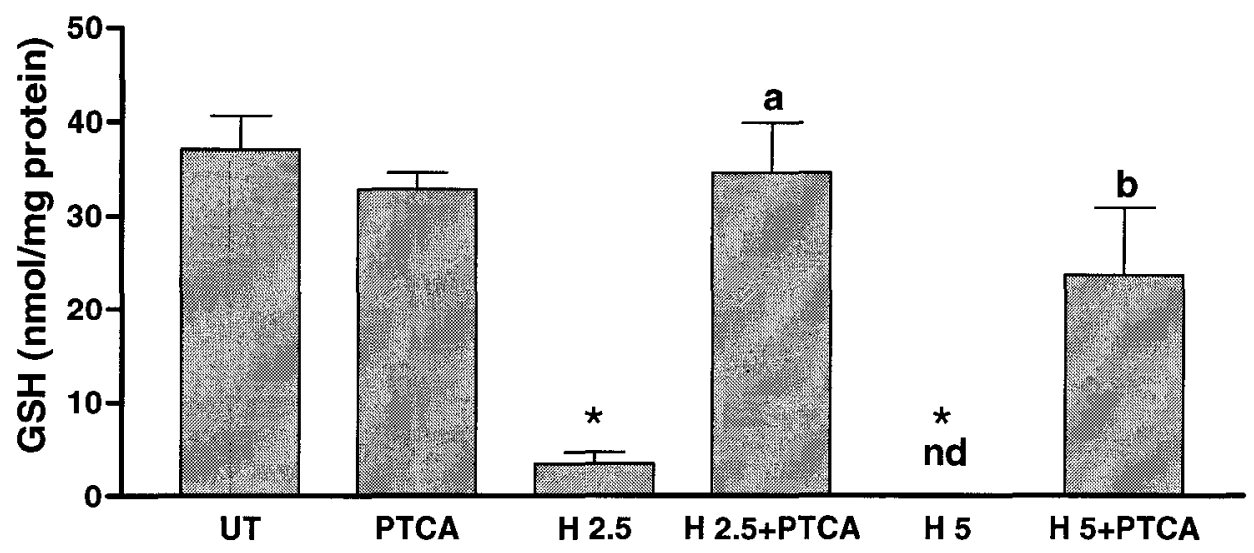

B

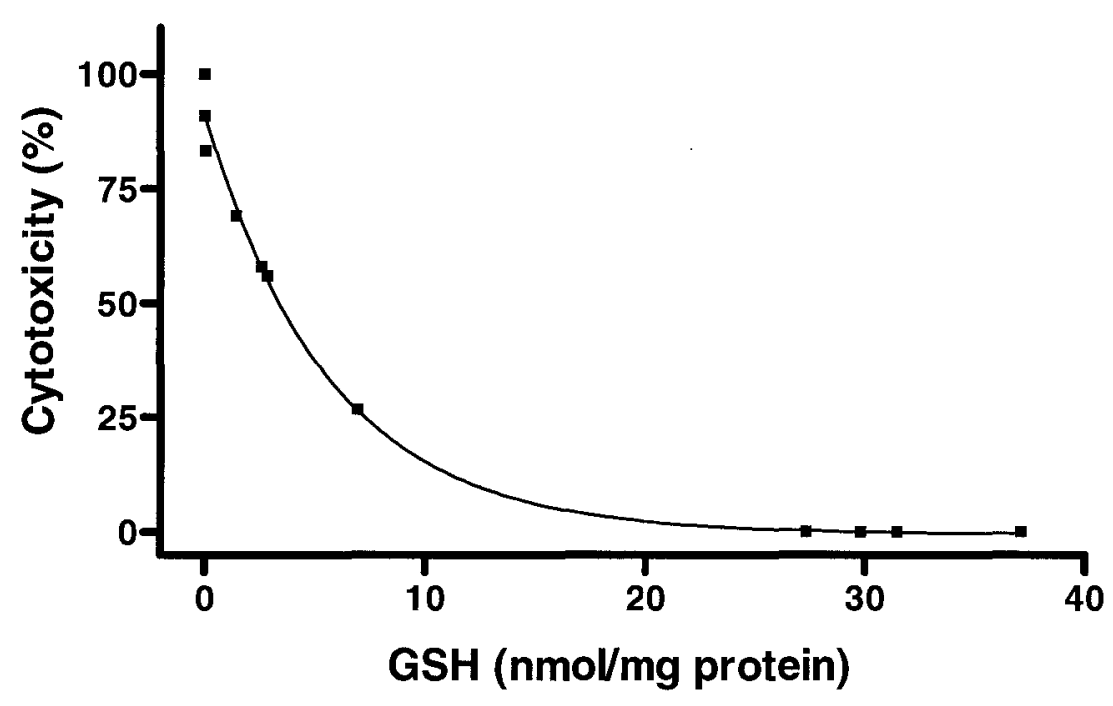

Fig. 18. PTCA attenuates HNE-induced GSH depletion and cytotoxicity. (A) GSH concentration. Sample preparation was as described in Fig. 17 and cell extracts were collected at $3 \mathrm{~h}$. "nd" indicated none detected. (B) Relationship between GSH concentration and Jurkat $\mathrm{T}$ cell death. GSH concentration determined at $3 \mathrm{~h}$ and cell viability at $24 \mathrm{~h}$ after HNE treatment. Cytotoxicity is expressed as inverse of cell viability. Each point presented value obtained with a given treatment. Plot included data from all experiments in cells in which both cytotoxicity and GSH were determined. ${ }^{*} \mathrm{P}<0.05$ compared to $\mathrm{UT},{ }^{\mathrm{a}, \mathrm{b}} \mathrm{P}<0.05$ compared to HNE 2.5 and $5 \mu \mathrm{M}$, respectively. 
From the above results, we plotted the cytotoxicity vs. GSH concentration. As shown in Fig. 18B, there was a close correlation $\left(\mathrm{R}^{2}=0.9908\right)$ between GSH concentration and cytotoxicity. And it appears that when GSH was depleted to about 80-90\% of controls (threshold level), the cytotoxicity was ensued.

\section{Effects of MDA and BSO on intracellular GSH concentrations and cell viability}

The effect of MDA (2.5-10 $\mu \mathrm{M})$, another lipid peroxidation product, on intracellular GSH concentrations was also investigated. As shown in Fig. 19A, the basal GSH concentrations were 30.6 and $41.9 \mathrm{nmol} / \mathrm{mg}$ protein, respectively, at 3 and 6 h. GSH concentrations were $32.7,34.5$, and $33.2 \mathrm{nmol} / \mathrm{mg}$ protein, respectively, $3 \mathrm{~h}$ after cells exposed to MDA at 2.5, 5 and $10 \mu \mathrm{M}$. The effects of various doses of MDA $(2.5-10 \mu \mathrm{M})$ on intracellular GSH concentrations at $6 \mathrm{~h}$ were $41.7,40.4$ and 41.6 $\mathrm{nmol} / \mathrm{mg}$ protein, respectively. In contrast to the results of HNE, MDA had no effect on GSH concentration in Jurkat T cells.

$\mathrm{BSO}$, an inhibitor of GSH biosynthesis, has been demonstrated to decrease GSH concentrations in many cell lines. As shown in Fig. 19B, Jurkat T cells treated with BSO for $24 \mathrm{~h}, \mathrm{GSH}$ concentrations decreased to $0.511 \pm 0.074 \mathrm{nmol} / \mathrm{mg}$ protein $(2.5 \mathrm{mM})$ and $0.02 \pm 0.031 \mathrm{nmol} / \mathrm{mg}$ protein $(5 \mathrm{mM})$, respectively. Effects of BSO on $\mathrm{T}$ cell survival was further examined in Jurkat $\mathrm{T}$ cells treated with BSO. Cell viabilities in the BSO treated group at 2.5 and $5 \mathrm{mM}$ were $106 \%$ and $74 \%$ of controls, respectively (Fig. 19C). The results suggest that BSO (at $2.5 \mathrm{mM}$ ) had no significant effect on cytotoxicity but depletes intracellular GSH concentrations in Jurkat T cells. 


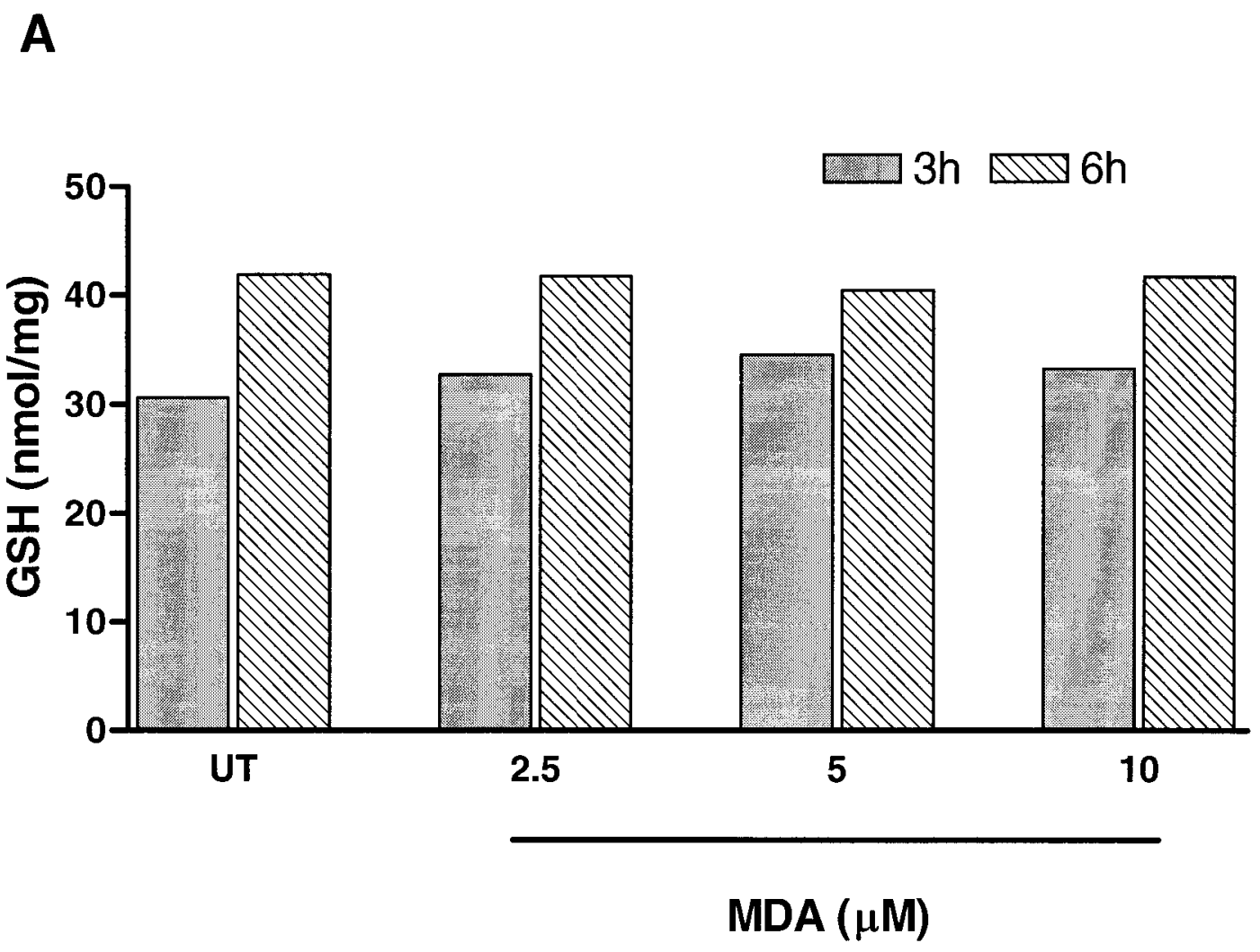

Fig. 19. Effects of MDA and BSO on intracellular GSH concentration and cytotoxicity. (A) GSH concentrations. Jurkat T cells were untreated (UT) or treated with MDA (2.5, 5 and $10 \mu \mathrm{M}$ ). Cells were harvested at 3 and $6 \mathrm{~h}$ after MDA treatment. (B) GSH concentration. Jurkat T cells were untreated (UT) or treated with BSO (2.5 and $5 \mathrm{~m} \mathrm{M})$. Cells were harvested at $24 \mathrm{~h}$ after BSO treatment. Data were normalized to protein concentration $(\mathrm{nmol} / \mathrm{mg})$ and represented as mean $\pm \mathrm{SD}$ of three separate experiments. (C) Trypan blue exclusion assay. Sample preparation was as described in Fig. 19B. Data were normalized to the untreated control (which is set to 100\%) and represented as the mean \pm SD of five separate experiments. . $\mathrm{P}<0.05$ and ${ }^{* * *} \mathrm{P}<0.01$ compared to UT. 
B

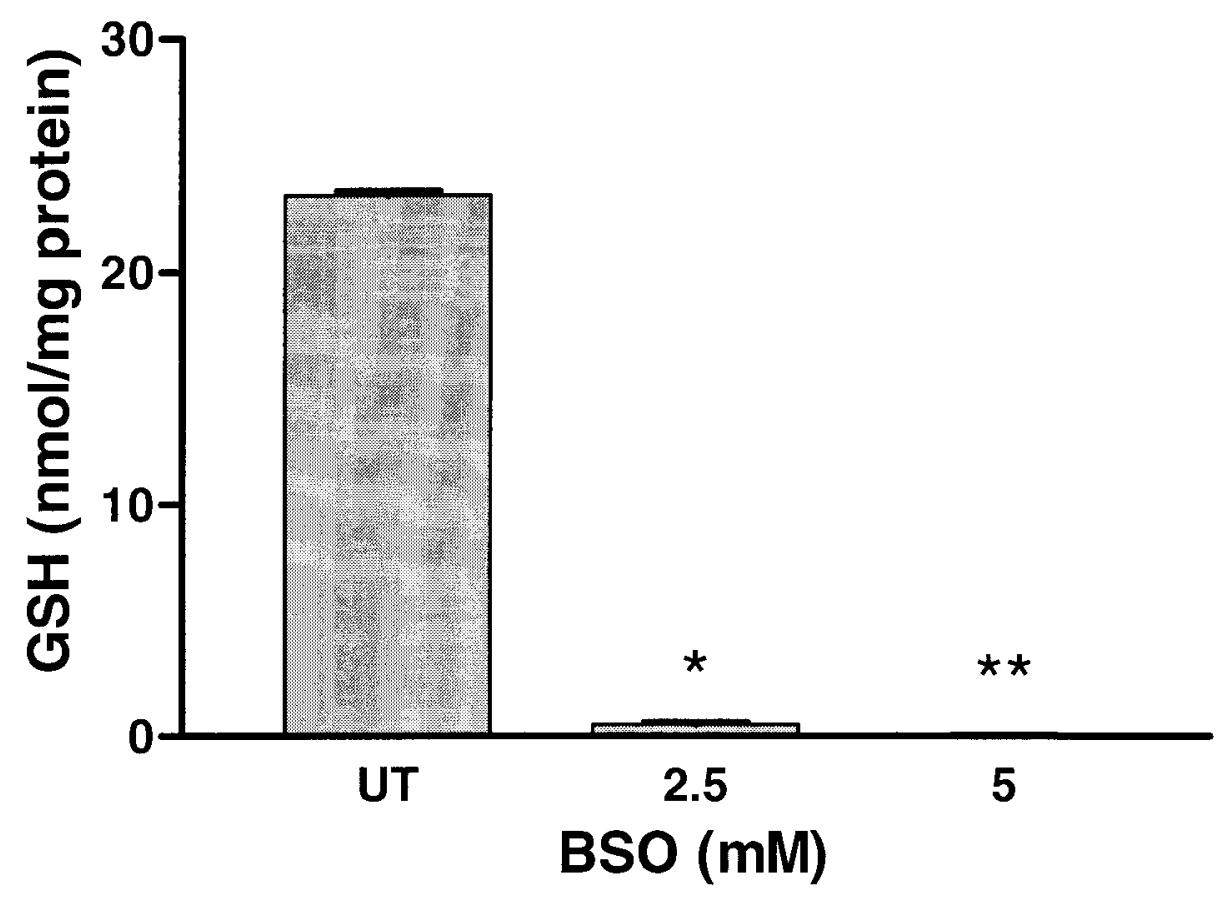

C

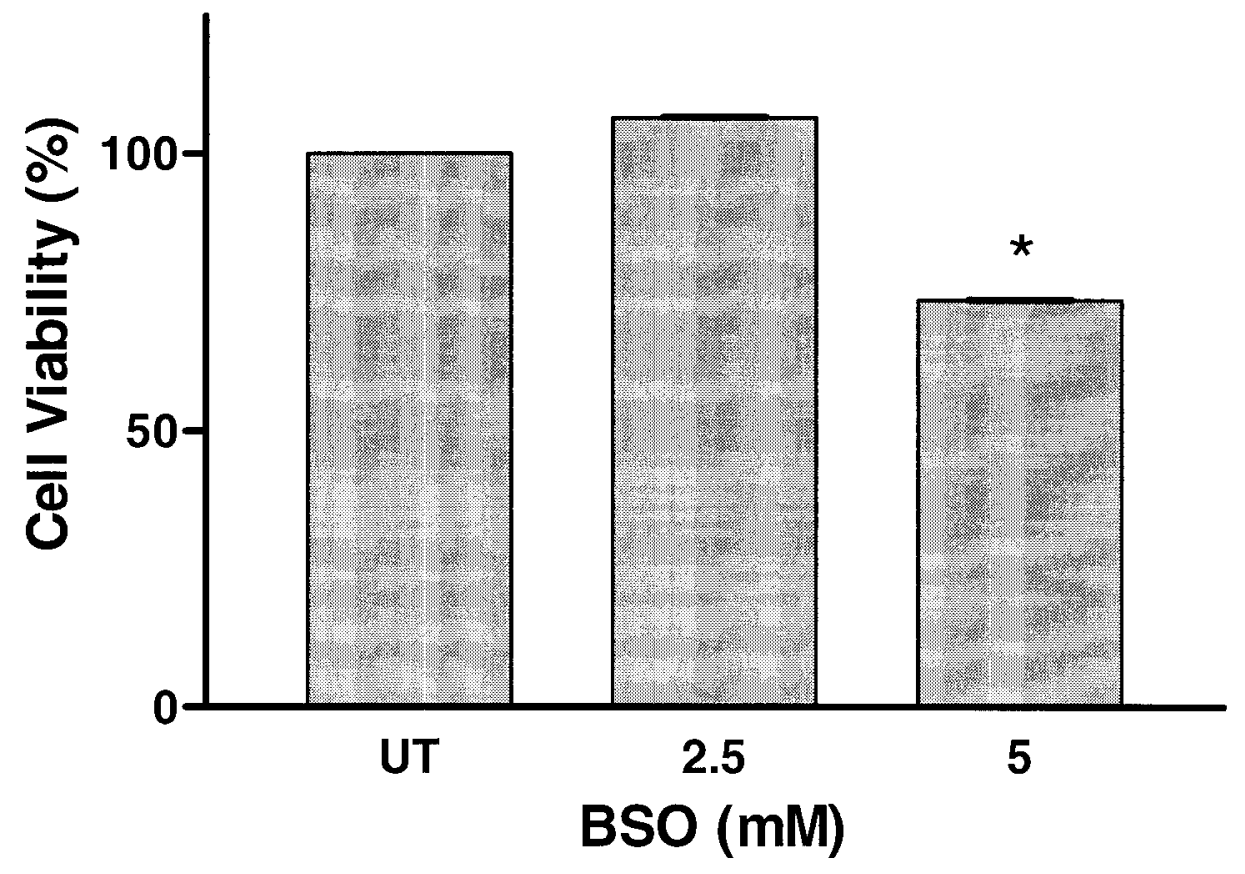




\section{PTCA protects against HNE-induced decrease of Akt activation}

The serine/threonine kinase (Akt/PKB) has been shown to be critical for $\mathrm{T}$ lymphocyte survival and inhibition of Akt leads to apoptotic T cell death. Our previous results showed that HNE induced a time-and dose-dependent decreases of $p$ Akt. In untreated Jukat T cells, Akt is constitutively phosphorylated at Ser-473, and the basal concentration of $p$-Akt was $28.6 \pm 1.0 \mathrm{unit} / \mathrm{mg}$. $p$-Akt concentrations were decreased to $73 \%$ and $11 \%$ of the untreated values, respectively, on HNE at 2.5 and 5 $\mu \mathrm{M}$. In Jurkat T cells pretreated with PTCA, $p$-Akt concentrations were increased to about $115 \%$ and $70 \%$, respectively, of the untreated value. PTCA alone had no effect on the $p$-Akt activation (Fig. 20A).

We further confirmed the increased $p$-Akt levels by immunoblot analysis on phospho-Akt and Akt protein expression on cells treated with $\mathrm{HNE}(2.5$ and $5 \mu \mathrm{M})$. As shown in Fig. 20B, treatment of Jurkat T cells with HNE decreased phospho-Akt protein expression and PTCA pretreatment protected against HNE-induced downregulation of phospho-Akt protein at $6 \mathrm{~h}$. We reprobed the same membrane with anti-Akt primary antibody. The results demonstrated a similar pattern as phospho-Akt protein expression, indicating that not only phospho-Akt was inactivated but Akt kinase was depleted $6 \mathrm{~h}$ after HNE treatment.

In addition, we plotted GSH concentration vs. $p$-Akt levels, there was a close correlation $\left(\mathrm{R}^{2}=0.9668\right)$ between the GSH concentration and cell survival as indexed by $p$-Akt levels. Thus, the threshold phenomenon in HNE-induced cytotoxicity vs. GSH (Fig. 18B) shown above was also observed in GSH vs. survival (Fig. 20C). All 
A

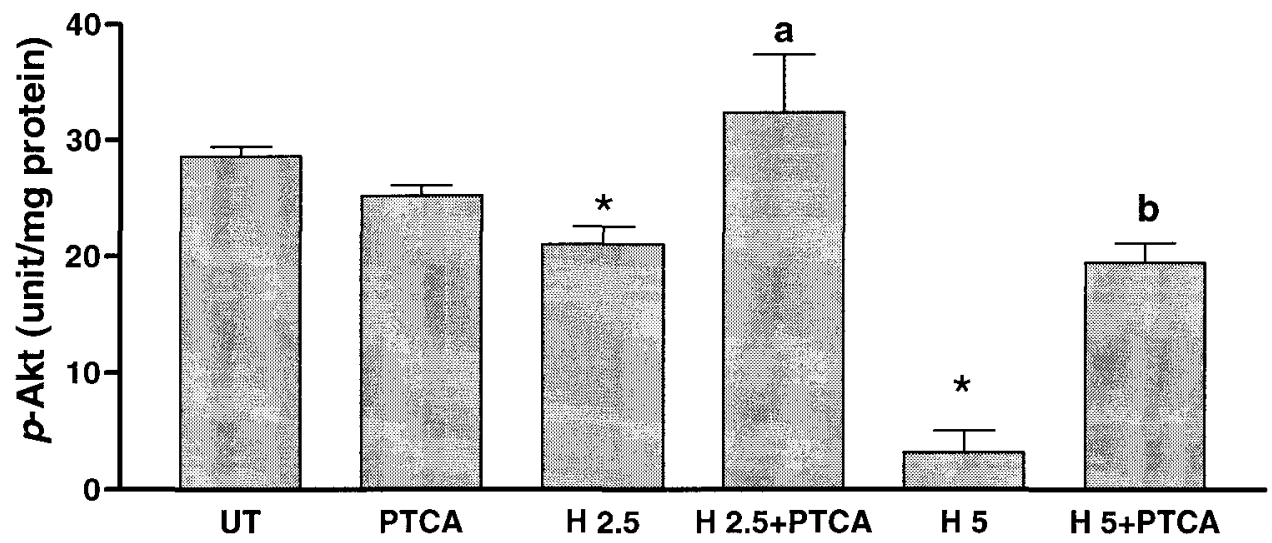

Fig. 20. PTCA protects against HNE-induced downregulation of Akt kinase expression. Sample preparation was as described in Fig. 18. (A) $p$-Akt concentrations. Cell extracts were harvested at $6 \mathrm{~h}$ after HNE treatment. Data were normalized to protein concentration and $p$-Akt concentration expressed as unit/mg protein. Data are represented as mean $\pm \mathrm{SD}$ of three separate experiments . ${ }^{*} \mathrm{P}<0.05$ compared to UT, ${ }^{\mathrm{a}, \mathrm{b}}$ $\mathrm{P}<0.05$ compared to HNE 2.5 and $5 \mu \mathrm{M}$, respectively. (B) Western blotting. Total cell lysates were collected at $6 \mathrm{~h}$ for Western blot analysis as described in Materials and Methods. Akt and phospho-Akt were detected at $6 \mathrm{~h}$ by immunoblot ting using an antiAkt and phospho-Akt antibodies. Blots were stripped and reprobed with antibody to $\beta-$ actin to ensure equivalent loading. A representative gel out of three experiments is shown. (C) Relationship between GSH concentration and $p$-Akt concentrations in Jurkat T cells. GSH concentration determined at $3 \mathrm{~h}$ and $p$-Akt concentrations at $6 \mathrm{~h}$ after HNE treatment. Each point presented value obtained with a given treatment. Plot includes data from all experiments in cells in which both GSH and $p$-Akt concentrations were determined. 
B

p-Akt

t-Akt

$\beta$-Actin
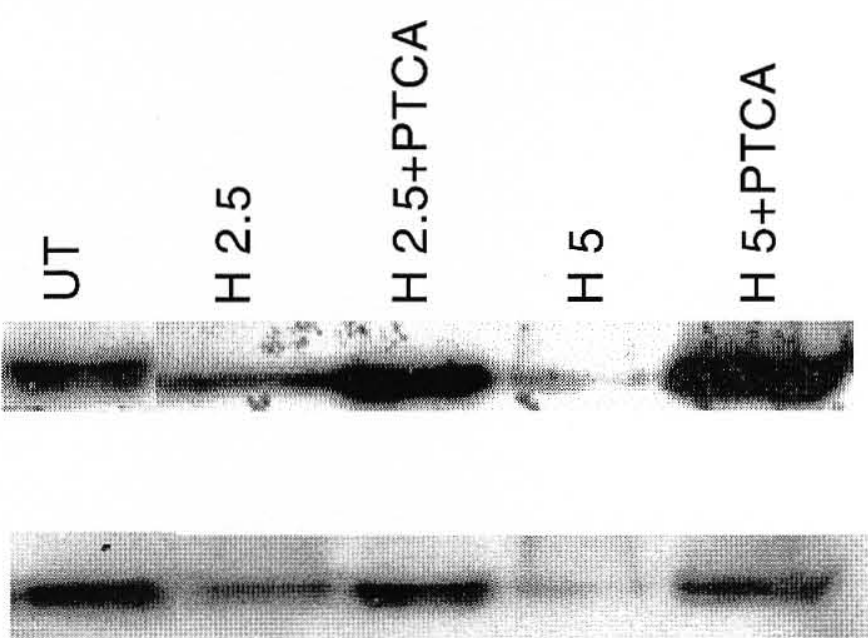

C

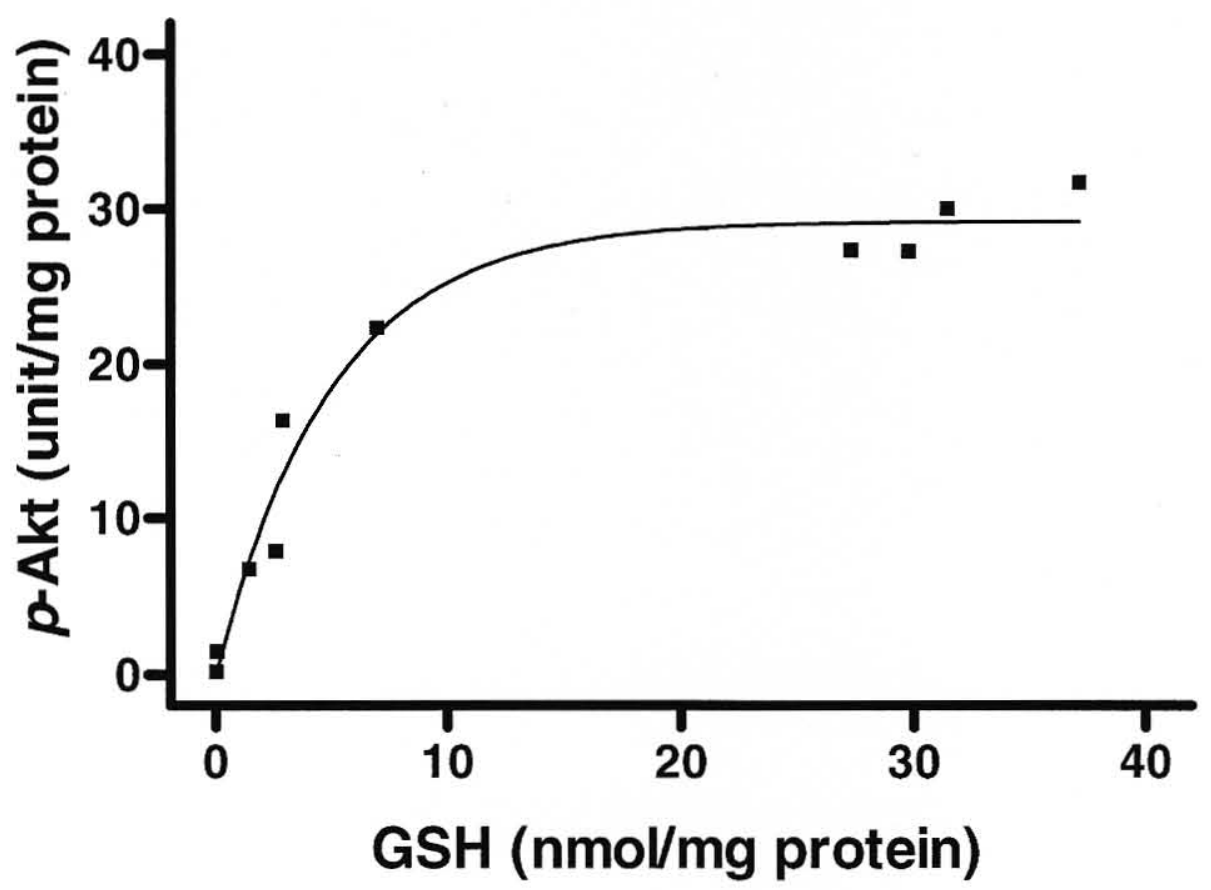


together, these results suggested that PTCA protects against HNE-induced cytotoxicity possibly through upregulation of $p$-Akt.

\section{PTCA decreases HNE-induced PP2A activation}

PP2A is serine/threonine phosphatase and studies have shown that PP2A dephosphorylated and inactivated Akt in vitro (Van Kanegan et al., 2005). To confirm the involvement of $\mathrm{PP} 2 \mathrm{~A}$ in the process of HNE-mediated Akt dephosphorylation, we examined whether the overall catalytic activity of PP2A was upregulated after HNE treatement. Using a nonradioactive serine/threonine phosphatase assay kit with the phosphopeptide K-R-pT-I-R-R as a substrate, we measured the amount of phosphate released, which indicates PP2A catalytic activity. As shown in Fig. 21A, cells exposed to $\mathrm{HNE}(2.5$ and $5 \mu \mathrm{M})$ after $30 \mathrm{~min}, \mathrm{PP} 2 \mathrm{~A}$ activities were increased to $150 \%(202 \pm$ $41 \mathrm{pmol}$ phosphate $/ \mu \mathrm{g}$ protein/ $10 \mathrm{~min})$ and $210 \%(288 \pm 28 \mathrm{pmol}$ phosphate $/ \mu \mathrm{g}$ protein/ $10 \mathrm{~min}$ ), respectively, of the untreated value. Pretreatment of Jurkat cells with PTCA for $1 \mathrm{~h}$ before the addition of $\mathrm{HNE}(2.5$ and $5 \mu \mathrm{M})$, PP2A activities were decreased to $121 \%(166 \pm 40 \mathrm{pmol}$ phosphate / $\mu \mathrm{g}$ protein/ $10 \mathrm{~min})$ and $104 \%(142 \pm$ $49 \mathrm{pmol}$ phosphate / $\mu \mathrm{g}$ protein/ $10 \mathrm{~min}$ ), respectively, of the untreated value. PTCA alone had no effect on the PP2A activity. The results on PP2A activity were further confirmed by protein expression. As shown in Fig. 21B, treatment of Jurkat T cells with $\mathrm{HNE}(2.5,5$ and $10 \mu \mathrm{M})$ increased PP2A expression on both A subunit (62KDa) and $\mathrm{C}$ subunit (36KDa). Pretreatment of Jurkat T cells with PTCA inhibit HNEinduced activation of PP2A protein. Together, the results demonstrated that HNE induced dose-dependent increases in PP2A activity, which further confirmed by 


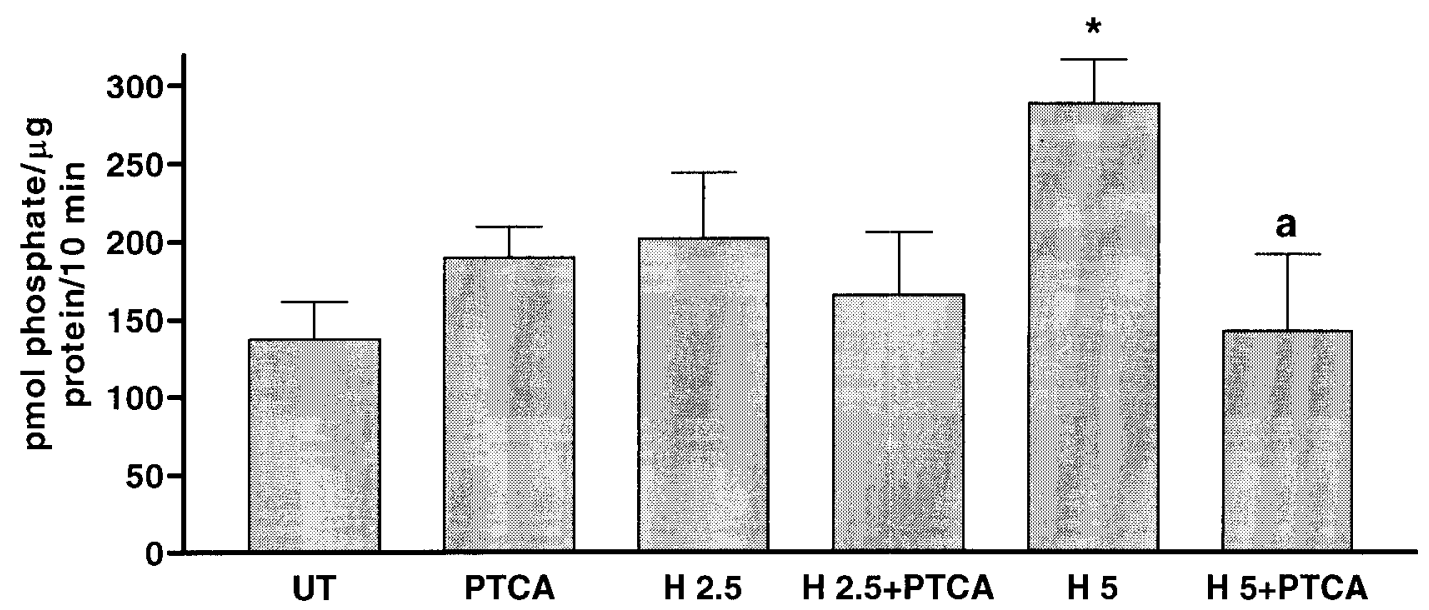

Fig. 21. PTCA inhibits HNE-induced PP2A activation. Sample preparation was as described in Fig. 17. (A) Cell extracts were harvested at 30 min after HNE treatment. PP2A activity was measured using PP2A immunoprecipitation assay kit as described in Materials and Methods. Data were normalized to protein concentration and PP2A activity expressed as pmol phosphate $/ \mu \mathrm{g}$ protein $/ 10 \mathrm{~min}$. Data are represented as mean \pm $\mathrm{SD}$ of three separate experiments. ${ }^{*} \mathrm{P}<0.05$ compared to UT, ${ }^{a} \mathrm{P}<0.06$ compared to HNE 5 $\mu \mathrm{M}$. (B) Western blotting. Total cell lysates were collected at $6 \mathrm{~h}$ for Western blot analysis as described in Materials and Methods. PP2Ac and PP2Aa were detected at $6 \mathrm{~h}$ by immunoblotting using an anti-PP2Ac and PP2Aa antibodies. Blots were stripped and reprobed with antibody to $\beta$-actin to ensure equivalent loading. A representative gel out of three experiments is shown. 


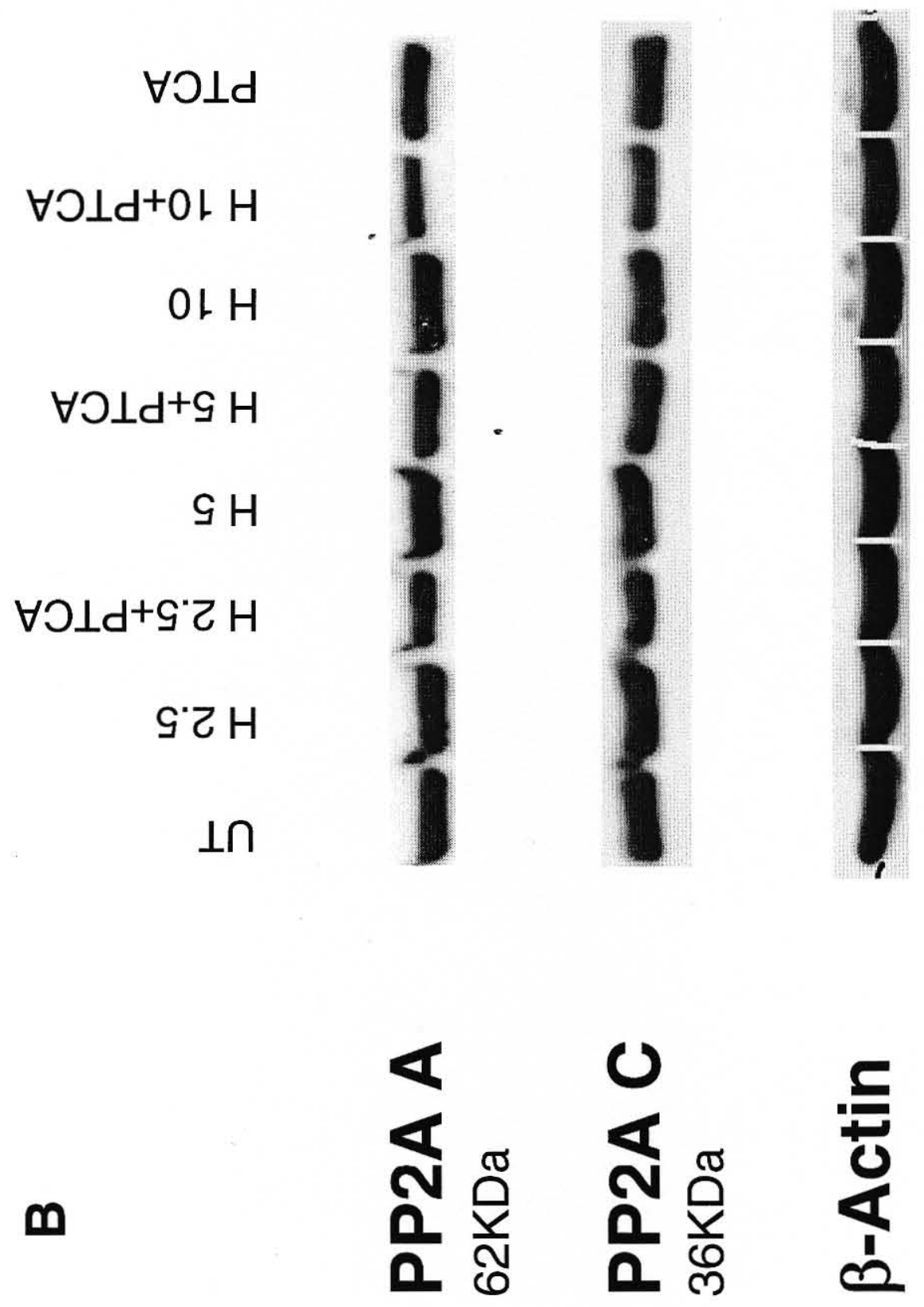


immunoblot analysis. Also, pretreatment of Jurkat T cells with PTCA blocked these effects.

\section{Effects of PTCA on HNE-induced FasL and c-FLIPs expression}

Fas/FasL-mediated apoptosis is a common mechanism for $\mathrm{T}$ cell death in many situations including activation-induced cell death (AICD), as well as Akt inhibitioninduced death (Uriarte et al., 2005). In our previous studies, we demonstrated that HNE-induced apoptosis is through FasL and FADD. Thus, we further examined the effects of PTCA on FasL expression. As shown in Fig. 22A, treatment of Jurkat T cells with HNE increased FasL expression at higher concentration and PTCA pretreatment circumvented HNE-dependent upregulation of FasL protein at $6 \mathrm{~h}$. To further investigate if the effect of the above events were at the transcriptional level, we analyzed FasL mRNA levels by real time-PCR. HNE at $2.5 \mu \mathrm{M}$ had no effect on FasL mRNA. Similar to FasL expression, pretreatment of Jurkat cells with PTCA markedly reduced the FasL mRNA to about four-fold compared to HNE ( $5 \mu \mathrm{M})$ alone (Fig. 22B). Thus, PTCA was shown to down-regulate FasL gene expression induced by HNE.

c-FLIP is an anti-apoptotic protein, and has been shown to inhibit Fasmediated apoptosis (Krueger et al., 2001). Since PTCA protects against apoptosis and down-regulates FasL expression induced by HNE, we further examined the effects of PTCA on c-FLIP S $_{\mathrm{S}}$ expession. Western analysis was performed on Jurkat T cells which showed that c-FLIP levels were decreased after HNE treatment (Fig. 23). Treatment of Jurkat T cells with PTCA plus HNE $(2.5$ or $5 \mu \mathrm{M})$ led to significant 


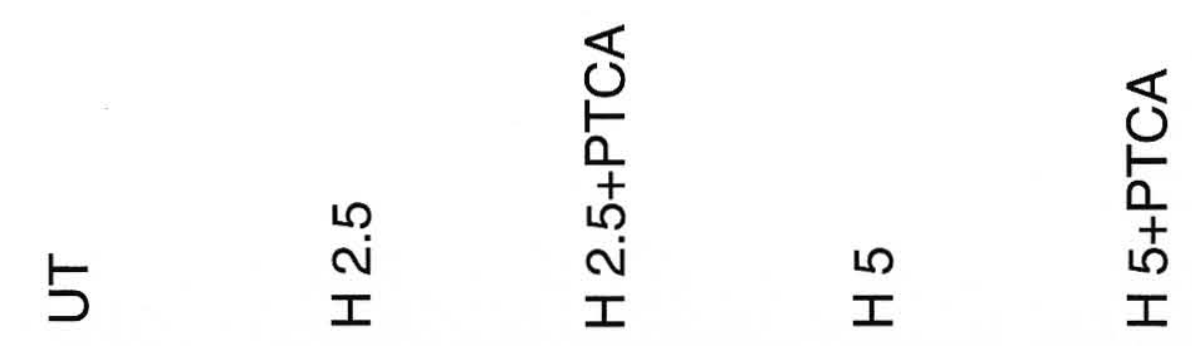

FasL

\section{$\beta$-Actin}

Fig. 22. PTCA protects against HNE -induced upregulation of FasL. Sample preparation was as described in Fig. 17. (A) Western blotting. Total cell lysates were collected at $6 \mathrm{~h}$ for Western blot analysis as described in Materials and Methods. FasL was detected at $6 \mathrm{~h}$ by immunoblotting using an anti-FasL-specific antibody. Blots were stripped and reprobed with antibody to $\beta$-actin to ensure equivalent loading. A representative gel out of three experiments is shown. (B) Real time-PCR. Total RNA was isolat ed from cells, untreated (UT) or treated with $\mathrm{HNE}(2.5$ and $5 \mu \mathrm{M})$ at $6 \mathrm{~h}$. FasL mRNA levels were determined by real time PCR. Data are represented as mean $\pm \mathrm{S}$ D of five separate experiments. ${ }^{*} \mathrm{P}<0.05$ compared to UT, ${ }^{a} \mathrm{P}<0.05$ compared to HNE $5 \mu \mathrm{M}$. 


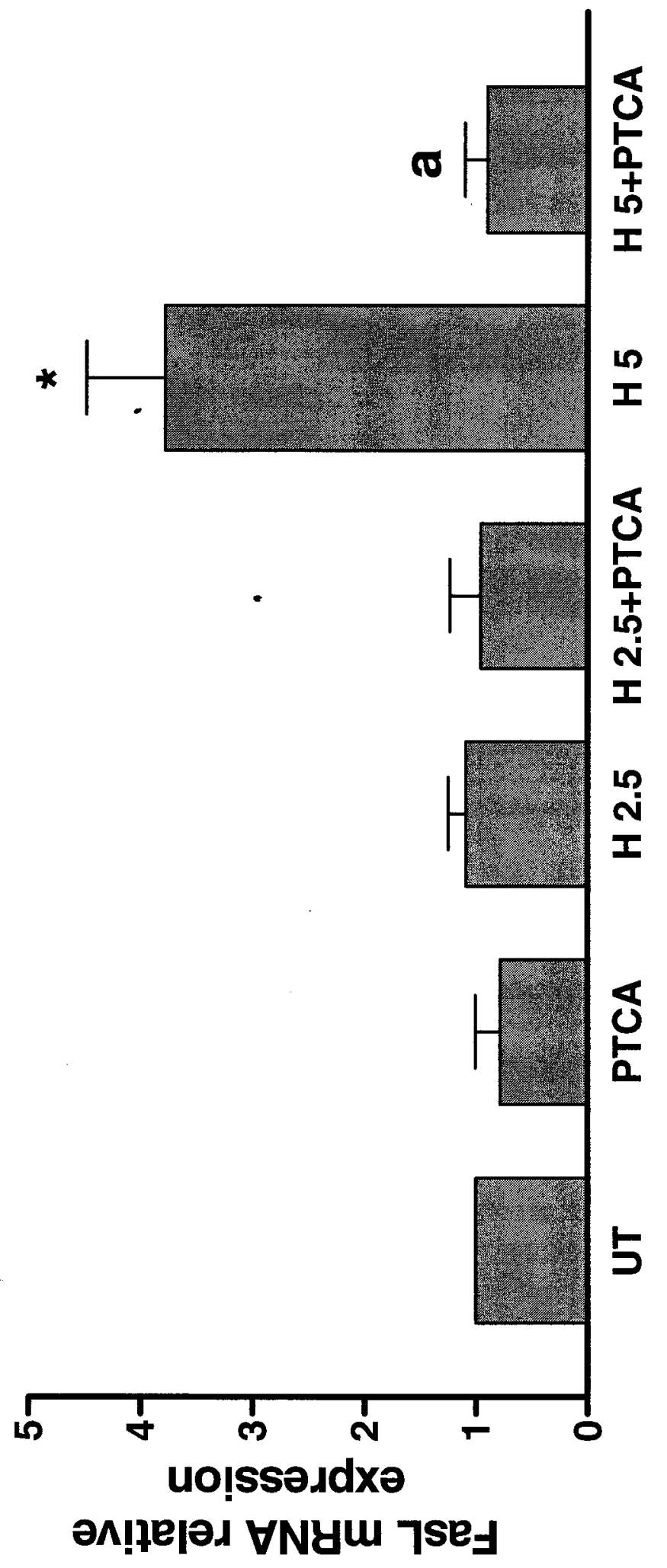




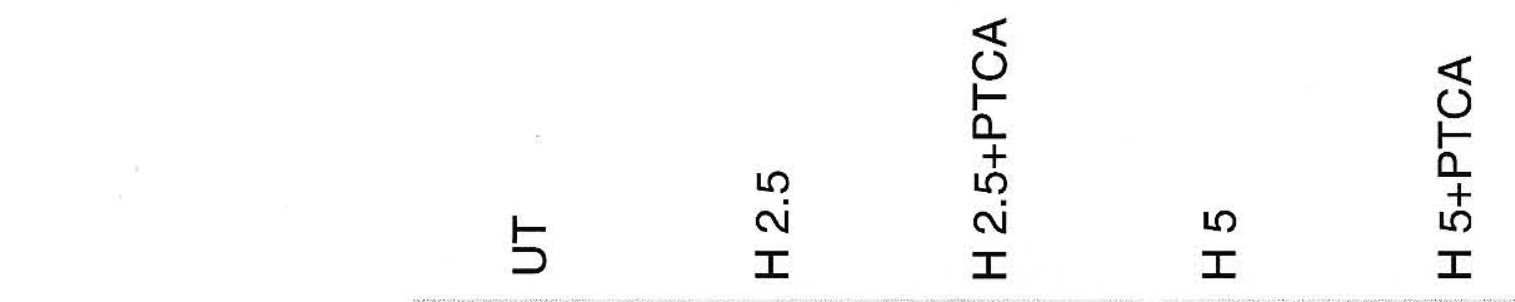

\section{C-FLIPs}

\subsection{KDa}

\section{$\beta$-Actin}

Fig. 23. Effects of BSO on Akt, p-Akt, FasL and c-FLIP srotein expression. Sample preparation was as described in Fig. 19B. (A) Western blotting. Total cell lysates were collected at 24 and $48 \mathrm{~h}$ for Western blot analysis as described in Materials and $\mathrm{M}$ ethods.

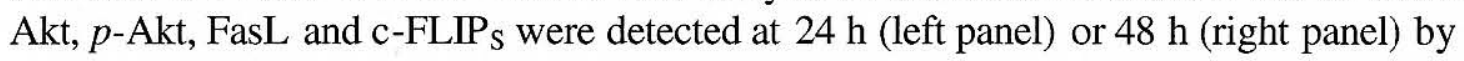
immunoblotting using anti-Akt, $p$-Akt, FasL and c-FLIP ${ }_{\gamma / \delta}$ antibodies. (B) Western blotting. Jurkat T cells were pretreated with BSO at $5 \mathrm{mM}$ for $24 \mathrm{~h}$ before the addition of MDA at 10 $\mu \mathrm{M}$ at 2 or $24 \mathrm{~h}$. Cells were untreated (UT), or treated with BSO $(5 \mathrm{mM})$ or MDA $(10 \mu \mathrm{M})$, or BSO plus MDA. Blots were stripped and reprobed with antibody to $\beta$-actin to ensure equivalent loading (data not shown). A representative gel out of two experiments is shown. (C) Trypan blue exclusion assay. Sample preparation was described in Fig. 19B. Data were normalized to the untreated control (which is set to $100 \%$ ) and represented as the mean $\pm \mathrm{S}$ D of five separate experiments . ${ }^{*} \mathrm{P}<0.001$ compared to UT, ${ }^{\mathrm{a}, \mathrm{b}} \mathrm{P}<0.01$ compared to BSO and MDA, respectively. 
increases in c-FLIP levels. Thus, PTCA was shown to circumvent c-FLIPS $_{S}$ downregulation induced by HNE.

\section{Correlation of GSH content with lipid peroxidation}

We have observed that BSO decreases GSH concentrations without affecting cell viability (Fig. 19). We further examined the effect of BSO on Akt, phospho-Akt, FasL and c-FLIPS protein expression. As shown in Fig. 24A, treatment of Jurkat T cells with BSO (2.5 and $5 \mathrm{mM}$ ) for 24 and $48 \mathrm{~h}$, phospho-Akt was not changed at $24 \mathrm{~h}$, but was decreased slightly at $48 \mathrm{~h}$. In correspondence with BSO treatment on survival (Fig. 19C), there was no change on total Akt protein expression both at 24 and $48 \mathrm{~h}$. The results suggest that inhibition of GSH-concentration may slightly induce Akt inactivation through dephosphorylation, but total Akt protein expression was not affected. Further, we found that BSO has no effect on FasL and c-FLIPs protein expression.

Since HNE significantly decreased T cell survival and GSH concentration, we then examined the effect of another lipid peroxidation product, MDA, on T cell survival. Jurkat $\mathrm{T}$ cells treated with MDA $(10 \mu \mathrm{M})$ or BSO $(5 \mathrm{mM})$ alone had no effect on cell viability (Fig. 24C). However, pretreatment of Jurkat cells with BSO before the addition of MDA $(10 \mu \mathrm{M})$ significantly decreased Akt and phospho-Akt expression (Fig. 24B) as well as produced a profound cell death (33\% of controls) (Fig. 24C). These results demonstrated that GSH depletion caused by BSO sensitizes Jurkat T cells to the secondary hit caused by lipid peroxides and induces the potentiation of cytotoxicity, suggesting that GSH may play an important role in T cell viability. 
Fig. 24. Effects of BSO on Akt, $p$-Akt, FasL and c-FLIP protein expression. Sample preparation was as described in Fig. 20B. (A) Western blotting. Total cell lysates were collected at 24 and $48 \mathrm{~h}$ for Western blot analysis as described in Materials and Methods. Akt, $p$-Akt, FasL and c-FLIPS were detected at $24 \mathrm{~h}$ (left panel) or $48 \mathrm{~h}$ (right panel) by immunoblotting using anti-Akt, $p$-Akt, FasL and c-FLIP ${ }_{\gamma / \delta}$ antibodies. (B) Western blotting. Jurkat T cells were pretreated with BSO at $5 \mathrm{mM}$ for $24 \mathrm{~h}$ before the addition of MDA at $10 \mu \mathrm{M}$ at 2 or $24 \mathrm{~h}$. Cells were untreated (UT), or treated with BSO (5 mM) or MDA (10 $\mu \mathrm{M})$, or BSO plus MDA. Blots were stripped and reprobed with antibody to $\beta$-actin to ensure equivalent loading (data not shown). A representative gel out of two experiments is shown. (C) Trypan blue exclusion assay. Sample preparation was as described in Fig. 8B. Data were normalized to the untreated control (which is set to $100 \%$ ) and represented as the mean \pm SD of five separate experiments. ${ }^{*} \mathrm{P}<0.001$ compared to UT, ${ }^{\mathrm{a}, \mathrm{b}} \mathrm{P}<0.01$ compared to BSO and MDA, respectively. 

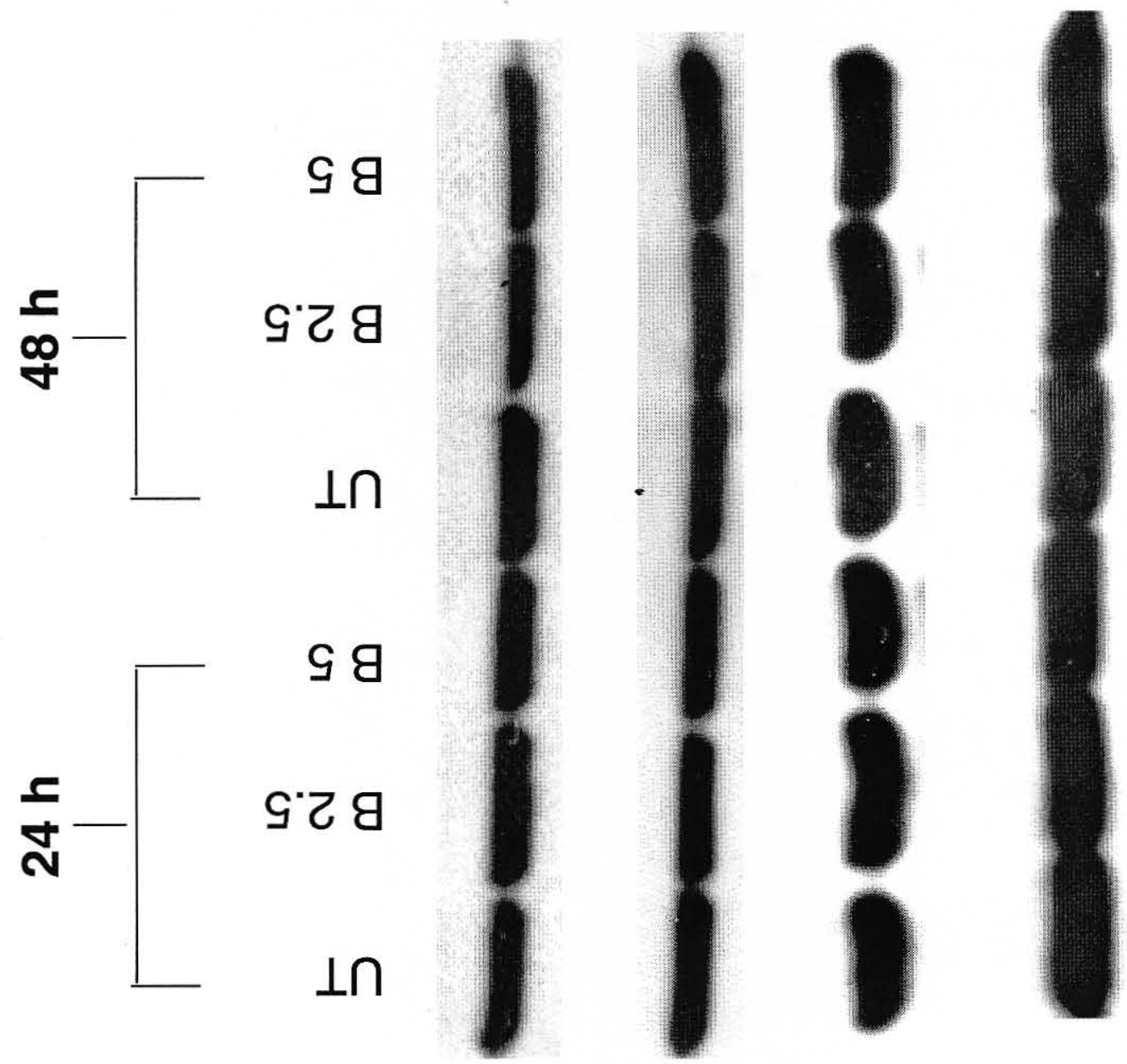

$-$

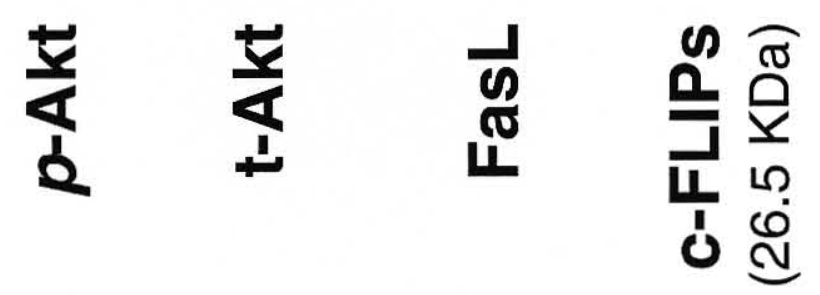




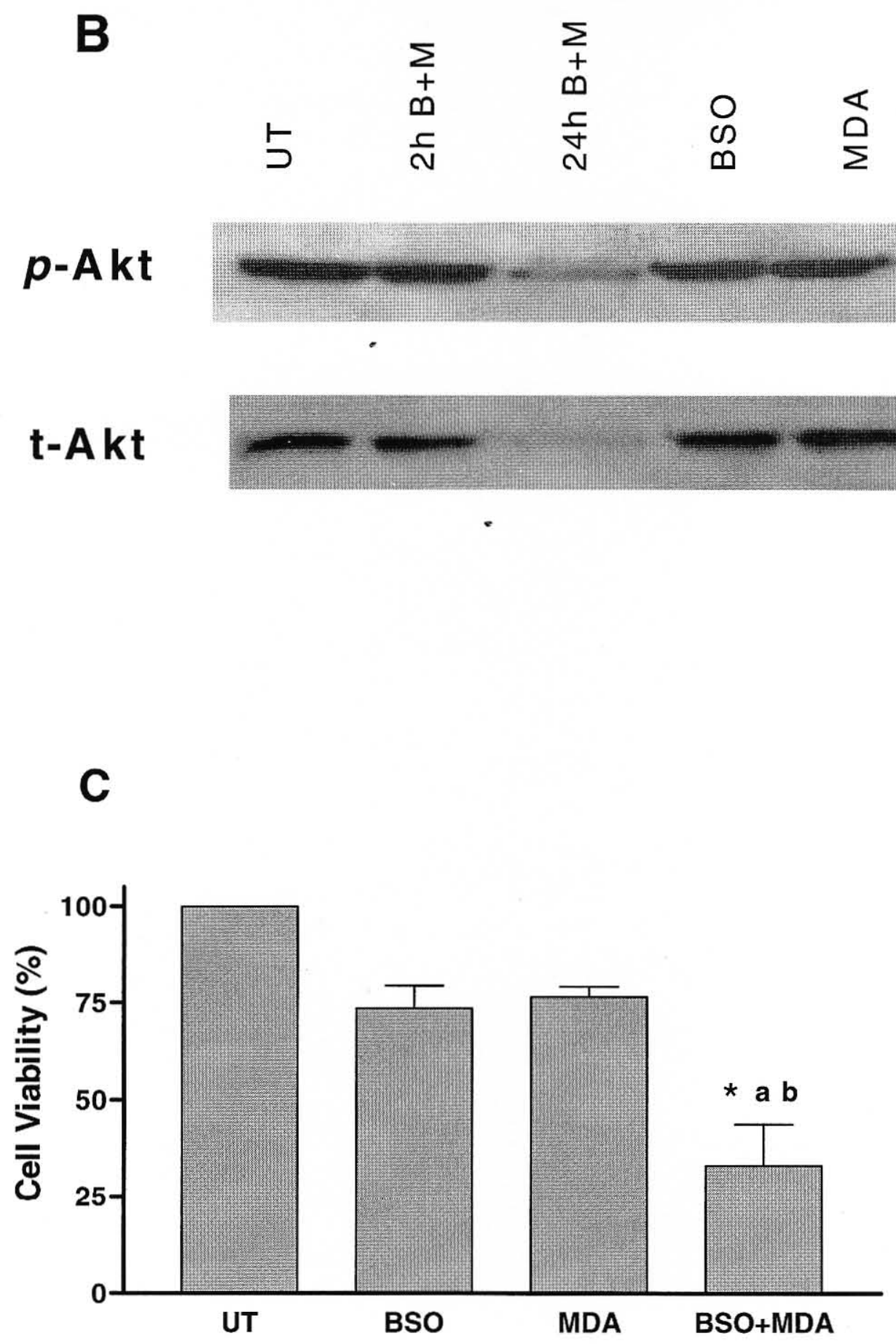




\section{DISCUSSION}

Clinical studies have demonstrated that oxidative stress is an important pathological factor in several immunosuppressive diseases. A critical factor in immunosuppression is the loss of $\mathrm{CD}^{+} \mathrm{T}$ lymphocytes, which are the central regulators of both cell-mediated and humoral immune responses (Cook, 1999). In chapter II, we demonstrated that HNE induces Fas-mediated apoptosis and cytotoxicity in Jurkat $\mathrm{T}$ cells. However, the underlying mechanism is not clear. Numerous studies suggest that intracellular events such as GSH depletion, caspase activation, DNA fragmentation, chromatin condensation, and cytochrome c release may be involved in the apoptotic pathway initiated by HNE (Uchida, 2003). The present study focuses on the role of GSH in HNE-induced toxicity as well as the possible cytoprotection by a GSH precursor, namely PTCA.

\section{Role of GSH in Cytotoxicity}

GSH is the most abundant antioxidant in the body. It plays an important role in the circumvention of cellular oxidative stress and in the maintenance of intracellular thiol redox status (Khanna et al., 1998). Clinically, a decreased level of cellular GSH has been observed in association with a number of pathological conditions including diabetes, liver cirrhosis, drug poisoning, age-related disorders, and AIDS (Sen, 1997). In addition, GSH content in many cultured cell lines including Jurkat T lymphocytes plays an important role in cell cycle, function, proliferation, and survival (Soderdahl et al., 2003). Previously, we found that HNE decreases intracellular GSH in a dose- and time-dependent manner, and their correlates with the induction of DNA fragmentation. The HNE-induced decreases in intracellular GSH concentration could be due to the 
utilization of GSH by HNE to form HNE-GSH adducts. In the present study, restoration of intracellular GSH levels achieved by PTCA, a GSH precursor, on cell survival and GSH enhancement was observed. PTCA functions similar to NAC by supplying Cys for GSH synthesis in a prodrug form, but PTCA releases Cys spontaneously and is independent of enzymatic hydrolysis (Nagasawa et al., 1984). Our work is the first demonstration that PTCA attenuates HNE-induced cytotoxicity is possibly due to GSH restoration in Jurkat T lymphocytes. PTCA has been shown to attenuate APAP- and PAP-induced hepatic GSH depletion and hepatotoxicity in mice (Srinivasan et al., 2001) and hamsters (Fu et al., 2004). Studies have shown that PTCA restored the APAP-induced depletion of total hepatic and mitochondria GSH in SwissWebster mice (Nagasawa et al., 1984). Other antioxidant such as NAC was shown to block HNE-induced DNA fragmentation in Jurkat cells (Liu et al., 2000). Others have also shown that pretreatment of Jurkat cells with anethole dithiolethione $(10-50 \mathrm{mM}$, $18 \mathrm{~h}$ ) attenuated $\mathrm{HNE}$ and $\mathrm{H}_{2} \mathrm{O}_{2}$-induced cytotoxicity and $\mathrm{GSH}$ depletion (Khanna et al., 1998). In HIV-infected patients, NAC administration resulted in a relative increase in the CD4/CD8 ratio (Look et al., 1998) and a slower decline of the $\mathrm{CD}^{+} \mathrm{T}$ cell count (Akerlund et al., 1996). However, there is controversy over changing GSH concentrations. L-2-Oxothiazolidine 4-carboxylate, another Cys precursor, significantly increased serum GSH concentrations in HIV-infected patients (Raju et al., 1994). Together, our results along with others suggest that GSH plays an important role in HNE-induced cytotoxicity. Further, PTCA protects against HNE-induced cytotoxicity, possibly mediated by increasing intracellular GSH concentrations. 
Unlike the profound effect of HNE on T cell GSH depletion, our results showed that MDA (2.5-10 $\mu \mathrm{M})$, another lipid peroxidation product, had no effect on GSH levels either at 3 or $6 \mathrm{~h}$, suggesting that GSH is attacked by HNE to a greater effect from MDA. BSO, an inhibitor of GSH biosynthesis, has been shown to disturb the redox balance and enhance the vulnerability of PC12 cells to oxidative stress (Seyfried et al, 1999). In contrast to the effect of PTCA on GSH enhancement, pretreatment with BSO for $24 \mathrm{~h}$, significantly depleted GSH without affecting T cell viability (Fig. 19). Similar studies were performed with diethyl maleate (DEM), a GSH scavenger. It depletes GSH within $1 \mathrm{~h}$ in hepatocytes and produces no appreciable change in cell viability (Chen et al., 2005). Additional studies have focused on the sensitization of cells to oxidative stress. Spitz et al. (1991), demonstrated that pretreatment of Chinese hamster fibroblasts and clonogenic cells with BSO potentiates HNE-induced cytotoxicity by causing about $90 \%$ depletion of GSH, which corresponds with a loss in the cell ability to metabolize HNE. Others also have demonstrated a significant increase of cytotoxicity in hepatocytes with a combination of BSO and S-nitroso-Nacetyl-D,L-penicillamine, a nitric oxide donor. This combined regimen led to an increase in LDH release and oxidative stress, disruption of mitochondrial membrane potential, and a decrease in ATP content (Chen et al., 2005). These results agree with our finding that GSH depletion sensitized T cells to the effect of MDA (Fig. 24C).

A plot of cell viability vs. GSH concentration under the different experimental conditions of this study (Fig. 18B) demonstrates a GSH threshold phenomenon in HNE-induced cytotoxicity in $\mathrm{CD}^{+} \mathrm{T}$ lymphocytes, which was also observed in in vivo studies (Fu et al., 2004). There was no decrease in T cell viability at GSH 
concentrations approximately above $20 \%$ of the untreated controls. Thus, intracellular GSH plays an important role in cell viability; at GSH depletion of $80-90 \%$, which most likely involves depletion of mitochondria GSH, results in cytotoxicity.

\section{Role of GSH in the survival factor, Akt}

The serine-threonine kinase Akt (or PKB) is critical for survival and protection against apoptosis in various cells (Burgering and Coffer, 1995; Franke et al., 1995). Specifically in T lymphocytes, the balance between survival and apoptosis is directly associated with immune function. Up-regulated Akt promotes cell survival by phosphorylating a variety of downstream key proapoptotic targets such as GSK-3 (Cross et al., 1995) and caspase-9 (Cardone et al., 1998), and activating transcriptional factors such as NFkB and Forkhead (Kops and Burgering, 1999) in T lymphocytes. Results in the first chapter have shown that HNE downregulated Akt phosphorylation and activation. In the present study, we found that PTCA pretreatment attenuates HNE-induced decreases of Akt activation (Fig. 20). Similarly, NAC, a Cys precursor, has been shown to activate Akt and decrease apoptosis in Jurkat T cells by blocking adaphostin-mediated ROS generation (Yu et al., 2004). Others have shown that NAC completely reversed $\mathrm{N}$-ethylmaleimide-induced inhibition of Akt phosphorylation and apoptosis via inactivation of PP2A in vascular smooth muscle cells (Yellaturu et al., 2002). Interestingly, Liu et al. (2003) showed that pretreatment of the Jurkat $T$ cells with Cys before HNE restored the activity of Akt almost to the untreated levels. They further demonstrated that inhibition of PP2A by a PP2A inhibitor, okadaic acid, prevented HNE-induced Akt dephosphorylation. It is likely NAC, as well as PTCA, reversed ROS induced dephosphorylation of Akt. Thus, PTCA protects against HNE- 
induced inactivation of PI3K/Akt, possibly mediated by restoring phosphorylation of Akt kinase through downregulation and association of PP2A.

GSH is critical for ETV6-NTRK3-transformed murine fibroblast cell growth and studies demonstrated that depletion of GSH by BSO inhibited $p$-Akt phosphorylation in these transformed cells (Kim et al., 2005). In addition, another GSH depleting agent, DEM, was shown to inhibit $p$-Akt expression in rat fibroblast cells (Esposito et al., 2003). In contrast, we have not observed any changes in active or total Akt levels in cells treated with BSO for less than $24 \mathrm{~h}$, when $90 \%$ of GSH was depleted (Figs. 19 and 24). Most of the above experiments were performed by exposing cells to different concentrations and conditions of ROS. In our model, we treated Jurkat T cells with BSO in a complete (10\%) serum RPMI medium; however, others starved the fibroblasts for $48 \mathrm{~h}$ before DEM addition ( $1 \mathrm{mM}, 30 \mathrm{~min}$ ). Also, it could yield different effects on Akt downregulation via different targets within specific cell types such as ETV6-NTRK3 cell, which are especially sensitive to GSH for basal cellular functions (Kim et al., 2005). Interestingly, our results showed that the extent of GSH depletion (48 h BSO treatment) and/or second oxidant addition (10 $\mu \mathrm{M}$ MDA) inhibited Akt activation either through dephosphorylation or a significant degradation of Akt kinase. Together, we and others demonstrated that loss of Akt phosphorylation as well as loss of viability was potentiated if the cell sensitized by GSH depletion before or after oxidative stress.

A plot of $p$-Akt level vs. GSH concentration under different experimental conditions (Fig. 20C) shows a similar GSH threshold phenomenon as that of HNEinduced loss of survival in $\mathrm{CD}^{+} \mathrm{T}$ cells (Fig. 18B). Cells are viable as indexed by $p$ - 
Akt concentration as long as intracellular GSH concentration is maintained at about $20 \%$ of basal levels. This study demonstrated for the first time the close relationship between GSH, cytotoxicity, and cell survival. Also the results suggest that the active Akt is tightly regulated by intracellular GSH concentration.

Previously, we reported that PP2A is upregulated promptly under HNE treatment and PP2A and Akt simultaneously regulate HNE-induced cytotoxicty, however, the mechanism is still not clear. PP2A is a trimeric enzyme composed of a catalytic subunit (PP2Ac), a constant regulatory subunit (PR-65 or PP2Aa) and a variable regulatory subunit $\left(\mathrm{B}, \mathrm{B}^{\prime} \mathrm{B}^{\prime \prime}\right)$. It has been suggested that $\mathrm{PP} 2 \mathrm{~A}$, as other Ser/Thr phosphatases, plays a role in apoptosis (Gjertsen and Doskeland, 1995), probably via phosphorylation and dephosphorylation of target proteins in the survival and/or apoptotic signaling pathways. Our present studies demonstrate for the first time, that PTCA pretreatment attenuated HNE-induced increases of PP2A activation in Jurkat T cells. Analysis of cell lysates by antibodies directed at the PP2A regulatory A subunit demonstrated the loss of this subunit at $6 \mathrm{~h}$. At the same time, there was less of a decrease in the amount of the catalytic subunit (Fig. 21). Similarly, others demonstrated that Jurkat cells treated with anti-Fas antibody increased PP2A activity and protein expression, then caspase-3 inhibitors pretreatment would significantly protect against this enhancement (Santoro et al, 98). Our results and those of others suggest the possibility that upregulating PP2A activity is due to cleavage and removal of the regulatory A subunit from the core enzyme. Also it suggests that without the regulatory A subunit, the catalytic $\mathrm{C}$ subunit is still stable in the cytosol. However, our results further demonstrate the novelty that PTCA, an antioxidant, inhibits HNE- 
induced PP2A upregulation and Akt downregulation followed by apoptotic cell death is regulated by increasing phosphoryaltion of Akt kinase.

\section{Role of Akt in Fas-mediated signaling}

Akt is involved in the inhibition of Fas-mediated apoptosis by associating with intracellular GSH levels, lymphokine and co-stimulatory molecules (Hausler et al., 1998). Others have demonstrated that Akt kinase regulates FasL expression and DNA fragmentation in vascular smooth muscle cells and cervical cancer (HeLa) cells (Suhara et al., 2002; Uriarte et al., 2005). Previously, our laboratory showed that Akt inhibition by LY294002 induces FasL expression and subsequent Fas-mediated apoptosis in Jurkat T cells (Uriarte et al., 2005). The present studies showed that exposure of $\mathrm{T}$ cells to $\mathrm{HNE}$ results in inhibiting of Akt activation that leads to FasFasL-dependent apoptosis in Jurkat T cells. However, we observed no increases in FasL transcripts at the lower HNE concentration $(2.5 \mu \mathrm{M})$, which may be due to: 1$)$ downregulation of Fas expression in cells or 2) regulation by a posttranscriptional mechanism. There are variety of effectors and repressors that lie upstream and downstream in the Fas-mediated cell death machinery, along with the recruitmentactivation pathway. This regulation may occur at the level of receptors, such as receptor endocytosis or hydrolysis of membrane-bound FasL by metalloproteinase to a soluble form. Most importantly, regulation of $\mathrm{c}-\mathrm{FLIP}_{\mathrm{S}}$ plays a role in blocking the association of caspase- 8 with FADD in the early stage of signal transduction. c-FLIP is a cytoplasmic protein and has sequence homology with caspase-8, and blocks apoptosis by competitively inhibiting caspase-8 in human keratinocytes (Marconi et al., 2004). Our results demonstrate that HNE induced Fas-mediated apoptosis also leads to 


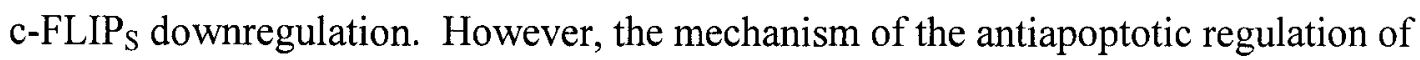
c-FLIPS in T cells treated with HNE is not completely understood. Studies have shown that Akt regulates Fas-mediated death signals through c-FLIP $P_{S}$ expression in endothelial cells (Suhara et al., 2001). Adenovirus-mediated transfection of constitutively active Akt gene abolished homocysteine-mediated downregulation of $\mathrm{c}$ FLIP in endothelial cells (Suhara et al., 2004). Others demonstrated that the PI3-kinase inhibitor, wortmannin, partially suppressed eicosapentaenoic acid (EPA)-induced cFLIP $_{S}$ restoration in endothelial cells (Suzuki et al., 2003). Together, our result suggest that Akt directly upregulated c-FLIP expression and prevented Fas-mediated apoptosis.

\section{Effect of PTCA on Fas-mediated signaling}

In the present study, we have shown that PTCA restored intracellular GSH concentrations, which could then prevent HNE-induced FasL expression both at the protein and transcriptional levels (Fig. 22). Others have also found that inhibition of tert-butylhydroperoxide (tBH)-induced FasL expression, along with antioxidants GSH and NAC, blocked tBH-induced apoptosis in human retinal pigment epithelial cells (Jiang et al., 2000). It is well known that expression of FasL is under redox regulation (Kasibhatla et al., 1999). Upon Fas triggering ( $\alpha$-APO-1) with the antibodies (CH-11), BSO depleted GSH by inhibiting its biosynthesis, increases Fas DISC formation in leukemia cells (Friesen et al., 2004). We further demonstrated that PTCA prevents HNE-induced c-FLIP downregulation, as well as Akt inactivation. To our knowledge, this is the first report that GSH plays a role in HNE-induced Fas-mediated apoptosis by preventing the loss of $p$-Akt and c-FLIPs expression in human T lymphocytes. Others 
have shown that pretreatment of multiple myeloma cells with NAC or DTT blocked oleanane triterpenoid-induced apoptosis and c-FLIP downregulation (Ikeda et al., 2004). Our results clearly indicate that restoration of GSH by PTCA protects against HNE-induced Fas-mediated apoptotic cell death, which is mediated through redox sensitive Akt and c-FLIPS signaling molecules.

Overall, our study demonstrates that, in addition to other known antiapoptotic functions, GSH regulates Akt kinase in T lymphocytes; this involves the regulation of

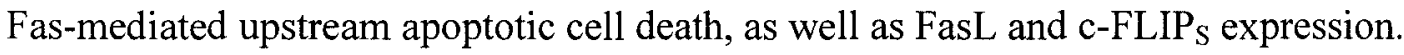
PTCA protects against HNE-induced toxicity and could possibly be used in the treatment of oxidative stress-induced immunosuppressive diseases. 


\section{CHPATER IV}

\section{ROLE OF MAT AND SAME IN HNE-INDUCED CYTOTOXICITY}

\section{INTRODUCTION}

The studies of HNE toxicity in human $\mathrm{CD} 4^{+} \mathrm{T}$ lymphocytes described in this chapter were designed to test the possible role of SAMe and MAT II in toxicity. In an attempt to assess MAT expression, extractions from HNE treated cells were analyzed for MAT II enzymatic activity and gene transcription. To evaluate the role of SAMe and GSH in toxicity, the effects of HNE on SAMe concentrations and the ability of PTCA protects against HNE-induced MAT downregulation and SAMe depletion were determined. To evaluate the role of transcriptional activator of MAT 2A in toxicity, the effects of HNE on c-Myb expression and PTCA protection on HNE toxicity were examined.

\section{MATERIALS AND METHODS}

\section{Cell culture}

Jurkat $\mathrm{T}$ cells were obtained and prepared as described in Chapter II. 


\section{Chemicals}

SAMe, heptanesulfonic acid, MPA, and SAH were purchased from Sigma Chemical Co. (St. Louis, MO). Anti-caspase-3 and $\beta$-Actin antibodies were purchased from Santa Cruz Biotechnology (Santa Cruz, CA).

\section{RNA isolation and real time PCR analysis}

Reverse transcriptase polymerase chain reaction (RT-PCR) assays were used to assess MAT 2A mRNA levels in Jurkat T cells. The specific primers were designed for human GAPDH and MAT 2A using Primer3 software program. The following primers were used in real time PCR:

hGAPDH-RT-FP1： 5' TGGGCTACACTGAGCACCAG 3'

hGAPDH-RT-RP1: 5' GGGTGTCGCTGTTGAAGTCA 3'

hMAT2A FP 5' ACAATCTACCACCTACAGCCAAGT 3'

hMAT2A RP 5' GCATAAGAGACCTGAACAAGAACC 3'

The relative gene expression of MAT2A was analyzed using $2^{-\Delta \Delta \mathrm{Ct}}$ method as described in Chapter II.

\section{MAT activity assay}

$15 \times 10^{6}$ Jurkat cells were homogenized in $500 \mu 1$ cold $10 \mathrm{mM}$ Tris- $\mathrm{HCl}, \mathrm{pH}$ 7.5, containing $0.3 \mathrm{M}$ sucrose, $0.1 \% \beta$-mercaptoethanol, $1 \mathrm{mM}$ benzamidine, $0.1 \mathrm{mM}$ PMSF and $10 \mu \mathrm{g} / \mathrm{ml}$ soybean trypsin inhibitor. Cells were subjected to 3 cycles of freezing/thawing and then were centrifuged (100,000 x g for $30 \mathrm{~min})$ for the extraction. An aliquot of $160 \mu \mathrm{l}$ from the resulting supernatant was incubated with $90 \mu \mathrm{l}$ of reaction mixture containing $75 \mathrm{mM}$ Tris-HCl, $\mathrm{pH} 8,250 \mathrm{mM} \mathrm{KCl}, 9 \mathrm{mM} \mathrm{MgCl}_{2}, 10$ mM DTT, $5 \mathrm{mM}$ ATP and $5 \mathrm{mM}$ methionine. The incubation was performed for 30 
min at $37^{\circ} \mathrm{C}$ and was stopped by the addition of $70 \mu 125 \%$ MPA (on ice). Samples were centrifuged at $10,000 \mathrm{xg}$ for $2 \mathrm{~min}$. The supernatants were collected for HPLC analysis. MAT activity was obtained from the net SAMe formation (subtracted intracellular SAMe) and expressed as nmol of SAMe formed per $30 \mathrm{~min}$.

\section{Analysis of SAMe}

The intracellular concentrations of SAMe were assayed by reverse-phase HPLC in deproteinized extracts of cells by a modified method of Merali et al. (2000). Cell pellets were mixed with $0.25 \mathrm{ml}$ of $4 \%$ MPA and centrifuged at $10,000 \mathrm{x}$ g for $2 \mathrm{~min}$. The supernatants were collected for HPLC analysis. The HPLC system included a Waters 501 pump, a manual injector, and a $5 \mu \mathrm{m}$ Hypersil C18 reverse-phase column (250 $\times 4.6 \mathrm{~mm}$ ). The mobile phase consisted of $40 \mathrm{mM}$ ammonium phosphate, $8 \mathrm{mM}$ heptane sulfonic acid (ion-pairing reagent) and 6\% acetonitrile (pH 5.0) and was run isocratically at a rate of $1.0 \mathrm{ml} / \mathrm{min}$. SAMe was detected using a Waters 740 detector at $254 \mathrm{~nm}$. Standard solutions of SAMe and SAH were prepared in 4\% MPA. An internal standard, SAE, was added to all samples and standard solutions at a concentration of $100 \mathrm{nmol} / \mathrm{ml}$ (Merali et al., 2000; Chen et al., 1990).

\section{Western blot analysis}

Following treatment, cells were lysed by immunoprecipitation lysis buffer and total cellular proteins (65 $\mu \mathrm{g}$ of protein) were resolved on 10\% SDS-PAGE and subjected to standard immunoblotting procedures. The primary antibodies used in this study were as follows: anti-caspase-3 1:100 and $\beta$-Actin 1:1000. The appropriate secondary antibodies were used at 1:5000 for $\beta$-Actin and 1:15,000 for caspase-3. Proteins signals were visualized using the ECL system, as directed by the 
manufacturer. The molecular sizes of the developed proteins were estimated by comparison with prestained protein markers.

\section{Statistical analysis}

Analyses were performed as described in Chapter II.

\section{RESULTS}

Our previous studies have shown that HNE decreased intracellular SAMe concentrations in Jurkat $\mathrm{T}$ cells. The basal intracellular SAMe concentration was $1.1 \pm$ $0.14 \mathrm{nmol} / \mathrm{mg}$, and HNE significantly decreased SAMe levels at $6 \mathrm{~h}$. The extent of SAMe depletion by HNE $(2.5-20 \mu \mathrm{M})$ was about $50 \%$ of the control level.

Interestingly, even at the low $\mathrm{HNE}(2.5 \mu \mathrm{M})$ concentration, the SAMe levels was reduced to $50 \%$ of controls.

\section{HNE decreases MAT II activity}

MAT II is a critical enzyme in cellular metabolism and catalyzes the formation of SAMe from L-methionine and ATP. To determine whether HNE induced depletion of SAMe is due to an effect on MAT II activity, we measured this enzyme activity. As shown in Fig. 25, the MAT II activity of untreated cells was $6.5 \pm 0.4 \mathrm{nmol} / \mathrm{ml} / 30 \mathrm{~min}$. With increasing concentrations of $\operatorname{HNE}(2.5,5$, and $10 \mu \mathrm{M})$ MAT II activities were 92, 55 and $21 \%$, respectively, of the untreated value. The lowest MAT II activity $(1.4 \pm$ $0.4 \mathrm{nmol} / \mathrm{ml} / 30 \mathrm{~min}$ ) was observed in cells exposed to $10 \mu \mathrm{M} \mathrm{HNE}$. These results demonstrated that HNE induced a dose-dependent decrease in MAT II activity in Jurkat $\mathrm{T}$ cells. 


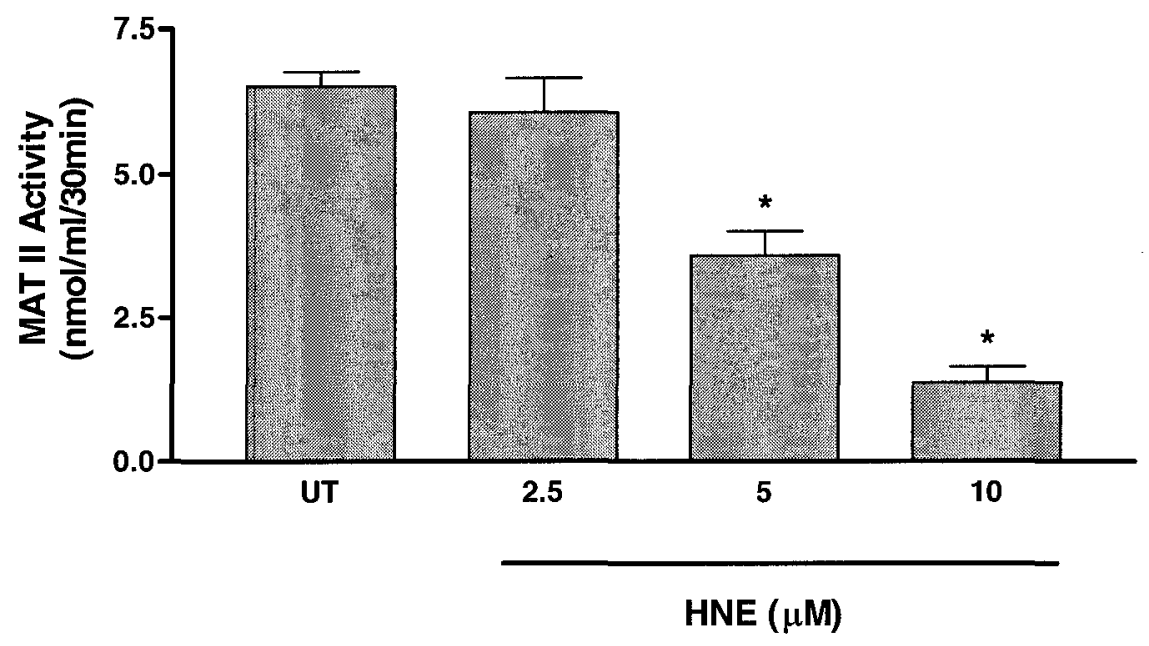

Fig. 25. HNE decreases MAT II activity. Jurkat T cells were untreated (UT) or treated with various concentrations of $\operatorname{HNE}(2.5,5$, and $10 \mu \mathrm{M})$ for $6 \mathrm{~h}$. MAT II activities were assayed at $6 \mathrm{~h}$ by the formation of SAMe using HPLC metho $\mathrm{d}$ as described in Materi als and Methods. Data are represented as mean $\pm \mathrm{S} D$ of three separate experiments . ${ }^{*} \mathrm{P}<0.05$ compared to UT. 


\section{HNE downregulates MAT 2A gene expression}

Upon $\mathrm{T}$ cell activation, a key mechanism for the increase in SAMe biosynthesis is increased transcription of MAT 2A, which is a catalytic subunit of MAT gene. We further examined the effect of HNE on MAT 2A gene expression. Total RNA was isolated from cells exposed to $\mathrm{HNE}(2.5,5$ and $10 \mu \mathrm{M})$ for $3 \mathrm{~h}$ and MAT 2A mRNA levels were assessed by real time PCR. As shown in Fig. 26, MAT 2A mRNA was significantly decreased to $0.6-, 0.4-$ and 0.2 -fold, respectively, of untreated value. HNE was found to decrease MAT 2A mRNA expression in a dose-dependent manner.

\section{Effects of PTCA on SAMe and MAT}

PTCA, a GSH precursor, has been shown to protect against cytotoxicity in $\mathrm{CD}^{+}{ }^{\mathrm{T}}$ lymphocytes. Our previous studies have shown that PTCA markedly attenuated HNE-induced decreases in intracellular SAMe concentrations to about $50 \%$ of the untreated control. PTCA alone had no effect on SAMe concentrations. In Jurkat T cells pretreated with PTCA, SAMe concentrations were increased to about $90 \%$ of the untreated control.

Whether PTCA attenuation of HNE-induced SAMe depletion is related to an effect on MAT activity is not known. We examined the effects of PTCA on MAT II activity. As shown in Fig. 27, MAT II activity of untreated cells was $6.5 \pm 0.4$ $\mathrm{nmol} / \mathrm{ml} / 30 \mathrm{~min}$. Treatment of Jurkat $\mathrm{T}$ cells with increasing concentrations of HNE $(2.5,5$, and $10 \mu \mathrm{M})$ resulted in MAT II activities that were 93, 55 and $21 \%$, respectively, of the untreated values. In Jurkat $\mathrm{T}$ cells pretreated with PTCA before the addition of $\mathrm{HNE}(2.5,5$ and $10 \mu \mathrm{M})$, MAT II activities were increased to 102,82 and 


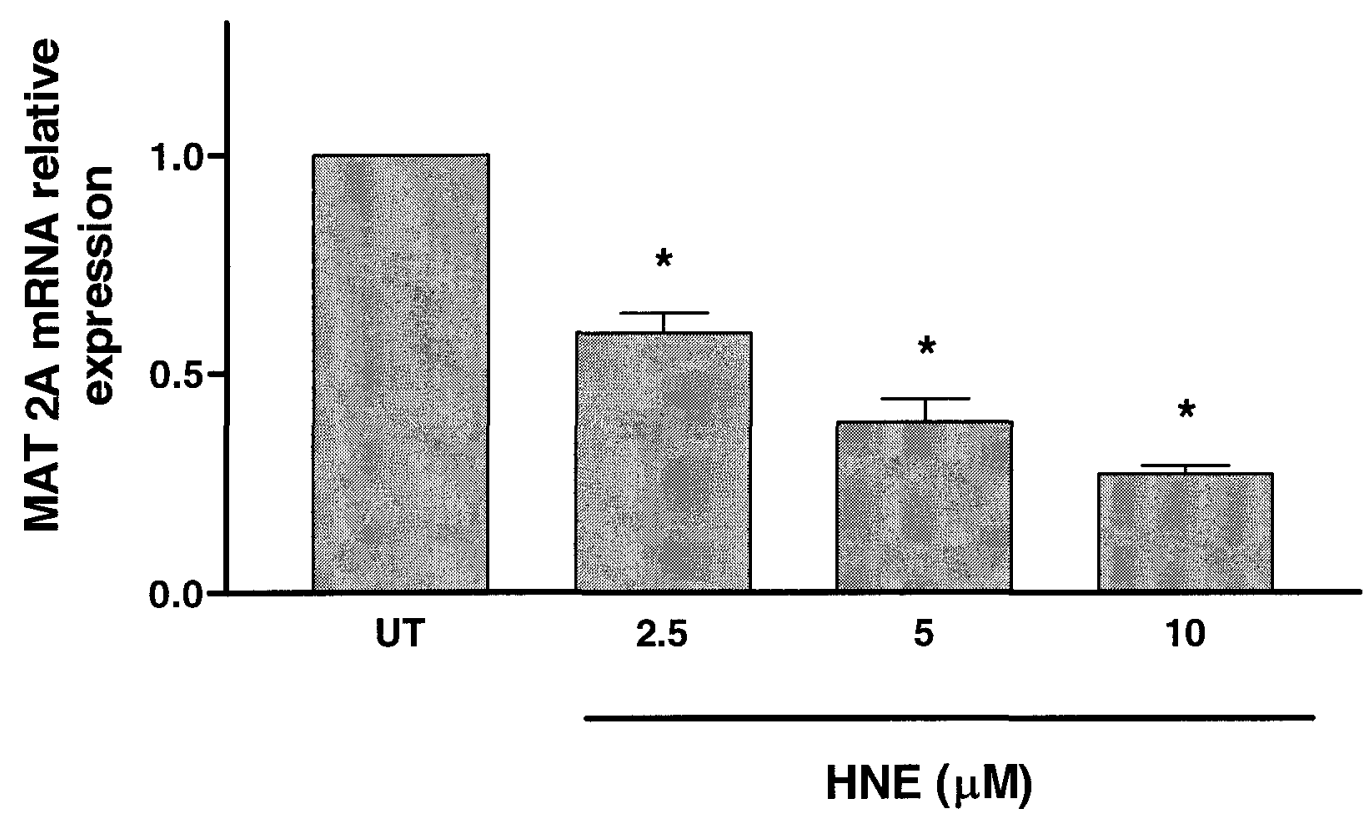

Fig. 26. HNE decreases MAT 2A mRNA levels. Jurkat $\mathrm{T}$ cells were prepared as described in Fig. 25. Total RNA was isolated at $3 \mathrm{~h}$ from cells untreated (UT) or treated with $\operatorname{HNE}(2.5,5$, and $10 \mu \mathrm{M})$. MAT $2 \mathrm{~A}$ mRNA levels were determined by real time PCR. Data are normalized to the untreated control (which is set to 1) and represented as mean \pm SD of four separate experiments. ${ }^{*} \mathrm{P}<0.05$ compared to UT. 


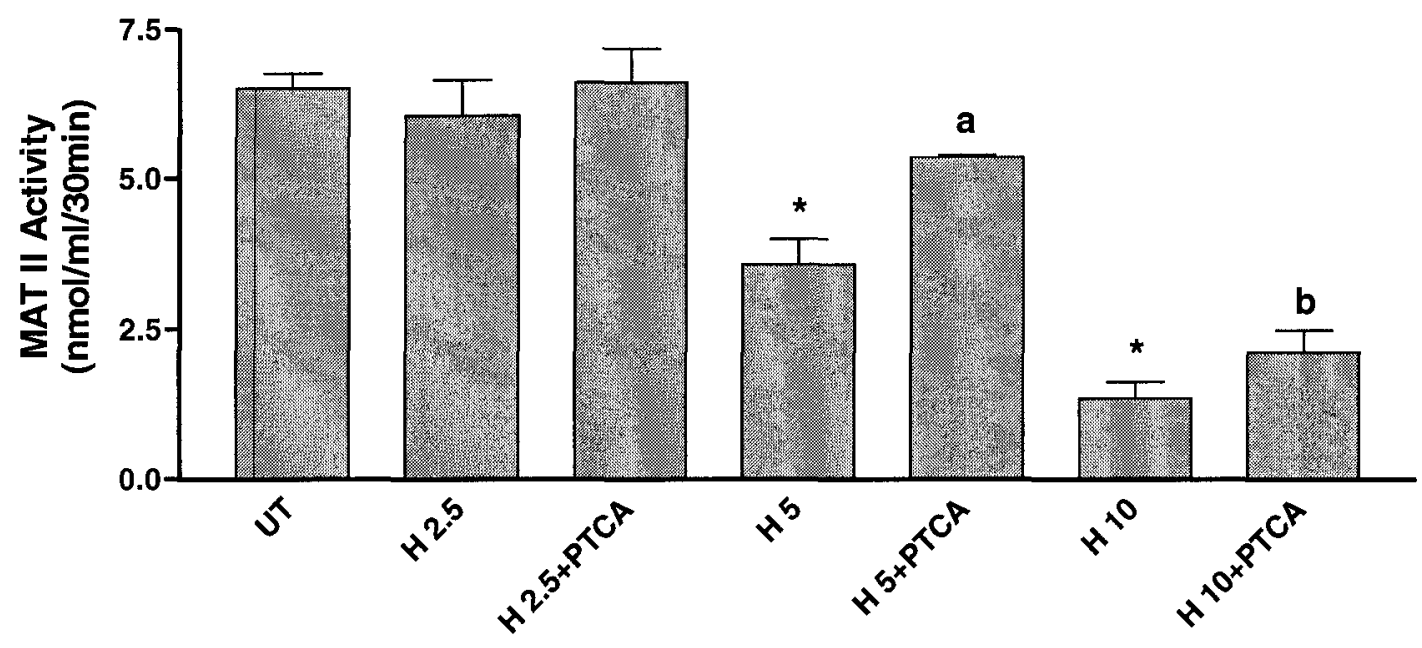

Fig. 27. PTCA attenuates HNE-induced decreases of MAT II activity. Jurkat T cells were pretreated with PTCA at $250 \mu \mathrm{M}$ for $1 \mathrm{~h}$ before the addition of $\mathrm{HNE}$ at $2.5,5$ or $10 \mu \mathrm{M}$. Cells were untreated (UT), or treated with PTCA $(250 \mu \mathrm{M})$ or HNE $(2.5,5$, and $10 \mu \mathrm{M})$, or PTCA plus HNE. MAT II activities were assayed at $6 \mathrm{~h}$ by the formation of SAMe using HPLC method as described in Materials and Methods. Data are represented as mean $\pm \mathrm{S} D$ of three separate experiments . ${ }^{*} \mathrm{P}<0.05$ compared to $\mathrm{UT},{ }^{\mathrm{a} . \mathrm{b}} \mathrm{P}<0.05$ compared to $\mathrm{HNE} 5$ and $10 \mu \mathrm{M}$, respectively. 


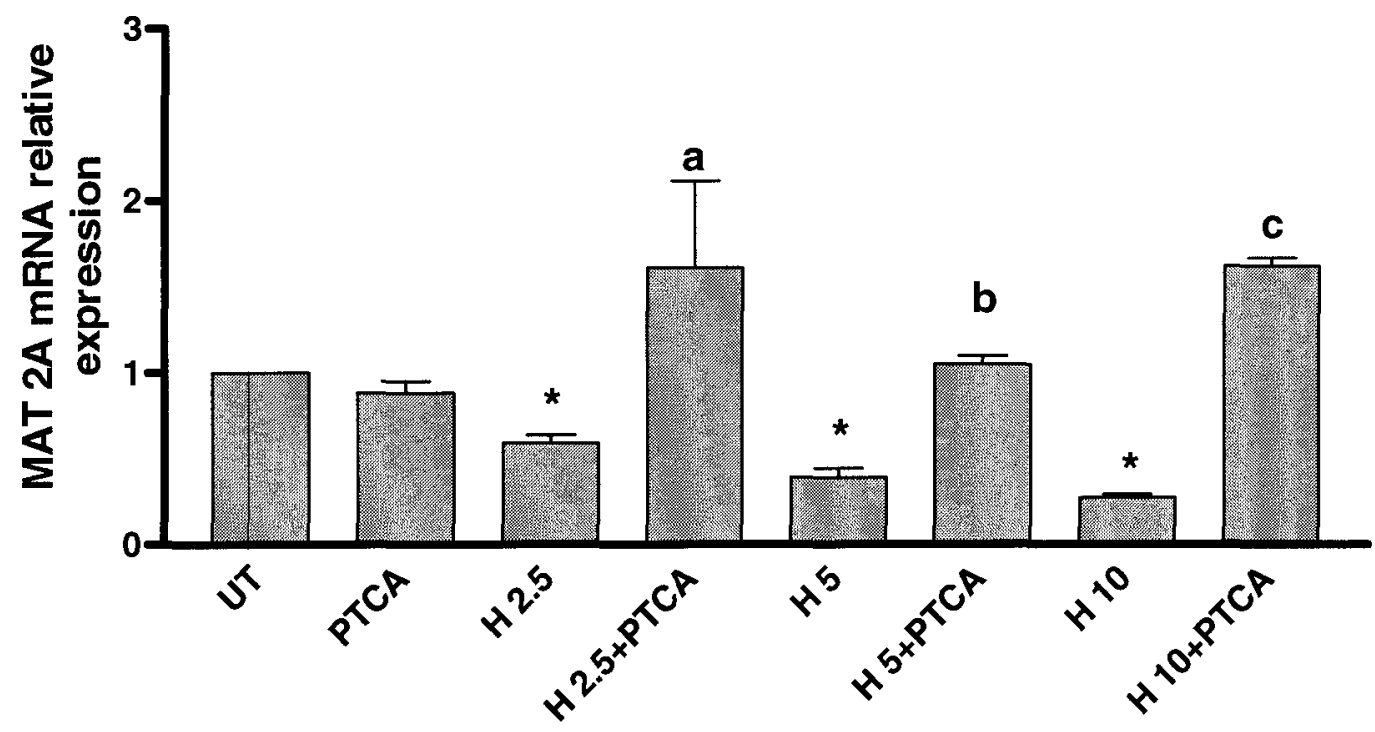

Fig. 28. PTCA attenuates HNE-induced decreases MAT 2A mRNA. Jurkat T cells were prepared as described in Fig. 27. Total RNA were isolated from Jurkat $\mathrm{T}$ cells at $3 \mathrm{~h}$, and MAT 2A mRNA levels were determined by real time PCR. Data are normalized to the untreated control (which is set to 1 ) and represented as mean $\pm \mathrm{SD}$ of four separate experiments. " $\mathrm{P}<0.05$ compared to UT, a,b,c $\mathrm{P}<0.05$ compared to HNE $2.5,5$ and $10 \mu \mathrm{M}$, respectively. 
$33 \%$, respectively, of the untreated value. These results demonstrated that PTCA attenuates HNE-induced decreases in MAT II activity.

Furthermore, a close correlation exists between the GSH concentrations vs. MAT II activity $\left(\mathrm{R}^{2}=0.9731\right)$. As shown in Fig. 29 , it appears that there is a threshold concentration of GSH of 90-95\% depletion before the MAT II activity decreases occurred.

The effect of PTCA on HNE reduced MAT 2A gene expression was further investigated. Total RNA was isolated from the cells pretreated with PTCA for $1 \mathrm{~h}$ before addition of HNE, and MAT 2A mRNA levels were assessed by real time PCR after $3 \mathrm{~h}$. As shown in Fig. 28, MAT 2A mRNA levels were significantly decreased to 0.6-, 0.4- and 0.3-fold, respectively, of untreated value at HNE concentration of 2.5, 5 and $10 \mu \mathrm{M}$. In Jurkat T cells pretreated with PTCA before addition of $\operatorname{HNE}(2.5,5$ and $10 \mu \mathrm{M})$, MAT 2A mRNA levels were increased to about 1.8 -fold of the untreated value. PTCA alone had no effect on MAT 2A mRNA expression. Thus, PTCA markedly upregulates HNE-induced decreases on MAT 2A gene expression.

\section{PTCA vs. c-Myb expression}

Since c-Myb is the transcriptional factor which up-regulates MAT 2A expression in activated Jurkat T cells, the effect of HNE on c-Myb expression was examined by immunoblot analysis. Similar to the effect of HNE on MAT 2A mRNA expression (Fig. 26), HNE was found to downregulate c-Myb in a dose-dependent manner (Fig. 30). At the highest concentration $(10 \mu \mathrm{M})$ of HNE, c-Myb was blocked completely. Further, PTCA pretreatment protects against HNE-induced c-Myb 


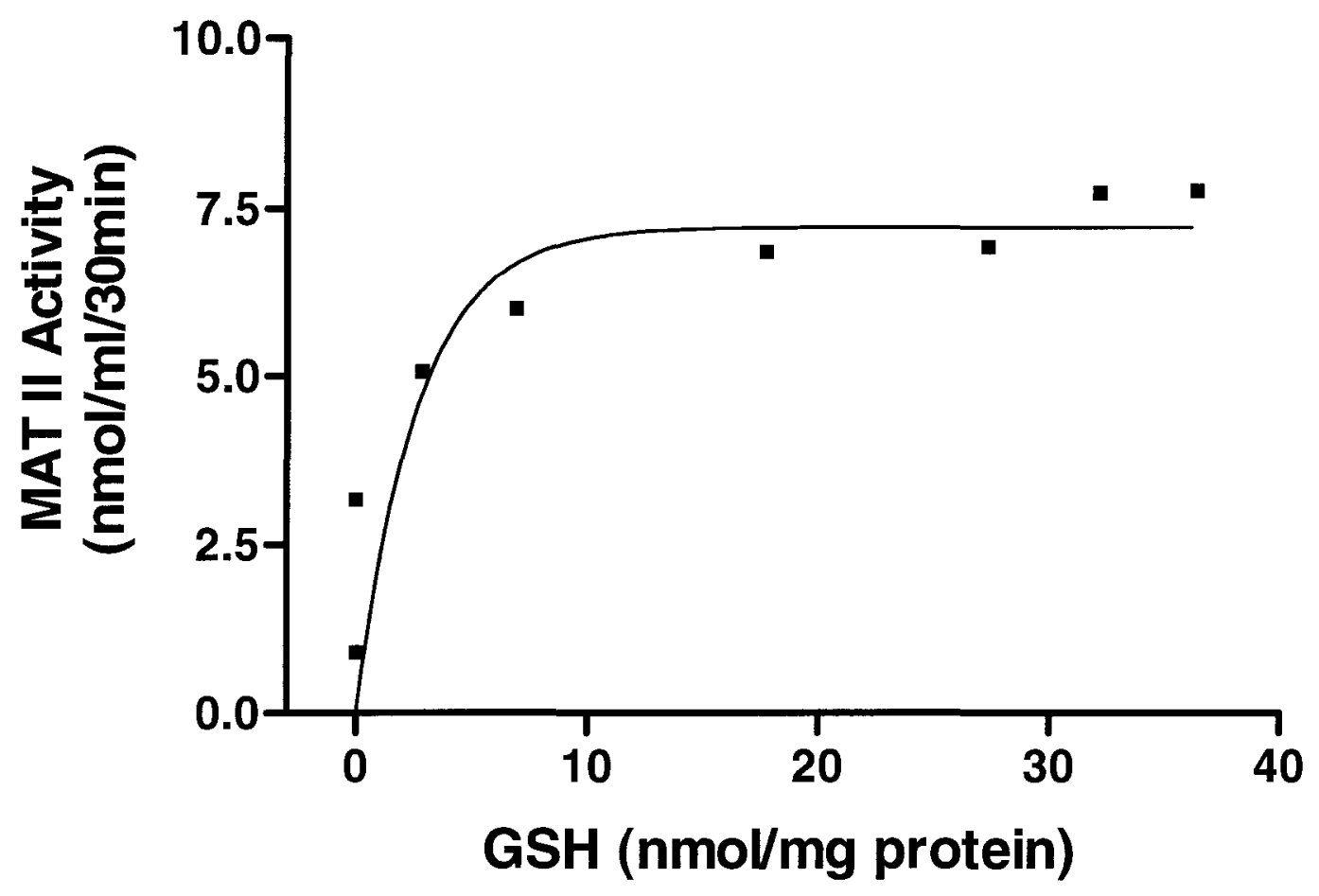

Fig. 29. Relationship between intracellular GSH concentrations and MAT II activity. GSH concentration determined at $3 \mathrm{~h}$ and MAT II activity at $6 \mathrm{~h}$ after HNE treatment. Each point presented value obtained with a given treatment. Plot included data from all experiments in cells in which both MAT II activity and GSH were determined. Values are from Figs. 25 and $27 ; R^{2}=0.9731$. 


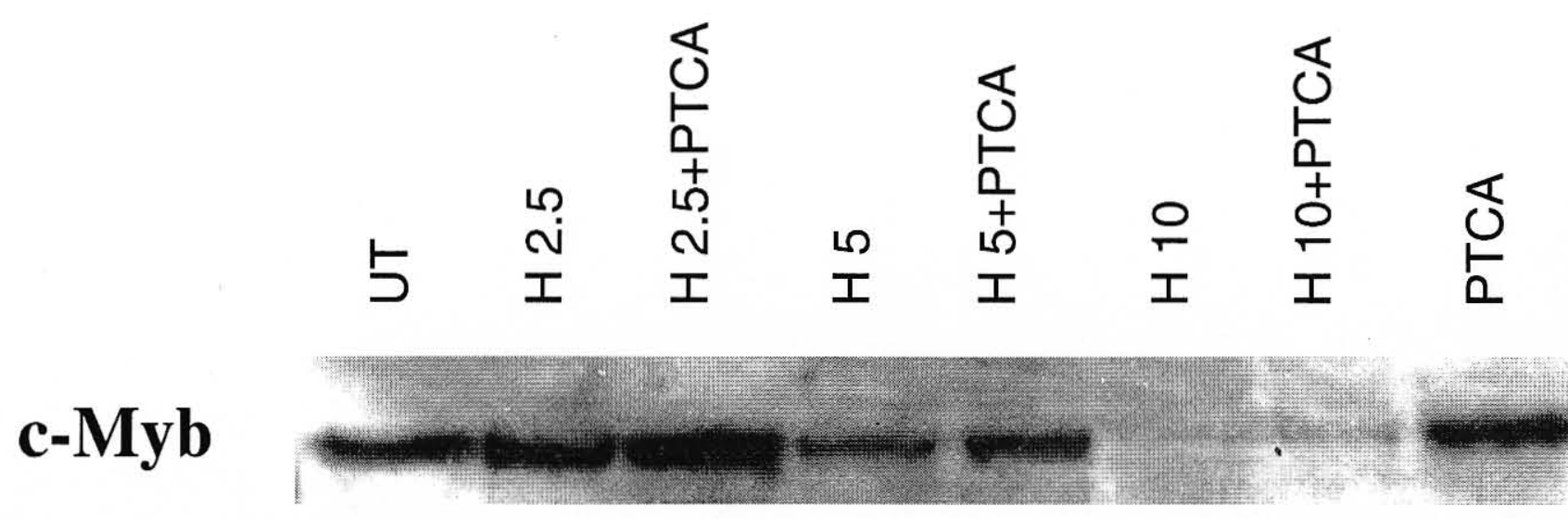

\section{$\beta$-Actin}

Fig. 30. PTCA protects against HNE-induced c-Myb expression. Jurkat T cells were prepared as described in Fig. 27. Total cell lysates were collected at $6 \mathrm{~h}$ for Western blot analysis as described in Materials and Methods. c-Myb was detected at $6 \mathrm{~h}$ by immunoblotting using an anti -c-Myb antibody. Blots were stripped and reprobed with antibody to $\beta$-actin to ensure equivalent loading. A representative gel out of three experiments is shown. 
downregulation. PTCA alone slightly increased expression of c-Myb. The results suggested that c-Myb is downregulated by HNE and PTCA protected against c-Myb downregulation, thus it is probably mediated by a redox sensitive transcription factor.

\section{PTCA vs. Caspase-3 activation}

Our previous studies have shown that PTCA, a GSH precursor, protects against HNE-induced cytotoxicity and apoptotic cell death. In Jurkat $\mathrm{T}$ cells pretreated with PTCA, DNA fragmentation, an index of apoptosis, was decreased to about 1.8-fold of the untreated value as compared to 2.5 -fold decrease in cells treated with HNE alone (previous study).

Caspase- 3 is the main executioner caspase, and its activation plays a critical role in downstream apoptosis signaling and leads to DNA fragmentation. We examined caspase- 3 activation in Jurkat T cells treated with $\operatorname{HNE}(2.5,5$ and $10 \mu \mathrm{M})$ alone $1 \mathrm{~h}$ following pretreated with PTCA. As shown in Fig. 31, HNE-induced a significant activation of caspase- 3 by increasing the cleavages from procaspase- 3 (at $32 \mathrm{KDa}$ ) to active caspase (at p17-20KDa) in a dose-dependent manner. PTCA pretreatment protected against the cleavage of procaspase-3. Additionally, PTCA produced no increase in cleavage products, suggesting that PTCA had no effect on caspase- 3 activation. The results showed that HNE-induces caspase- 3 dependent apoptosis and PTCA pretreatment protects against caspase- 3 activation induced by HNE. 


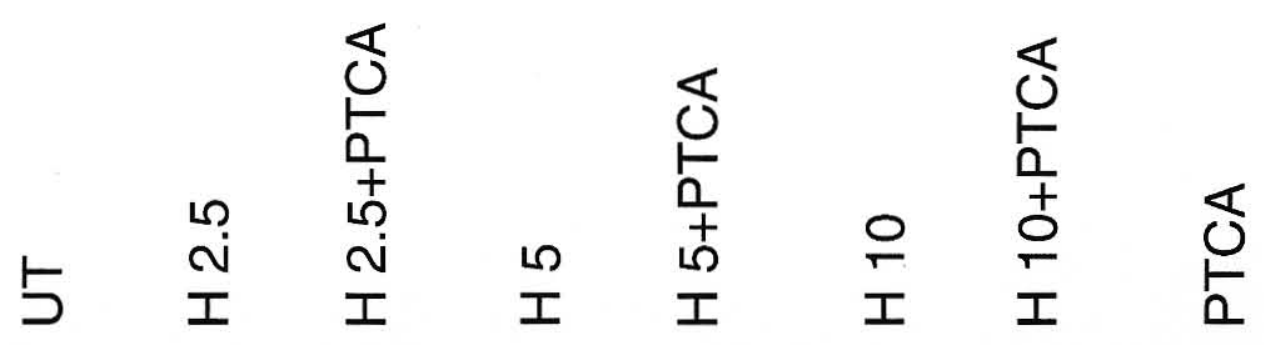

\section{Caspase-3 $32 \mathrm{kDa}$}

$20 \mathrm{kDa}$
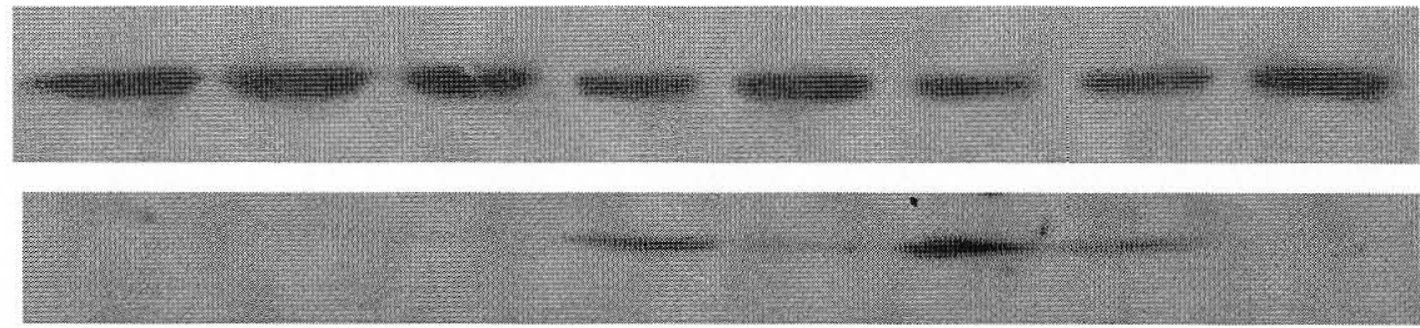

Fig. 31. PTCA protects against HNE-induced caspase-3 dependent apoptosis. Jurkat T cells were prepared as described in Fig. 27. Total cell lysates were collected at $8 \mathrm{~h}$ for Western blot analysis as described in Materials and Methods. Untreated cells (UT) were used as a negative control. Pro $(32 \mathrm{KDa})$ and active $(20 \mathrm{KDa})$ caspase- 3 was detected at $8 \mathrm{~h}$ by immunoblot ting analysis. Blots were stripped and reprobed with antibody to $\beta$-actin to ensure equivalent loading. A representative gel out of three experi ments is shown. 


\section{DISCUSSION}

Methionine adenosyltransferase (MAT, EC 2.5.1.6) is the rate limiting enzyme that catalyzes the biosynthesis of SAMe from L-methionine and ATP (Cantoni, 1953). Various studies have shown the relevance and importance of SAMe and MAT in oxidative stress-induced hepatic damage (Lu, 2000). Administration of BSO, an inhibitor of GSH biosynthesis, leads to a $60 \%$ decrease of hepatic MAT activity in Wistar rats (Corrales et al., 1991). APAP administration induced a 72\% suppression of MAT activity concomitant with GSH depletion in Swiss-Webster mice (Shirota et al., 2002). Clinically, patients with alcoholic cirrhosis have decreased SAMe biosynthesis due to decreased expression of MAT 1A and hepatic MAT activity (Mato et al., 2002). Previously, our laboratory has shown that ethanol treatment produced a significant reduction of MAT 2A and MAT II in MOLT-4 and Jurkat T cells. These notions led us to study whether MAT II could be targeted by oxidative agents, such as the lipid peroxidation end products, and HNE in different tissues, such as lymphocytes. Along with similar results in liver from other studies, we were the first to observe that HNE treatment effectively inhibited MAT II activity in a dose dependent manner in Jurkat T cells.

The MAT 2A gene encodes the MAT II isozyme and is expressed wildely in all tissues including fetal and transformed hepatocytes and cells such as erythrocytes and lymphocytes (Kotb and Kredich, 1985). MAT 2A gene expression is deeply influenced by the cell cycle and is correlated with cell proliferation (De La Rosa et al., 1995). Consistent with this finding, studies have shown that IL-2 and phorbol ester stimulated MAT 2A expression in Jurkat T cells (LeGros et al., 1997). Dexamethasone 
(DEX), a known inhibitor of T-lymphocyte activation, blocked IL-2 and phorbol 12myristate 13-acetate (PMA)-mediated regulation of MAT 2A expression. Interestingly, DEX treatment alone had no effect on the basal mRNA level of MAT 2A (Zeng et al., 2001). Our results showed that not only does HNE significantly inhibit MAT II activity, but this decrease correlated with the decay in MAT 2A mRNA levels. Thus, these results suggest that the MAT 2A gene is targeted by HNE.

SAMe, as a methyl donor, is involved in the production of nucleic acids (DNA and RNA), proteins, neurotransmitters, hormones, and phospholipids, and it functions as an antioxidant. SAMe is also required for cell proliferation. In fact, upon activation of T-lymphocytes, both the SAMe pool size and the rate of SAMe utilization increase and is accompanied by induction of MAT 2A and MAT II (Honchel et al, 1992; De La Rosa et al., 1992). Most importantly, the inhibition of SAMe biosynthesis blocks T cell proliferation (German et al., 1983; Kotb and Geller, 1993). SAMe also functions as a GSH precursor through the transsulfuration pathway. Studies have shown that decreases in SAMe result in GSH deficiency under oxidative stress (Honchel et al, 1992; Wang and Spitzer, 1997). An increased flux of ${ }^{13} \mathrm{C}$-labeled methionine into Sadenosylhomocysteine (SAH) in human lung epithelial-like (A549) cells demonstrated the utilization of SAMe. In addition, the formation of cystathionine increased, indicating that at least part of the SAMe generated was directed toward cysteine/GSH in the transsulfuration pathway (Panayiotidis et al., 2006). Our previous work demonstrated that HNE significantly decreased intracellular SAMe and GSH concentrations. Compared with the time course of GSH depletion (previous studies) and to Fas-mediated apoptotic signaling, HNE decreased intracellular SAMe at a later 
time point ( $6 \mathrm{~h}$, previous study). These results suggest that SAMe depletion occurs: 1$)$ at least in part, when there is an inhibition of methionine breakdown at the level of the SAMe synthesis; 2) after the extensive utilization of GSH through the transsulfuration pathway by HNE. The concomitant decrease in hepatic SAMe and GSH concentrations was also observed in alcoholic patients and chronic alcoholic diet feed animal models (Sprague-Dawley rats) (Koch et al., 1991; Honchel et al, 1992; Wang and Spitzer, 1997).

Restoration of intracellular SAMe levels has been shown to play a role in maintaining MAT 1A gene expression and protecting against cytotoxicity in rat hepatocytes, suggesting it is a "proof of concept" supplementation ( $\mathrm{Lu}$ and Mato, 2005). However, there are several disadvantages using SAMe supplementation directly which include: 1) difficulty in crossing membranes; 2) low biological availability by oral or parenteral administration; 3 ) two biological isomers (the inactive $\mathrm{R}, \mathrm{S}$ and the active S,S forms) in the medium; 4) high cost. Our preliminary study has shown that SAMe pretreatment potentiated HNE induced cytotoxicity in Jurkat T cells, though the GSH and SAMe concentrations were increased. Others observed a rapid elevation of serum aminotransferases such as ALT and AST during SAMe treatment of patients with liver diseases. Thus, SAMe administration is considered to be controversial.

In this study, we observed the effect of PTCA, a GSH precursor, on intracellular SAMe concentration. PTCA has been shown to block APAP-induced GSH depletion and hepatotoxicity in rats and mice (Song, 1994; Fu, 2001). PTCA functions similar to NAC by supplying Cys for GSH synthesis in a prodrug form; but 
PTCA releases Cys independently from enzymatic hydrolysis. We have shown that PTCA attenuated GSH depletion, thereby preventing HNE toxicity in Jurkat T cells. Shirota et al. (2002) have shown that NAC attenuates APAP-induced hepatic depletion of GSH and SAMe in Swiss-Webster mice by maintaining MAT activity. Others have also shown that GSH concentration regulates MAT activity in rat liver during ischemia-reperfusion (Ito et al., 1999). Together, PTCA significantly restores SAMe concentration in Jurkat $\mathrm{T}$ cells possibly through the transsulfuration pathway.

A plot of MAT II activity vs. GSH concentration under different experimental conditions (Fig. 29) shows a similar GSH threshold phenomenon as that of HNEinduced loss of survival and p-Akt level in $\mathrm{CD}^{+}{ }^{+} \mathrm{T}$ lymphocytes (Figs. 18 and 20). These and earlier results support the concept that a reduction in GSH to $20 \%$ of control levels may be critical for cell survival. HNE-mediated decreases in intracellular GSH concentrations could then result in an inactivation of MAT II as well as decrease SAMe levels.

Our results further demonstrated a 2 to 3 -fold increase on MAT 2A mRNA in Jurkat T cells pretreated with PTCA, compared to HNE alone. Others have shown that NAC and PTCA attenuate APAP-induced decreases of MAT activity in Swiss-Webster mice (Shirota et al., 2002). Administration of the antioxidant coenzyme Q10 to rats prior to ischemia protected against both the reductions in MAT activity and the hepatic GSH level induced by ischemia-reperfusion (Ito et al., 1999). In A549 and Jurkat cells, MAT 2A mRNA levels were significantly increased during hyperoxia $\left(95 \% \mathrm{O}_{2}\right)$ (Ito et al., 1999; Zeng et al., 2001). Together, these results directly support the important role GSH plays in the activation of the MAT 2A and the MAT II enzyme which is redox 
sensitive reaction. Further, we observed the involvement of the transsulfuration pathway in the metabolic response to HNE in Jurkat T cells.

The effect of HNE on the MAT 2A gene expression is likely to be a result of its effect on the MAT 2A transcriptional regulator, c-Myb. c-Myb is a 75- to $80-\mathrm{KDa}$ protein that functions as a transcriptional regulator for cell proliferation, differentiation, and survival during hematopoiesis (Oh and Reddy, 1999). The mutated c-Myb site located at -350 to -333 on the MAT 2A promoter was shown to abolish the induction of MAT 2A promoter activity and c-Myb nuclear-binding activity mediated by IL-2 and phorbol ester in Jurkat cells (Zeng et al., 2001). In contrast, overexpression c-Myb in quiescent Jurkat $\mathrm{T}$ cells increased MAT 2A promoter activity, suggesting c-Myb plays an important role in upregulating MAT 2A expression during T cell expansion (Venturelli et al., 1990; Furukawa et al., 1990). Although multiple gene targets regulated by c-Myb transactivation have been identified in $\mathrm{T}$ lymphocytes (Andersson et al., 1999), there is little information on genes that are relevant for $\mathrm{CD}^{+} \mathrm{T}$ lymphocyte survival. Studies have shown that $1 \mu \mathrm{M}$ HNE inhibited c-myb mRNA at 1 $\mathrm{h}$ whereas $10 \mu \mathrm{M}$ HNE inhibited c-Myb expression at 3-6 h in leukemia HL-60 cells (Barrera et al., 1996). Similarly, our results showed that c-Myb expression decreased dose-dependently from $2.5 \mu \mathrm{M}$ and were completely blocked at $6 \mathrm{~h}$ after treated with $10 \mu \mathrm{M}$ HNE (Fig. 31). All together, these results demonstrate that HNE-induced downregulation of MAT 2A gene expression occurs through a decrease of c-Myb. This finding suggests that the MAT $2 \mathrm{~A}$ gene is directly associated with T cell survival and is an important target gene for $\mathrm{c}-\mathrm{Myb}$ in the regulation of $\mathrm{T}$ cell growth. 
Additionally, studies have shown the c-Myb protein that is bound specifically to DNA fragments is negatively regulated by phosphorylation of the amino-terminus with the protein kinase CKII (Oelgeschlager et al., 1995). This suggests DNA-binding may be regulated by secondary protein modifications. Others have shown that $c-m y b$ transcription is activated by protein kinase B following IL-2 stimulation and is required for PKB/PI3K-mediated protection from apoptosis in T cells (Lauder et al., 2001). Also it is known that c-Myb activity is required for Akt, a survival factor, during $\mathrm{T}$ cell activation and that the c-Myb gene is regulated only by components of the PI-3K pathway (Lauder et al., 2001). Based on our PTCA results, the mechanism of upregulation of c-Myb might possibly be through multiple pathways and may include increased redox restoration and kinase phosphorylation.

Both intracellular antioxidant concentrations (GSH and SAMe) and c-Myb have been shown to be important regulators for cell proliferation and survival in $\mathrm{CD} 4^{+} \mathrm{T}$ lymphocytes (German et al., 1983; Venturelli et al., 1990). However, fewer studies have investigated the association of GSH/SAMe and c-Myb. Our results are the first to show that the restoration of endogenous antioxidant concentrations by PTCA influences the expression of c-Myb in vitro (Fig. 31). As a transcription factor, the DNA binding activity of c-Myb is suggested to be regulated by a reduction-oxidation mechanism. Oxidation by diamide of the Myb-proteins in vitro inhibits their interaction with DNA, whereby the diamide effect is reversible by supplementation with reducing agents such as DTT (Guehmann et al., 1992).

Since SAMe and MAT are critical for CD4+ T lymphocytes survival and proliferation, downregulation effects of HNE on MAT II expression and activity and 
consequent SAMe deficiency may lead to apoptotic T cell death. During apoptosis, caspase-3 has been demonstrated to cleave vital proteins such as poly (ADP-ribose) polymerase (PARP) and to amplify upstream caspase signals leading to DNA fragmentation at the end stage of apoptosis (Liu et al., 2000). Our previous work characterized HNE-mediated $\mathrm{CD} 4^{+} \mathrm{T}$ cell apoptosis by recruiting procaspase-8, an initiating caspase, to DISC through Fas/FasL pathway in the early stage and thereby activating a series of caspase cascades. In the present study, we demonstrated that inhibition of SAMe biosynthesis by HNE led to activation of caspase-3. Recently, our laboratory has shown that cycloleucin, a MAT inhibitor, significantly increases caspase- 3 and -8 cleavages and leads to DNA fragmentation. More importantly, we demonstrated for the first time that PTCA can attenuate HNE-induced caspase-3 activation (Fig. 31), along with its protection against HNE-induced apoptosis in CD4 ${ }^{+}$ T cells. Other antioxidant such as NAC was also shown to block HNE-induced caspase-3 activation and DNA fragmentation in Jurkat T cells (Liu et al., 2000). Further, pretreatment of Jurkat $\mathrm{T}$ cells with anethole dithiolethione (10-50 mM, $18 \mathrm{~h}$ ) restored HNE-induced cytotoxicity (Khanna et al., 1998). Thus, our results confirmed findings of others on the protective effect of antioxidants and suggest that PTCA protects against HNE-induced caspase- 3 activation and caspase- 3 dependent apoptosis, possibly through GSH restoration.

In conclusion, we have identified MAT II and SAMe are critical molecular components required for $\mathrm{CD} 4^{+} \mathrm{T}$ cell survival, and $\mathrm{HNE}$ downregulates MAT II expression and activity resulting in SAMe depletion. Based on these findings, we postulate that investigation of the effects of $\mathrm{HNE}$ on $\mathrm{CD}^{+} \mathrm{T}$ cell MATII activity, 
SAMe levels, and survival will provide important information concerning mechanisms of immunosuppression. Additionally, attenuation of HNE-induced apoptotic T cell death by GSH prodrug (PTCA) provides a potential therapeutic use in treating immune dysfunction associated with other immnunosuppressive disorders such as HIV/HCV infection and diabetes. 


\section{CHAPTER V \\ SUMMARY AND CONCLUSION}

The principle hypotheses of the project were that 1) human $\mathrm{CD}^{+} \mathrm{T}$ lymphocytes (Jurkat) would be susceptible to HNE-induced cytotoxicity but relatively resistant to MDA, 2) HNE-induced cytotoxicity involves an early formation of DISC, which is Fas-FasL -dependent pathway and can be detoxified by restoration of GSH and concomitant activation of Akt kinase, 3) and that SAMe depletion and MAT II downregulation by HNE might be involved in HNE-induced cytotoxicity.

\section{Summary of results}

1. HNE inhibits Akt activation, enhances FasL expression, and induces DISC formation with increased binding of FADD leading to caspase-8 activation

2. DISC formation and caspase- 8 activation are critical initiating events in the HNE induced Fas-mediated apoptotic death in $\mathrm{CD}^{+} \mathrm{T}$ lymphocytes.

3. HNE causes dose dependent Akt downregulation and PP2A upregulation, concomitantly, both are regulated by GSH.

4. HNE causes dose- and time-dependent decreases in intracellular GSH concentrations. 
5. PTCA, a GSH precursor, attenuates HNE-induced intracellular GSH depletion and protected against HNE-induced Fas-mediated apoptotic cell death through Akt and c-FLIP .

6. BSO, a GSH depleting agent, increases sensitization to lipid peroxidation and potentiates cytotoxicity by Akt inactivation and dephosphorylation.

7. MAT II and SAMe are critical molecular targets affected by $\mathrm{HNE}$ in $\mathrm{CD} 4^{+} \mathrm{T}$ lymphocytes.

8. HNE down-regulates MAT II activity and MAT 2A expression resulting in intracellular SAMe depletion in $\mathrm{CD}^{+} \mathrm{T}$ lymphocytes.

9. A close correlation was established between GSH, cytotoxicity, survival factor and MAT II activity.

10. HNE down-regulates $\mathrm{c}-\mathrm{Myb}$ expression, which is a transcription activator of MAT 2A.

11. PTCA restores intracellular SAMe levels, MAT II activity, upregulates MAT 2A and c-Myb expression and prevents HNE-induced caspase-3 dependent apoptotic cell death.

\section{Conclusion}

1. A complete signaling pathway on HNE-induced cytotoxicity was established.

2. A critical threshold level of GSH was found to be associated with HNE induced cytotoxicity, decreases $p$-Akt activity, and inhibition of MAT II activity and PTCA can protect against these.

3. PTCA may be beneficial in the treatment of immunosuppressive disorders involving $\mathrm{CD}^{+} \mathrm{T}$ cell depletion, such as HIV and HCV infection. 


\section{REFERENCES}

Andersson, K.B., Berge, T., Matre, V., and Gabrielsen, O.S. (1999). Sequence selectivity of c-Myb in vivo. Resolution of a DNA target specificity paradox. J Biol Chem. 274: 21986-21994.

Barrera, G., Di Mauro, C., Muraca, R., Ferrero, D., Cavalli, G., Fazio, V.M., Paradisi, L. and Dianzani, M.U. (1991). Introduction of differentiation in human HL-60 cells by 4-hydroxy nonenal, a product of lipid peroxidation. Exp. Cell Res. 197: 148-152.

Barrera, G., Pizzimenti, S., Serra, A., Ferretti, C., Ffazio, V.M., Saglio, G.., and Dianzani, M.U. (1996). 4-hydroxynonenal specifically inhibits c-myb but does not affect c-fos expressions in HL-60 cells. Biochem Biophys Res Commun. 227: 589-593.

Bauer, B. and Baier, G. (2001). Protein kinase C and Akt/protein kinase B in CD4+ T lymphocytes: new partners in TCR/CD28 signal integration. $\mathrm{Mol}$ Immunol. 38: 1087-1099.

Benedetti, A., Comporti, M., Fulceri, R., and Esterbauer, H. (1984). Cytotoxic aldehydesoriginating from the peroxidation of liver microsomal lipids. Identification of 4,5-dihydroxydecenal. Biochim. Biophys. Acta 792: 172181.

Brunner, T., Wasem, C., Torgler, R., Cima, I., Jakob, S., and Corazza, N. (2003). Fas (CD95/Apo-1) ligand regulation in T cell homeostasis, cell-mediated cytotoxicity and immune pathology. Semin. Immunol. 15: 167-176.

Burgering, B.M. and Coffer, P.J. (1995). Protein kinase B (c-Akt) in phosphatidylinositol-3-OH kinase signal transduction. Nature 376: 599-602.

Calabrese, V., Scapagnini, G., Latteri, S., Colombrita, C., Ravagna, A., Catalano, C., Pennisi, G., Calvani, M., and Butterfield, D.A. (2002). Long-term ethanol administration enhances age-dependent modulation of redox state in different brain regions in the rat: protection by acetyl carnitine. Int. J. Tissue React. 24: 97-104.

Cambiaggi, C., Dominici, S., Comporti, M., and Pompella A. (1997). Modulation of human $\mathrm{T}$ lymphocyte proliferation by 4-hydroxynonenal, the bioactive product of neutrophil-dependent lipid peroxidation. Life Sci. 61: 777-785.

Cantoni, G.L. (1953). S-adenosylmethionine; a new intermediate formed enzymatically from L-methionine and adenosinetriphosphate. J. Biol. Chem. 204: 403-416.

Cardone, M.H., Roy, N., Stennicke, H.R., Salvesen, G.S., Franke, T.F., Stanbridge, E., Frisch, S., and Reed, J.C. (1998). Regulation of cell death protease caspase- 9 by phosphorylation. Science 282: 1318-1321. 
Cederbaum, A.I. (1989). Role of lipid peroxidation and oxidative stress in alcohol toxicity. Free Radic. Biol. Med. 7: 537-539.

Chandra, A.; Srivastava, S.; Petrash, J.M.; Bhatnagar, A.; Srivastava, S.K. (1997). Modification of aldose reductase by S-nitrosoglutathione. J. Biochem. 36:15801-15809.

Chang, W., (2004). Mechanism of oxidative stress induced cell toxicity. Master thesis, University of Louisville.

Chen, J., Martin, B. L., and Brautigan, D. L. (1992). Regulation of protein serinethreonine phosphatase type-2A by tyrosine phosphorylation. Science 257 , 1261-1264.

Chen, T., Pearce, L.L., Peterson, J., Stoyanoysky, D., and Billiar, T.R. (2005). Glutathione depletion renders rat hepatocytes sensitive to nitric oxide donormediated toxicity. Hepatology. 42: 598-607.

Chen, T.S., Richie, J.P., Jr., and Lang, C.A. (1990). Life span profiles of glutathione and acetaminophen detoxification. Drug Metab. Dispos. 18: 882-887.

Chinnaiyan, A.M., O'Rourke, K., Tewari, M., and Dixit, V.M. (1995). FADD, a novel death domain-containing protein, interacts with the death domain of Fas and initiates apoptosis. Cell 81: 505-512.

Clot, P., Tabone, M., and Albano, E. (1994). Monitoring oxidative damage in patients with liver cirrhosis and different daily alcohol intake. Gut 35: 16371643.

Cook, R.T. (1999). Alcohol abuse, alcoholism, and damage to the immune system-a review. Alcohol Clin. Exp. Res. 22: 1927-1942.

Corrales, F., Ochoa, P., Rovas, C., Martin-Lomas, M., Mato, J.M., and Pajares, M.A. (1991). Inhibition of glutathione synthesis in the liver leads to Sadenosyl-L-methionine synthetase reduction. Hepatology. 14: 528-533.

Corrales, F., Gimenez, A., Alvarez, L., Caballeria, J., Pajares, M.A., Andreu, H., Pares, A., Mato, J.M. and Rodes, J. (1992). S-Adenosylmethionine treatment prevents carbon tetrachloride induced $S$-adenosylmethionine synthetase inactivation and attenuates liver injury. Hepatology 16: 1022-1027.

Cross, D.A, Alessi, D.R., Cohen, P., Andjelkovich, M., and Hemmings, B.A. (1995). Inhibition of glycogen synthase kinase- 3 by insulin mediated by protein kinase B. Nature 378: 785-789.

Datta, S.R., Dudek, H., Tao, X., Masters, S., Fu, H., Gotoh, Y., and Greenberg, M.E. (1997). Akt phosphorylation of BAD couples survival signals to the cellintrinsic death machinery. Cell 91: 231-241.

De La Rosa, J., LeGros, Jr. H.L., Valentine, M., and Geller, A. (1995).

Chromosomal localization and catalytic properties of the recobinant $\alpha$ subunit of human lymphocyte methionine adenosyltransferase. J. Biol. Chem. 270: 21860-21868.

De La Rosa, J., Geller, A.M., LeGros, Jr. H.L., and Kotb M. (1992). Induction of interleukin-2 production but not methionine adenosyltransferase activity or s-adenosylmethionine turnover in Jurkat T cells. Cancer Res. 52: 33613366. 
del Peso, L., Gonzalez-Garcia, M., Page, C., Herrera, R., and Nunez, G. (1997). Interleukin- 3-induced phosphorylation of BAD through the protein kinase Akt. Science 278: 687-689.

Droge, W., Pottmeyer-Gerber, C., Schmidt, H. and Nick, S. (1986). Glutathione augments the activation of cytotoxic T lymphocytes in vivo. Immunobiology 172: $151-156$.

Esposito, F., Chirico, G., Montesano Gesualdi, N., Posadas, I., Ammendola, R., Russo, T., Cirino, G., and Cimino, F. (2003). Protein kinase B activation by reactive oxygen species is independent of tyrosine kinase receptor phosphorylation and requires SRC activity. J Biol Chem. 278: 20828-20834.

Esterbauer, H., Schaur, R.J., and Zollner, H. (1991). Chemistry and biochemistry of 4-hydrdoxynonenal, malonaldehyde, and related aldehydes. Free Radic. Biol. Med.11: 81-128.

Franke, T.F., Yang, S.I., Chan, T.O., Datta, K., Kazlauskas, A., Morrison, D.K., Kaplan, D.R., and Tsichlis, P.N. (1995). The protein kinase encoded by the Aky proto-oncogene is a target of the PDGF-activated phosphatidyllinositol 3-kinase. Cell 81: 727-736.

Friesen, C., Kiess, Y, and Debatin, K.M. (2004). A critical role of glutathione in determining apoptosis sensitivity and resistance in leukemia cells. Cell Death Differ. 11: S73-S85.

Fu, X., Chen, T.S., Ray, M.B., Nagasawa, H.T., Williams, W.M. (2004). pAminophenol-induced hepatotoxicity in hamsters: role of glutathione. J Biochem Mol Toxicol.18: 154-161.

Furukawa, Y., Piwnica-Worms, H., Ernst, T.J., Kanakura, Y., and Griffin, J.D. (1990). cdc2 gene expression at the G1 to $\mathrm{S}$ transition in human $\mathrm{T}$ lymphocytes. Science. 250: 805-808.

German, D.C., Bloch, C.A., and Kredich, N.M. (1983). Measurements of Sadenosylmethionine and L-homocysteine metabolism in cultured human lymphoid cells. J. Biol. Chem. 258: 10997-11003.

Gioacchini, A.M., Calonghi, N., Boga, C., Cappadone, C., Masotti, L., Roda, A. and Traldi P. (1999). Determination of 4-hydroxy-2-nonenal at cellular levels by means of electrospray mass spectrometry. Rapid Commun. Mass Spectrom. 13: 1573-1579.

Gjertsen, B.T. and Doskeland, S.O. (1995). Protein phosphorylation in apoptosis. Biochim Biophys Acta. 1269: 187-199.

Grethe, S. and Pron-Ares, M.I. (2006). p38 MAPK regulates phosphorylation of Bad via PP2A-dependent suppression of the MEK1/2-ERK1/2 survival pathway in TNF-alpha induced endothelial apoptosis. Cell Signal. 18: 531 540.

Guehmann, S., Vorbrueggen, G., Kalkbrenner, F., and Moelling, K. (1992). Reduction of a conserved Cys is essential for Myb DNA-binding. Nucleic Acids Res. 20: 2279-2286.

Halvorsen, E.M., Dennis, J., Keeney, P., Sturgill, T.W., Tuttle, J.B., and Bennett, J.B. Jr. (2002). Methylpyridinium (MPP(+))- and nerve growth factor- 
induced changes in pro- and anti-apoptotic signaling pathways in SH-SY5Y neuroblastoma cells. Brain Res. 952: 98-110.

Hamilos, D.L. and Wedner, H.J. (1985). The role of glutathione in lymphocyte activation. I. Comparison of inhibitory effects of buthionine sulfoximine and 2-cyclohexene-1-one by nuclear size transformation. J. Immunol 135: 27402747.

Hausler, P., Papoff, G., Eramo, A., Reif, K. Cantrell, D.A., and Ruberti, G. (1998). Protection of CD95-mediated apoptosis by activation of phosphatidylinositide 3-kinase and protein kinase B. Eur J Immunol. 28: 57 69.

Honchel, R., Ray, M.B., Marsano, L., Cohen, D., Lee, E., Shedlofsky, S., and McClain, C.J. (1992). Tumor necrosis factor in alcohol enhanced endotoxin liver injury. Alcohol. Clin. Exp. Res. 16: 665-669.

Ikeda, T, Nakata, Y, Kimura, F., Sato, K., Anderson, K., Motoyoshi, K., Sport, M., and Kufe, D. (2004). Induction of redox imbalance and apoptosis in multiple myeloma cells by the novel triterpenoid 2-cyano-3,12-dioxoolean1,9-dien-28-oic acid. Mol Cancer Ther. 3: 39-45.

Irmler, M., Thome, M., Hahne, M., Schneider, P., Hofmann, K., Steiner, V., Bodmer, J.L., Schroter, M., Burns, K., Mattmann, C., Rimoldi, D., French, L.E., and Tschopp, J. (1997). Inhibition of death receptor signals by cellular FLIP. Nature 388: 190-195.

Ito, K., Miwa, N., Hagiwara, K., Yano, T., Shimizu-Saito, K., Goseki, N., Iwai, T., and Horikawa, S. (1999). Regulation of methionine adenosyltransferase activity by the glutathione level in rat liver during ischemia-reperfusion. Surg Today. 29: 1053-1058.

Ivaska, J., Nissinen, L., Immonen, N., Eriksson, J.E., Kahari, V.M. and Heino, J. (2002). Integrin alpha 2 beta 1 promotes activation of protein phosphatase $2 \mathrm{~A}$ and dephosphorylation of Akt and glycogen synthase kinase 3 beta. $\mathrm{Mol}$ Cell Biol. 22: 1352-1359.

Jamnicki-Abegg, M., Weihrauch, D., Pagel, P.S., Kersten, J.R., Bosnjak, Z.J., Warltier, D.C., and Bienengraeber, M.W. (2005). Isoflurane inhibits cardiac myocyte apoptosis during oxidative and inflammatory stress by activating Akt and enhancing Bcl-2 expression. Anesthesiology. 103: 1006-1014.

Jiang, S., Wu, M.W., Sternberg, P., and Jones, D.P. (2000). Fas mediates apoptosis and oxidant-induced cell death in cultured hRPE cells. Invest Ophthalmol Vis Sci. 41: 645-655.

Kajimoto, G.S., Umayahara, Y., Kaneto, H., Watada, H., Kuroda, A., Kawamori, D., Yasuda, T., Matsuhisa, M., Yamasaki, Y., and Hori, M. (2002). Probucol preserves pancreatic beta-cell function through reduction of oxidative stress in type 2 diabetes. Diabetes Res. Clin. Pract. 57: 1-10.

Kalinich, J.F., Ramakrishnan, R., McClain, D.E., and Ramakrishnan, N. (1999). 4Hydroxynonenal, an end-product of lipid peroxidation, induces apoptosis in human leukemic T- and B-cell lines. Free Radic. Res. 33: 349-358.

Kasibhatla et al., Genestier, L., and Green, D.R. (1999). Regulation of fas-ligand expression during activation-induced cell death in T lymphocytes via nuclear factor kappaB. J Biol Chem. 274: 987-992. 
Khanna, S., Sen, C.K., Roy, S., Christen, M.O., and Packer, L. (1998). Protective effects of anethole dithiolethione against oxidative stress-induced cytotoxicity in human Jurkat T cells. Biochem. Pharmacol. 56: 61-69.

Kim, S.J., Kim, H.G., Lim, H.W., Park, E.H., and Lim, C.J. (2005). Up-regulation of glutathione biosynthesis in NIH3T3 cells transformed with the ETV6NTRK3 gene fusion. Mol Cells. 19: 131-136.

Koch, O.R., Galeotti, T., Bartoli, G.M., and Boveris, A. (1991). Alcohol-induced oxidative stress in rat liver. Xenobiotica 21: 1077-1084.

Kops, G.J. and Burgering, B.M. (1999). Forkhead transcription factors: new insights into protein kinase B (c-akt) signaling. J. Mol. Med. 77: 656-665.

Kotb, M. and Kredich, N. (1985). S-adenosylmethionine synthetase from human lymphocytes-purification and characterization. J. Biol. Chem. 260: 39233930.

Kotb, M. and Geller, A. (1993). Methionine adenosyltransferase: structure and function. Pharmac. Ther. 59: 125-143.

Krueger, A., Schmitz, I., Baumann, S., Krammer, P.H., and Kirchhoff, S. (2001a). Cellular FLICE-inhibitory protein splice variants inhibit different steps of caspase-8 activation at the CD95 death-inducing signaling complex. J. Biol. Chem. 276: 20633-20640.

Krueger, A., Baumann, S., Krammer, P.H., and Kirchhoff, S. (2001). FLICEinhibitory proteins: regulators of death receptor-mediated apoptosis. $\mathrm{Mol}$. Cell. Biol. 21: 8247-8254.

Kruman, I., Bruce-Keller, A.J., Bredesen, D., Waeg, G., and Mattson, M.P. (1997). Evidence that 4-hydroxynonenal mediates oxidative stress-induced neuronal apoptosis. J. Neurosci. 17: 5089-5100.

Lang, C.A., Mills, B.J., Mastropaolo, W., and Liu, M.C. (2000). Blood glutathione decreases in chronic diseases. J Lab. Clin. Med.135: 402-405.

Lauder, A., Castellanos, A. and Weston K. (2001). c-Myb transcription is activated by protein kinase $\mathrm{B}(\mathrm{PKB})$ following interleukin 2 stimulation of T cells and is required for PKB-mediated protection from apoptosis. Mol Cell Biol. 21: 5797-5805.

LeGros, Jr. H.L., Geller, A., and Kotb, M. (1997). Differential regulation of methionine adenosyltransferase in superantigen and mitogen stimulated human T lymphocytes. J. Biol. Chem. 272: 16040-16047.

Liu, W., Kato, M., Andwaral, A., and Akhand I. (2000). 4-hydroxynonenal induces a cellular redox status-related activation of the caspase cascade for apoptotic cell death. J. Cell. Sci. 113: 635-641.

Liu, W., Akhand, A.A., Takeda, K., Kawamoto, Y., Itoigawa, M., Kato, M., Suzuki, H., Ishikawa, N, and Nakashima, I. (2003). Protein phosphatase 2Alinked and -unlinked caspase-dependent pathways for downregulation of Akt kinase triggered by 4-hydroxynonenal. Cell Death Differ. 10: 772-781.

Livak, K.J. and Schmittgen, T.D. (2001). Analysis of relative gene expression data using real-time quantitative PCR and $2^{-\Delta \Delta C}$ method. Methods 25: 402-408.

Lu, S.C. (2000). S-adenosylmethionine. Int. Jour. Biochem. Cell Biol. 32: 391-395. 
Lu, S.C. and Mato, J.M. (2005). Role of methionine adenosyltransferase and Sadenosylmethionine in alcohol-associated liver cancer. Alcohol. 35: 227234.

MacGregor, R.R. (1986). Alcohol and immune defense. JAMA 256: 1474-1479.

Marconi, A., Atzel, P. Panza, C., Fila, C., Tiberio, R., Truzzi, F. Wachter, T., Leverkus, M., and Pincelli, C. (2004). FLICE/caspase-8 activation triggers anoikis induced by betal-integrin blockade in human keratinocytes. $J$ Cell Sci. 117: 5815-5823.

Martinez-Lorenzo, M.J., Alava, M.A., Gamen, S., Kim, K.J., Chuntharapai, A., Pineiro, A., Naval, J., and Anel, A. (1998). Involvement of APO2 ligand/TRAIL in activation-induced death of Jurkat and human peripheral blood T cells. Eur. J. Immunol. 28: 2714-2725.

Mato, J.M., Avila, M.A., Ortiz, P., and Pajares, M.A. (1997). SAdenosylmethionine synthesis: molecular mechanisms and clinical implications. Pharmacol. Ther. 73: 265-280.

Mato, J.M., Corrales, F.J., Lu, S.C., and Avila, M.A. (2002). SAdenosylmethionine: a control switch that regulates liver function. FASEB J. 16: 15-26.

McClowskey, T.W., Chavan, S., Lakshmi Tamma, S.M., and Pahwa, S. (1998). Comparison of seven quantitative assays to assess lymphocytic cell death during HIV infection: measurement of induced apoptosis in anti-Fas treated Jurkat cells and spontaneous apoptosis in peripheral blood mononuclear cells from children infected with HIV. AIDS Res. Hum. Retroviruses 14: 1413-1422.

Medema, J.P., Scaffidi, C., Kischkel, F.C., Shevchenko, A., Mann, M., Krammer, P.H., and Peter, M.E. (1997). FLICE is activated by association with the CD95 death-inducing signaling complex (DISC). EMBO J. 16: 2794-2804.

Meister, A, Metabolism and function of glutathione. In: Dolphin, D., Poulson R. and Avramovic, O. (Eds.) (1989). Glutathione: Chemical, Biochemical and Medical Aspects. John Wiley, New York. 367-474.

Merali, S., Vargas, D., Franklin, M., and Clarkson, A.B.Jr. (2000). SAdenosylmethionine and Pneumocystis carinii. J. Biol. Chem. 275: 1495814963.

Michiels, C. and Remacle, J. (1991). Cytotoxicity of linoleic acid peroxide, malondialdehyde and 4-hydroxynonenal towards human fibroblasts. Toxicology. 66: 225-234.

Minotti, G., Di Gennaro, M., D’ Ugo, D., and Granone, P. (1991). Possible source of iron for lipid peroxidation. Free Radical. Res. Commun. 1: 99-106.

Murata, H., Ihara, Y., Nakamura, H., Yodoi, J., Sumikawa, K., and Kondo, T. (2003). Glutaredoxin exerts an antiapoptotic effect by regulating the redox state of Akt. J Biol Chem. 278: 50226-50233.

Nagasawa, H.T., Goon, D.J., Muldoon, W.P., and Zera, R.T. (1984). 2-Substituted thiazolidine-4(R)-carboxylic acids as prodrogs of 1-cysteine. Protection of mice against acetaminophen hepatoxicity. J. Med. Chem. 27: 591-596.

Nakamura, H., Masutani, H., and Yodoi, J. (2002). Redox imbalance and its control in HIV infection. Antioxid. Redox. Signal. 4: 455-464. 
Navas, S., Martin, J., Ouiroga, J.A., Castillo, I., and Carreno, V. (1998). Genetic diversity and tissue compartmentalization of the hepatitis $C$ virus genome in blood mononuclear cells, liver, and serum from chronic hepatitis $\mathrm{C}$ patients. J Virol. 72: 1640-1646.

Noshita, N., Lewen, A., Sugawara, T., and Chan, P.H. (2001). Evidence of phosphorylation of Akt and neuronal survival after transient focal cerebral ischemia in mice. J. Cereb. Blood Flow Metab. 21: 1442-1450.

Oelgeschlager, M., Krieg, J., Luscher-Firzlaff, J.M., and Luscher, B. (1995). Casein kinase II phosphorylation site mutations in c-Myb affect DNA binding and transcriptional cooperativity with NF-M. Mol Cell Biol. 15: 5966-5974.

Oh, I.H. and Reddy, E.P. (1999). The myb gene family in cell growth, differentiation and apoptosis. Oncogene. 18: 3017-3033.

Ouyang, Y.B., Tan, Y., Comb, M., Liu, C.L., Martone, M.E., Siesjö, B.K., and Hu, B.R. (1999). Survival- and death-promoting events after transient cerebral ischemia: phosphorylation of Akt, release of cytochrome $\mathrm{c}$ and activation of caspase-like proteases. J. Cereb. Blood Flow Metab. 19: 1126-1135.

Panayiotidis, M.I., Stabler, S.P., Ahmad, A., LeGros, L.H.Jr., Hernandez-Saavedra, D., Schneider, B.K., Allen, R.H., Vasiliou, V., McCord, J.M., Kotb, M, and White, C.W. (2006). Activation of a novel isoform of methionine adenosyl transferase $2 \mathrm{~A}$ and increased S-adenosylmethionine turnover in lung epithelial cells exposed to hyperoxia. Free Radic Biol Med. 40: 348-358.

Peter, M.E. and Krammer, P.H. (2003). The CD95 (APO-1/Fas) DISC and beyond. Cell Death Differ. 10: 26-35.

Peterson, J.D., Herzenberg, L.A., Vasquez, K., and Waltenbaugh, C. (1998). Glutathione levels in antigen-presenting cells modulate Th1 versus Th2 response patterns. Proc. Natl. Acad. Sci. U.S.A. 95: 3071-3076.

Raju, P.A., Herzenberg, L.A., and Roederer, M. (1994). Glutathione precursor and antioxidant activities of $\mathrm{N}$-acetylcysteine and oxothiazolidine carboxylate compared in in vitro studies of HIV replication. AIDS Res Hum Retroviruses. 10: 961-967.

Resjo, S., Goransson, O., Harndahl, L., Zolnierowicz, S., Manganiello, V., and Degerman, E. (2002). Protein phosphatase 2A is the main phosphatase involved in the regulation of protein kinase B in rat adipocytes. Cell Signal. 14: $231-238$.

Richie, J.P. Jr, and Lang, C.A. (1987). The determination of glutathione, cyst(e)ine, and other thiols and disulfides in biological samples using high performance liquid chromatography with dual electrochemical detection. Anal. Biochem. 163: $9-15$.

Rigamonti, C., Mottaran, E., Reale, E., Rolla, R., Cipriani, V., Capelli, F., Boldorini, R., Vidali, M., Sartori, M., and Albano, E. (2003). Moderate alcohol consumption increase oxidative stress in patients with chronic hepatitis C. Hepatology 38: 42-49.

Romero, F.J., Bosch-Morell, F., Romero, M.J., Jareno, E.J., Romero, B., Marin, N., and Roma, J. (1998). Lipid peroxidation products and antioxidants in human disease. Environ. Health Perspect. 106: S1229-S1234. 
Salinas, M., Diaz, R., Abraham, N., Ruiz, De Galarreta, C.M., and Cuadrado, A. (2003). Nerve growth factor protects against 6-hydroxydopamine-induced oxidative stress by increasing expression of heme oxygenase- 1 in a phosphatidylinositol 3 kinase-dependent manner. J. Biol. Chem. 278: 13898-13904.

Santoro, M.F., Annand, R.R., Robertson, M.M., Peng, Y.W., Mankovich, J.A., Hackett, M.C., Ghayur, T., Walter, G., Wong, W.W., and Giegel, D.A. (1998). Regulation of protein phosphatase $2 \mathrm{~A}$ activity by caspase- 3 during apoptosis. J Biol Chem. 273: 13119-13128.

Schraven, B. and Peter, M.E. (1995). APO-1(CD95)-mediated apoptosis in Jurkat cells does not involve src kinases or CD45. FEBS Lett. 368: 491-494.

Sen, C.K. (1997). Nutritional biochemistry of cellular glutathione. J. Nutr. Biochem. 8: $660-672$.

Sen, C.K. (1998). Redox signaling and the emerging therapeutic potential of thiol antioxidants. Biochem. Pharmacol. 55: 1747-1758.

Serafini, M. (2000). Dietary vitamin E and T cell-mediated function in the elderly: effectiveness and mechanism of action. Review. Int. J. Dev. Neurosci. 18: 401-410.

Seyfried, J., Soldner, F., Schulz, J.B., Klockgether, T., Kovar, K.A., and Wullner, U. (1999). Differential effects of L-buthionine sulfoximine and ethacrynic acid on glutathione levels and mitochondrial function in PC12 cells. Neurosci Lett. 264: 1-4.

Shan, X.Q., Aw, T.Y., and Jones, D.P. (1990). Glutathione-dependent protection against oxidative injury. Pharmacol. Ther. 47: 61-71.

Shaw, M., Cohen, P., and Alessi, D.R. (1998). The activation of protein kinase B by $\mathrm{H}_{2} \mathrm{O}_{2}$ or heat shock is mediated by phosphoinositide 3-kinase and not by mitogen-activated protein kinase-activated protein kinase-2. Biochem J. 336: 241-246.

Shellito, J.E. and Olariu, R. (1998). Alcohol decreases T-lymphocyte migration into lung tissue in response to Pneumocystis carinii and depletes T-lymphocyte numbers in the spleens of mice. Alcohol Clin. Exp. Res. 22: 658-663.

Shirota, F.N., DeMaster, E.G., Shoeman, D.W., and Nagasawa, H.T. (2002). Acetaminophen-induced suppression of hepatic AdoMet synthetase activity is attenuated by prodrugs of L-cysteine. Toxicol. Lett. 132: 1-8.

Soderdahl, T., Enoksson, M., Lundberg, M., Holmgren, A., Ottersen, O.P., Orrenius, S., Bolcsfoldi, G., and Cotgreave, I.A. (2003). Visualization of the compartmentalization of glutathione and protein-glutathione mixed disulfides in cultured cells. FASEB J. 17: 124-126.

Smith, F.E. and Palmer, D.L. (1976). Alcoholism, infection and altered host defenses: a review of clinical and experimental observations. J. Chronic. Dis. 29: 35-49.

Song, H. (1994). Mouse and rat differences in $p$-aminophenol-induced liver and kidney toxicities. Ph.D. dissertation, University of Louisville.

Spitz, D.R., Sullivan, S.J., Malcom, R.R., and Roberts, R.J. (1991). Glutathione 
dependent metabolism and detoxification of 4-hydroxy-2-nonenal. Free Radic Biol Med. 11: 415-423.

Srinivasan, C., Williams, W.M., Nagasawa H.T. and Chen, T.S. (2001). Effects of 2(RS)-n-propylthiazolidine-4(R)-carboxylic acid on extrahepatic sulfhydryl levels in mice treated with acetaminophen. Biochem. Pharm. 61: 925-931.

Suhara, T., Mano, T., Oliveira, B.E., and Walsh, K. (2001). Phosphatidylinositol 3kinase/Akt signaling controls endothelial cell sensitivity to Fas-mediated apoptosis via regulation of FLICE-inhibitory protein (FLIP). Circ Res. 89: 13-19.

Suhara, T., Kim, H.S., Kirshenbaum, L.A., and Walsh, K. (2002). Suppression of Akt signaling induces Fas ligand expression: involvement of caspase and Jun kinase activation in Akt-mediated Fas ligand regulation. $\mathrm{Mol}$ Cell Biol. 22: 680-691.

Suzuki, T., Fukuo, K., Suhara, T., Yasuda, O., Sato, N., Takemura, Y., Tsubakimoto, M., and Ogihara, T. (2003). Eicosapentaenoic acid protects endothelial cells against anoikis through restoration of cFLIP. Hypertension. 42: 342-348.

Suhara, T., Fukuo, K., Yasuda, O., Tsubakimoto, M., Takemura, Y., Kawamoto, H., Yokoi, T., Mogi, M., Kaimoto, T, and Ogihara, T. (2004). Homocysteine enhances endothelial apoptosis via upregulation of Fas-mediated pathways. Hypertension. 43: 1208-1213.

Tibbetts, M.D., Zheng, L., and Lenardo, M.J. (2003). The death effector domain protein family: regulators of cellular homeostasis. Nat. Immunol. 4: 404409.

Uchida, K. (2003). 4-Hydroxy-2-nonenal: a product and mediator of oxidative stress. Review. Prog. Lipid Res. 42: 318-343.

Uriarte, S.M., Joshi-Barve, S., Song, Z., Sahoo, R., Gobejishvili, L., Jala, V.R., Haribabu, B., McClain, C., and Barve, S. (2005). Akt inhibition upregulates FasL, downregulates c-FLIPs and induces caspase-8-dependent cell death in Jurkat T lymphocytes. Cell Death Differ. 12: 233-242.

Van Kanegan, M.J., Adams, D.G., Wadzinski, B.E., and Strack, S. (2005). Distinct protein phosphatase $2 \mathrm{~A}$ heterotrimers modulate growth factor signaling to extracellular signal-regulated kinases and Akt. J Biol Chem. 280: 3602936036.

Venturelli, D., Travali, S., and Calasbretta, B. (1990). Inhibition of T-cell proliferation by a MYB antisense oligomer is accompanied by selective down-regulation of DNA polymerase alpha expression. Proc Natl Acad Sci U S A. 87: 5963-5967.

Wang, J.F. and Spitzer, J.J. (1997). Alcohol-induced thymocyte apoptosis is accompanied by impaired mitochondrial function. Alcohol 14: 99-105.

Yellaturu, C.R., Bhanoori, M., Neeli, I., and Rao, G.N. (2002). N-Ethylmaleimide inhibits platelet-derived growth factor BB-stimulated Akt phosphorylation via activation of protein phosphatase 2A. J Biol Chem. 277: 40148-40155.

Yu, C., Rahmani, M., Almenara, J., Sausville, E.A., Dent, P., and Grant, S. (2004). Induction of apoptosis in human leukemia cells by the tyrosine kinase inhibitor adaphostin proceeds through a RAF-1/MEK/ERK- and AKT- 
dependent process. Oncogene 23: 1364-1376.

Zeng, Z., Yang, H., Huang, Z., Chen, C., Wang, J., and Lu, S. (2001). The role of c$\mathrm{Myb}$ in the up-regulation of methionine adenosyltransferase 2A expression in activated Jurkat cells. Biochem. J. 353: 163-168. 


\title{
LIST OF ABBREVIATIONS
}

\author{
ADT, anethole dithiolethione \\ AICD, activation-induced cell death \\ APAP, acetaminophen \\ ASK1, apoptosis signal-regulating kinase 1 \\ BSO, buthionine sulfoximine \\ Cys, L-cysteine \\ DISC, death-inducing signaling complex \\ DEM, diethyl maleate \\ DTT, dithiolthreitol \\ EPA, eicosapentaenoic acid \\ ECL, enhanced chemiluminescence \\ FADD, Fas-associated death domain \\ FasL, Fas ligand \\ FLICE, FADD-like interleukin $1 ;$-converting enzyme \\ FLIP, FLICE inhibitory protein \\ GSK3, glycogen synthase kinase 3 \\ GSH, glutathione \\ GSSG, glutathione disulfide \\ HIV, human immunodeficiency virus \\ HO-1, heme oxygenase 1
}


HNE, 4-hydroxynonenal

HPLC, high performance liquid chromatography

$\mathrm{H}_{2} \mathrm{O}_{2}$, hydrogen peroxide

LDH, lactate dehydrogenase

MAT, methionine adenosyltransferase

MDA, malondialdehyde

MPA, monochloroacetic acid

MPP+, methylpyridinium

$\mathrm{NF}_{\kappa \mathrm{B}} \mathrm{B}$, nuclear factor-kappa $\mathrm{B}$

NAC, N-acetyl-cysteine

OTC, L-2-Oxothiazolidine 4-carboxylate

PAP, para-aminophenol

PBS, phosphate buffered saline

PDK1, phosphoinositide-dependent kinase-1

PHA, phytohemagglutinin

PMA, phorbol 12-myristate 13-acetate

PMSF, phenylmethylsulphonylfluoride

PP2A, protein phosphatase-2A

PTCA, 2(RS)-n-Propylthiazolidine-4(R)-carboxylic acid

SAH, S-adenosylhomocysteine

SAMe, S-Adenosyl-methionine

SDS-PAGE, sodium dodecyl solfate-polyacrylamide gel electrophoresis 


\section{CURRICULUM VITAE}

NAME: Wei-Yuan Chang

ADDRESS: Department of Pharmacology and Toxicology School of Medicine, University of Louisville Louisville, KY 40292

BORN: $\quad$ Taipei, Taiwan - Aug 12, 1977

EDUCATION \& TRAINING:

1992-1995 Wesley Girls High School, Taipei, Taiwan

1995-2000 B.S. Taipei Medical University, Taipei, Taiwan

2001-2004 M.S. University of Louisville, Louisville, Kentucky

2004-present $\mathrm{Ph}$. D. Pharmacology and Toxicology,

University of Louisville, Louisville, Kentucky (expected)

Dissertation title: Mechanism of 4-Hydroxynonenal

Toxicity in Jurkat CD4 ${ }^{+} \mathrm{T}$ Lymphocytes

\section{PRESENT POSITION:}

Graduate student; Department of Pharmacology and Toxicology

University of Louisville 